BRUNA LAHOS DE JESUS BACIC

ANÁLISE DA MANCHA URBANA A PARTIR DE SÉRIES TEMPORAIS DE IMAGENS LANDSAT: ESTUDO DE CASO NOS MUNICÍPIOS DO TRECHO OESTE DO RODOANEL MÁRIO COVAS 


\section{ANÁLISE DA MANCHA URBANA A PARTIR DE SÉRIES TEMPORAIS DE IMAGENS LANDSAT: ESTUDO DE CASO NOS MUNICÍPIOS DO TRECHO OESTE DO RODOANEL MÁRIO COVAS}

Dissertação apresentada à Escola Politécnica da Universidade de São Paulo, como parte dos requisitos para obtenção do título de Mestre em Ciências.

Área de Concentração: Engenharia de Transportes Informações Espaciais

Orientadora: Prof. ${ }^{a}$ Dr. ${ }^{\text {a }}$ Mariana Abrantes Giannotti 
Este exemplar foi revisado e corrigido em relação à versão original, sob responsabilidade única do autor e com a anuência de seu orientador.

São Paulo, de de

Assinatura do autor:

Assinatura do orientador:

Catalogação-na-publicação

Bacic, Bruna Lahos de Jesus

ANÁLISE DA MANCHA URBANA A PARTIR DE SÉRIES TEMPORAIS DE IMAGENS LANDSAT: ESTUDO DE CASO NOS MUNICÍPIOS DO TRECHO OESTE DO RODOANEL MÁRIO COVAS / B. L. J. Bacic -- versão corr. -- São Paulo, 2018.

$87 \mathrm{p}$.

Dissertação (Mestrado) - Escola Politécnica da Universidade de São Paulo. Departamento de Engenharia de Transportes.

1.Sensoriamento Remoto 2.Técnica de Votação 4.Rodoanel Mário Covas 5.Ciclo do Uso do Solo e Transportes I.Universidade de São Paulo. Escola Politécnica. Departamento de Engenharia de Transportes II.t. 


\section{Dedicatória}

À minha família e em especial, minha mãe, Janaina 


\section{Agradecimentos}

A Deus. À minha orientadora Prof ${ }^{a}$. Drạ . Mariana Abrantes Giannotti por todo o apoio, confiança, dedicação, imensurável motivação em todos os momentos, e ensinamentos que jamais serão esquecidos.

Ao Conselho Nacional de Desenvolvimento Científico e Tecnológico (CNPq) pela bolsa institucional, essencial para o financiamento desta pesquisa.

Ao Laboratório de Geoprocessamento (LabGeo/EP/USP) pela infraestrutura ofertada aos alunos e ao seu funcionário Leonardo, pela disponibilidade e toda ajuda no software $\mathrm{R}$.

A todos os colegas do LabGeo / GEOMOVE em especial ao Diego Bogado Tomasiello pelo apoio nas revisões, processamentos dos dados e análises. E a Júlia Matos, por seu apoio e amizade.

Aos professores e funcionários do Programa de Pós-Graduação em Engenharia de Transportes da EPUSP e aos colegas de disciplinas pelos aprendizados. Aos professores e funcionários do Programa de Pós-Graduação em Sensoriamento Remoto no INPE, onde cursei duas disciplinas primordiais a essência deste trabalho. Ao Laboratório de Sensoriamento Remoto do Departamento de Geografia - LASERE- por ceder o espaço e computador para processar algumas imagens.

A toda minha família, em especial meus irmãos e minha mãe que sempre apoiou. Ao Mateus pela confiança e incentivo para ingressar no mestrado além de todo o suporte durante estes anos para concluir.

E a todos que colaboraram direta e indiretamente na execução deste trabalho. 
"As cidades

são como as estrelas;

é preciso amá-las

para entende-las"

Flávio Villaça 


\section{RESUMO}

O presente estudo tem como objetivo avaliar a expansão da mancha urbana através da análise multitemporal dos índices BUILT-UP e NDBI calculados a partir de imagens de sensores remotos. A técnica de votação será explorada para, a partir de uma análise multitemporal, aprimorar a qualidade do mapeamento da área urbanizada. Paralelamente mapas coropléticos da população total residente são analisados para, em conjunto com a interpretação dos mapas oriundos da técnica de votação, subsidiarem a discussão sobre a relação entre a expansão das áreas construídas relacionadas não ao Rodoanel Mário Covas (SP-21) mas as rodovias que o interceptam. As explorações da aplicação do método de votação obtiveram resultados satisfatórios e apontaram que é de suma importância a heterogeneidade das mesmas para seus resultados serem aprimorados, além da importância da aquisição das imagens em períodos chuvosos a fim de manter a diferenciação do solo exposto com as áreas urbanas.

Palavras chaves: Técnica de Votação; índice Built-Up, Rodoanel Mário Covas; Sensoriamento Remoto.

\section{ABSTRACT}

The present study aims to evaluate the expansion of the urban spot through the multitemporal analysis of BUILT-UP and NDBI indices calculated from remote sensor images. The voting technique was explored in order to improve the quality of mapping of the urbanized area, based on a multitemporal analysis. At the same time, maps of the total resident population are analyzed in order to support the discussion of the relationship between the expansion of the built-up areas related to the Mário Covas Roadway (SP-21) and the highways that intercept him. Based on the results obtained, it was possible to observe that the urban sprawl is related not to the Rodoanel but like highways that intercept it. The explorations of the application of the voting method obtained satisfactory results and pointed out that the heterogeneity of the subtitles for their results and improved, as well as the importance of the acquisition of the images in rainy periods in order to maintain the difference between exposed soil and urban areas. Sensing;

Key words: Voting method; Built-Up index; Beltway Mario Covas; Remote 


\section{Lista de Figuras}

Figura 1: Ciclo de feedback do transporte de uso da terra. Fonte: Wegener, 2004. Tradução, Bacic (2017)

Figura 2: Ciclo do uso do solo e transportes. Adaptado de Paquette et al (1972).

Figura 3: Fluxograma do funcionamento da técnica de votação. Elaboração: Bacic, 2017. .35

Figura 4: Mapa de Localização do Rodoanel. Fonte: Maciel 2011. ................... 38

Figura 5: Mapa de localização dos municípios..................................................... 40

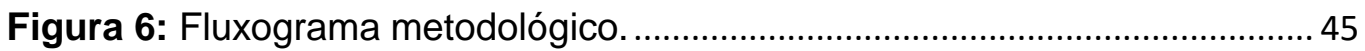

Figura 8: Localização dos Pontos de controle de verdade terrestre. .48

Figura 9: Mapeamento da Área Construída na RMSP utilizando a Técnica de votação aplicada nas imagens com e sem correção radiométrica - 2000. 50

Figura 10: Mapeamento da Área Construída na RMSP utilizando a Técnica de votação aplicada nas imagens com e sem correção radiométrica - 2010. 52

Figura 11: Mapeamento das áreas construídas a partir da técnica de votação 2000.

Figura 12: Mapa dos polígonos resultantes da aplicação da técnica de votação -2010 .

Figura 13: Polígonos da técnica de votação 2000 (A) e 2010 (B) 62

Figura 14: Polígonos de área construída gerado pela votação de 2000 e 2010 em Barueri - SP.

Figura 15: Polígonos de área construída gerado pela votação de 2000 e 2010 em Carapicuíba - SP. 65

Figura 16: Polígonos de área construída gerado pela votação de 2000 e 2010 em Cotia - SP 65

Figura 17: Polígonos de área construída gerado pela votação de 2000 e 2010 em Embu - SP

Figura 18: Polígonos de área construída gerado pela votação de 2000 e 2010 em Osasco - SP 68

Figura 19: Polígonos de área construída gerado pela votação de 2000 e 2010 em Santana de Parnaíba - SP 69

Figura 20: Mapa da área de Teste: Represa Auto Cotia...................................... 70

Figura 21: Mapa da área de Teste: Santana de Parnaíba 72 
Figura 22: Mapa coroplético de População total (v249) em cada polígono 2000 . 74

Figura 23: Mapa coroplético da população residente em cada polígono da técnica de votação -2010. .75 


\section{Lista de Quadros e Tabelas}

Tabela 1: Referências Bibliográficas pesquisadas para a escolha dos índices.

Tabela 3: Dados dos municípios. Fonte: IBGE 2010.

Tabela 4: Aumento da população nos municípios da área de estudo. Fonte: IBGE: Dados censitários 2000 e 2010.

Tabela 5: Fluxo de pessoas nos Municípios da RMSP em 2000. Adaptado de: Aranha, 2005. Dados: Censo 2000. Reorganização: Bacic (2018)

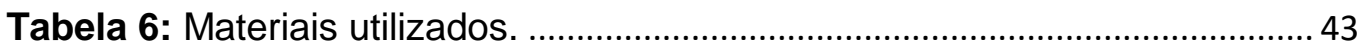

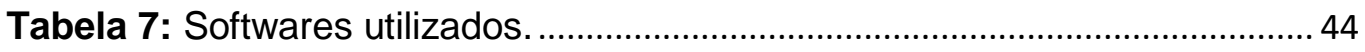

Tabela 8: Matriz de confusão da técnica de votação com correção radiométrica em 2000.

Tabela 9: Matriz de confusão da técnica de votação - 2000.

Tabela 10: Matriz de confusão da votação com correção radiométrica - 2010.

Tabela 11: Matriz de confusão da técnica de votação - 2010. 53

Tabela 12: Matriz de confusão do índice Built-Up de Dezembro (1999) referente ao conjunto de 2000 . 54

Tabela 13: Matriz de confusão do índice Built-Up de Janeiro (2000)................. 54

Tabela 14: Matriz de confusão do índice Built-Up de Maio (2000)...................... 55

Tabela 15: Matriz de confusão do índice Built-Up de Junho (2000).................... 55

Tabela 16: Matriz de confusão do índice Built-Up de Agosto (2000). ................. 56

Tabela 17: Matriz de confusão do índice Built-Up de Abril (2010)....................... 58

Tabela 18: Matriz de confusão do índice Built-Up de Maio (2010)...................... 58

Tabela 19: Matriz de confusão do índice Built-Up de Julho (2010).................... 59

Tabela 20: Matriz de confusão do índice Built-Up de Agosto (2010).................. 59

Tabela 21: Matriz de confusão do índice Built-Up de Novembro (2010)........... 60 


\section{Lista de Abreviaturas e Siglas}

\begin{tabular}{|c|c|}
\hline ANN & Artificial Neural Network \\
\hline BASI & Built-Up Areas Saliency Index \\
\hline BBI & Built-Up And Bareness Index \\
\hline CCR-Rodoanel & Companhia De Concessões Rodoviárias - Rodoanel \\
\hline CEM & Centro De Estudos Da Metrópole \\
\hline CPTM & Companhia Paulista de Trens Metropolitanos \\
\hline DERSA & Desenvolvimento Rodoviário S/A \\
\hline DNIT & Departamento Nacional De Infraestrutura De Transporte \\
\hline DOS & Dark Object Subtraction \\
\hline DT & Decision Tree \\
\hline EMPLASA & Empresa Paulista De Planejamento Metropolitano S.A \\
\hline ETM+ & Enhanced Thematic Mapper Plus \\
\hline GDAL & Geospatial Data Abstraction Library \\
\hline GLOVIS & Global Visualization Viewer \\
\hline IBGE & Instituto Brasileiro De Geografia E Estatística \\
\hline IBI & Index Based Built-Up Index \\
\hline IBI & Index-Based Built-Up Index \\
\hline IDH & Índice de Desenvolvimento Humano \\
\hline LANDSAT & Land Remote Sensing Satellite \\
\hline LST & Land Surface Temperature \\
\hline MNDWI & Modified Normalized Difference Water Index \\
\hline MTM & Mixed Topological Map Algorithm \\
\hline NDBal & Normalized Difference Bareness Index \\
\hline NDBI & Normalized Difference Built Index \\
\hline NDISI & Normalized Density Impervious Surface \\
\hline NDSI & Normalized Density Snow Index \\
\hline NDVI & Normalized Density Vegetation Index \\
\hline NDWI & Normalized Density Water Index \\
\hline NIR & Near Infrared \\
\hline NIRI & Normalized Infrared Index \\
\hline OLI & Operational Land Image \\
\hline
\end{tabular}




\begin{tabular}{ll}
\hline PEA & População Economicamente Ativa \\
\hline RMSP & Região Metropolitana De São Paulo \\
\hline SAVI & Soil-Adjusted Vegetation Index \\
\hline SIG & Sistema de Informações Geográficas \\
\hline SVM & Support Vector Machine \\
\hline SWIR & Short-Wave Infrared \\
\hline TM & Thematic Mapper \\
\hline USGS & United States Geological Survey \\
\hline UTM & Universal Transversa de Mercator \\
\hline VgNIR-BI & Visible Green Based Built-Up index \\
\hline VrNIR-BI & Visible Red Based Built-Up index \\
\hline WMS & Web Map Service \\
\hline
\end{tabular}




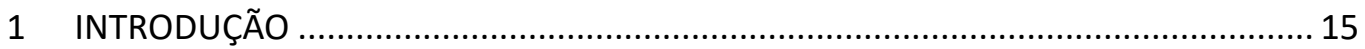

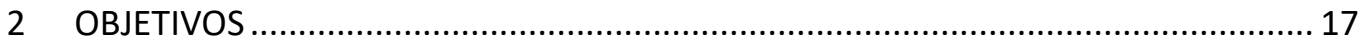

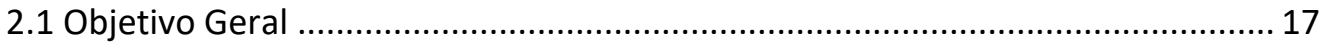

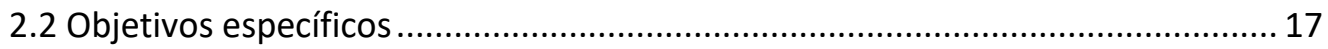

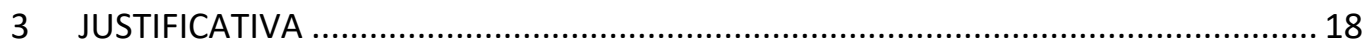

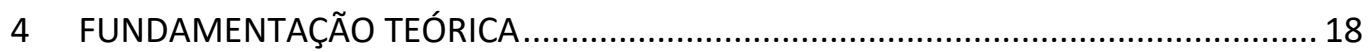

4.1 As relações entre o Rodoanel e o Espaço Urbano................................................. 18

4.1.1 O Ciclo do uso do Solo e Transportes ........................................................... 21

4.1.2 Rodoanel como "beltway" ....................................................................... 25

4.2 Sensoriamento Remoto em Áreas Urbanas ..................................................... 27

4.2.1 Aplicação dos Índices de Sensoriamento Remoto em áreas urbanas........... 27

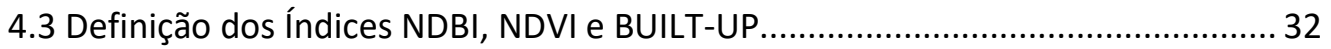

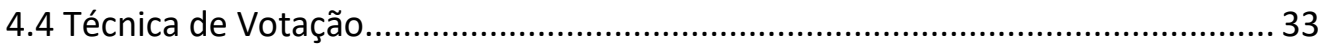

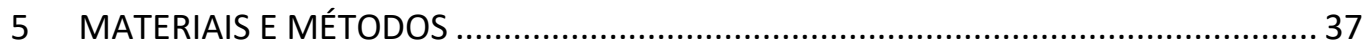

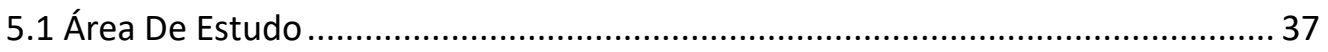

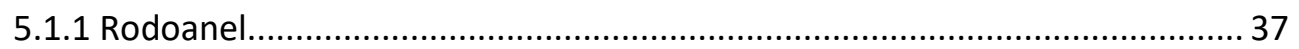

5.1.2 Municípios da Microrregião de Osasco......................................................... 39

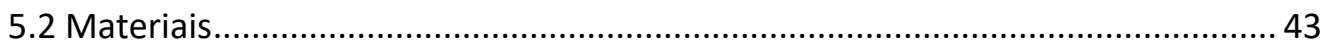

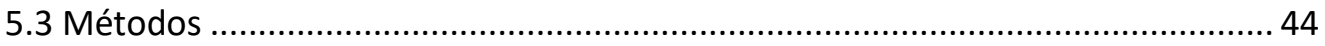

5.3.1 Mapeamento do uso do solo urbano .............................................................. 45

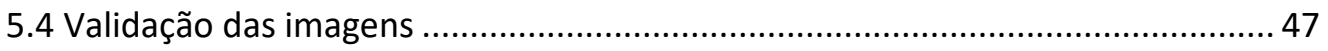

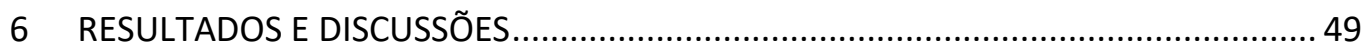

6.1 Aplicação da Correção Radiométrica no mapa de área construída ..................... 49

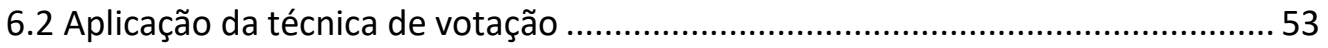

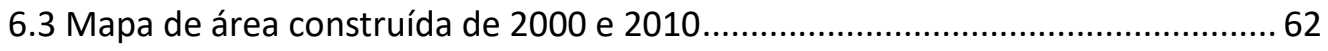

6.4 Mapeamento coroplético da população total .................................................... 73

7 CONCLUSÕES E RECOMENDAÇÕES .............................................................. 76 


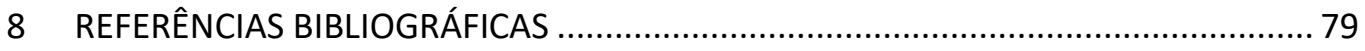

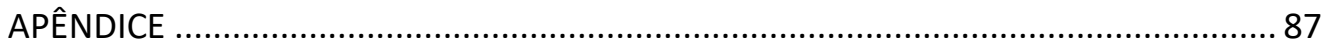




\section{INTRODUÇÃO}

O rápido aumento da taxa de urbanização Brasileira de $55,92 \%$ na década de 70 para $84,36 \%$ em 2010 (IBGE) ocasionou problemas de infraestrutura tal como o transporte público, problemas sociais e econômicos. O Brasil, de acordo com o censo do IBGE de 2010, possui 39 regiões metropolitanas, sendo a Região Metropolitana de São Paulo (RMSP) a maior em termos de população e simbolismo econômico. Atualmente estima-se que a RMSP possua cerca de 22 milhões de habitantes (EMPLASA, 2017).

O crescimento intenso da cidade de São Paulo fez com que os municípios adjacentes passassem a ser extremamente atrativos, devido ao menor custo de vida e a articulação ao espaço regional da capital do estado. As cidades médias nas regiões metropolitanas, passaram a atrair mais investimento e população, sendo que estas contribuíram com o crescimento de $49 \%$ do acréscimo populacional urbano entre as décadas de 1970 e 1990 (ANDRADE \& SERRA, 1999).

Vilaça (1998) aponta que há uma íntima relação entre as vias regionais de transporte e o crescimento da cidade, sendo que as rodovias geram um crescimento descontínuo em qualquer ponto (não concentrado como no caso de ferrovias e suas estações). As vias regionais de transporte constituem o mais poderoso elemento na atração da expansão urbana. A relação entre alteração na paisagem urbana e investimento em infraestrutura de transportes é uma preocupação recorrente quando se trata de planejamento urbano (MACIEL, 2011).

Uma via provoca o crescimento ou desenvolvimento urbano nesta ou naquela direção, ou seja, o arranjo espacial do crescimento. O primeiro efeito que uma via regional ou terminal de transporte urbano provoca nos terrenos adjacentes é a melhoria de sua acessibilidade e, a partir daí a sua valorização (VILAÇA, 1998).

O Rodoanel Mário Covas (SP-21) foi idealizado para ser uma alternativa, de modo a minimizar o congestionamento nas Marginais Tietê e Pinheiro proporcionando o acesso descomplicado entre as regiões interiores do Estado e 
Sul do país, além da interligação entre as principais estradas com o porto de Santos fora da área urbana (DNIT, 2016). O Rodoanel constitui um dos maiores investimentos de transporte viário da América Latina e no Brasil, cujo princípio das obras se deu em 1998 e seu término estava previsto para 2018, sendo que apenas no trecho oeste - inaugurado em 2002 - foi investido um total de $R \$ 2,6$ bilhões (MACIEL, 2011).

Embora a deterioração das áreas centrais não possa ser atribuída somente aos anéis viários, o espraiamento urbano (urban sprawl) está intimamente relacionado com automóveis, vias radiais e circuitos perimetrais de primeira classe (MACIEL, 2011). Rodrigue, Comtois e Slack (2009) salientam que o diâmetro da área urbanizada se expande na medida em que modos de transportes mais rápidos se disseminam.

Uma grande obra viária do porte do Rodoanel tem o poder de causar dois efeitos a longo prazo sobre o uso do solo, o primeiro é alterar a localização das atividades econômicas no espaço - relocalização de industrias e residências e o segundo é a eventual expansão da mancha urbana, ou seja, a transformação do uso agrícola para uso urbano (MACIEL 2011).

Para captar expansões da mancha urbana, o sensoriamento remoto tem sido utilizado pois viabiliza a análise, compreensão e monitoramento, além de possuir um baixo custo e alta velocidade de aquisição das informações, comparativamente a um levantamento de campo. O mapeamento da macha urbana permite a análise das áreas urbanas ocupadas, bem como a quantificação do crescimento das mudanças, que podem ser usados no plano de zoneamento e planejamento urbano.

He et al (2010) afirmam que as imagens orbitais podem ser utilizadas para o monitoramento da distribuição espacial urbana e são ferramentas valiosas para o estudo e compreensão da população e crescimento das cidades. A utilização de índices de interpretação de imagens tornam os resultados mais rápidos, eficientes e requerem menor intervenção humana do que uma classificação comum (ZHA et al., 2003).

He et al (2010), propôs o Built-Up Index com o propósito de desagregar as áreas construídas da vegetação em ambientes urbanos, com a utilização do 
mesmo é possível aperfeiçoar a identificação do crescimento urbano (LEE et al., 2010; IM et al., 2012; VARSHNEY, 2013).

A técnica de votação tem sido aplicada em trabalhos de sensoriamento remoto para aperfeiçoar os resultados de múltiplos classificadores (CAMPOS et al 2016). A técnica estabelece uma regra de maioria para os pixels, tomando como base o trabalho de Kittler (1998).

No presente trabalho o sensoriamento remoto será aplicado como subsidio para caracterizar as relações entre o Rodoanel (SP-21) e a evolução da mancha urbana nos municípios cruzados por esta rodovia. Para uma melhor compreensão do impacto da implantação do Rodoanel a partir da análise das manchas urbanas identificadas através da aplicação do índice Built-Up em imagens orbitais, associadas à aplicação de técnica de votação. Somado a isso, visa agregar mais informações para o estudo da evolução das áreas urbanas influenciadas pelo impacto da instalação do rodoanel.

\section{OBJETIVOS}

\subsection{Objetivo Geral}

Este trabalho tem como objetivo geral analisar o impacto do Rodoanel Mário Covas na expansão da mancha urbana nos municípios por ele atravessados.

\subsection{Objetivos específicos}

- Explorar o potencial dos índices NDBI, NDVI e BUILT-UP para a elaboração de mapas de áreas construídas.

- Aprimorar os resultados obtidos com o BUILT-UP através da técnica de votação. 


\section{JUSTIFICATIVA}

Apesar da grande quantidade de estudos envolvendo o Rodoanel com a finalidade de compreender os seus impactos a população vizinha à rodovia, não é claro na literatura qual o real impacto que este tem sobre a ocupação dos municípios que o permeia.

Sabe-se que, conforme apontado por Villaça (1988) uma via de transporte tende a favorecer o deslocamento da população e com isso, pode facilitar a moradia nas áreas beneficiadas. Então o desenvolvimento desta dissertação baseia-se na seguinte pergunta: O Rodoanel é capaz de influenciar o aumento populacional nos municípios que transpassa mesmo tendo suas particularidades com relação ao acesso à rodovia?

\section{FUNDAMENTAÇÃO TEÓRICA}

Nesta revisão de literatura foram abordados os assuntos principais deste trabalho, compreendendo tópicos referentes aos métodos que serão utilizados para a avaliação da evolução da mancha urbana, como a aplicação de índices em sensoriamento remoto de áreas urbanas. Para auxiliar na interpretação dos resultados e motivação da análise da evolução da mancha urbana, um breve tópico discute as relações entre o rodoanel e o espaço urbano.

\subsection{As relações entre o Rodoanel e o Espaço Urbano}

O espaço urbano, em conformidade com Correa (1995), é o conjunto de diferentes usos do solo justapostos entre $\mathrm{si}$, correspondentes as áreas de comércio e serviços, industriais, residenciais e lazer. Este espaço é produzido por diferentes agentes sociais, tais como os proprietários dos meios de produção (indústrias), proprietários fundiários, promotores imobiliários, estado, e os grupos sociais excluídos. 
A urbanização brasileira tem como principal característica a rápida transformação do espaço, marcada pela interação com as redes logísticas, especialmente estações ferroviárias e margens rodoviárias (SANTOS, 1993).

Damiani (2010) mostra que a expansão urbana a partir dos anos 1940 atingiu os municípios contíguos à São Paulo, intensificando o processo de segregação urbana, causando a separação do lugar de moradia do lugar de trabalho. Esse processo também foi acentuado graças à elite paulistana, que reservou a si a centralidade urbana, segregando-se espontaneamente na região sudoeste da cidade, a partir de uma zona de contato com o centro (VILLAÇA, 1998).

A segregação urbana ocorre atrelada ao processo de descentralização. $A$ descentralização ocorre, conforme Correa (1995) devido a criação de novos núcleos onde os preços são mais baixos das terras e impostos, infraestrutura implantada e facilidade de transporte e principalmente 0 crescimento demográfico, o que gera uma escassez de espaços livres na área central. Manifesta-se então a necessidade de uma malha de transportes que supra a crescente demanda de viagens.

O Rodoanel, surge como sistema viário perimetral, que forma um grande anel de valorização econômica do espaço. Este, determina um contexto espacial sobre a produção do espaço urbano (DAMIANI, 2010). O transporte concretiza a acessibilidade, esta, por sua vez cria uma valorização da terra, principalmente aos terrenos adjacentes às vias ou terminais, este aumento gera automaticamente uma mudança na ocupação (verticalização) e consequentemente uma nova demanda de transporte. Ou seja, locais com maiores níveis de acessibilidade têm mais chances de serem mais desenvolvidos e densos dos que os locais de difícil acesso (WEGENER, 2004).

A disposição das cidades próximas às estações ferroviárias no estado de São Paulo é um exemplo deste princípio, onde a população prefere se alocar onde tem facilidade no acesso a outros lugares e aos meios de produção (MONBEIG,1998). Após a abertura da ferrovia no oeste paulista, a região contava apenas com uma população dispersa que aglomerou-se tornando rapidamente uma cidade em expansão (MONBEIG,1998). 
Os deslocamentos diários da população (migração pendular) entre os bairros do município ou mesmo entre os municípios interligados por um contexto socioeconômico, como o da RMSP ocorrem em diversas direções e motivos, como trabalho, educação, saúde, comércio, lazer, etc. Aranha (2005) observou que em quase $1 / 3$ dos municípios que compõe a RMSP, mais da metade da população economicamente ativa (PEA) trabalha em município diferente do que reside, além do fato que em mais da metade da população migrante para o município de São Paulo, cuja residência anterior foi a capital, continua trabalhando ou estudando em São Paulo.

De acordo com Nigriello \& Oliveira (2013) os municípios de Embu, Osasco, Santana de Parnaíba e Cotia são tidos como "dormitórios", munícipios ou bairros onde a população supera a quantidade de empregos oferecidos e apenas Barueri tem taxa crescente de população e empregos.

Aranha (2005) ainda mostra a diferença da entrada e saída da população (dentro da RMSP) que reside em um município e trabalha ou estuda em outro. Apenas o município de Barueri tem uma diferença positiva, onde ingressam mais pessoas com o motivo trabalho ou estudo e isto se deve a grande oferta de serviços, localizados nos empreendimentos de Alphaville e Tamboré. Enquanto Osasco e Carapicuíba registram a primeira e segunda maiores diferenças negativas entre entradas e saídas nos deslocamentos intra RMSP.

O Município de São Paulo registrou o maior acréscimo populacional devido aos deslocamentos pendulares: da ordem de 508 mil, caracterizando-se como o principal receptor da pendularidade metropolitana, sendo destinatário de $58,2 \%$ dos deslocamentos regionais (ARANHA, 2005).

As migrações pendulares na RMSP também foram analisadas por Marques e Requena (2013), através dos dados censitários, apontando que o centro aparece em encolhimento enquanto as periferias estão em expansão ou adensamento entre os 2000 e 2010. Esse ir-e-vir constitui elemento integrante da realidade das grandes cidades e reflete, portanto, suas desigualdades sociais e espaciais (ARANHA, 2005). Os movimentos pendulares, portanto, influenciam na estruturação do urbano e a alteração de uma infraestrutura de transporte, como no estudo de caso discutido neste trabalho, pode afetar a acessibilidade 
que, por sua vez, exerce influência sobre o uso do solo conforme discutido na seção a seguir.

\subsubsection{O Ciclo do uso do Solo e Transportes}

A oferta de transporte tem relação direta com o uso do solo: o tipo de uso demanda uma determinada estrutura e à medida que é suprida esta necessidade, novas possibilidades de deslocamento surgem, que por sua vez exige novas estruturas de transportes, dando origem a um processo denominado "Ciclo do uso do solo e transportes" (WEGENER E FURST, 1999).

De acordo com Arruda (2005) existem vários modelos que explicam as interações do espaço urbano com as teorias e necessidades de transportes. Um dos exemplos citados pelo autor é um dos primeiros modelos que integra os aspectos dos sistemas de transportes e uso do solo e foi desenvolvido por Lowry na década de 1960. Seu objetivo era explicar a conformação urbana das áreas residenciais e os centros de atividades a elas associados, a partir da concentração demográfica.

De acordo com Wegener (2004) o uso do solo determina a necessidade de interação de transporte, e este, por sua vez, proporciona a acessibilidade, que influencia o desenvolvimento espacial.

A inter-relação do uso do solo e transportes é representada pelo ciclo de uso do solo-transportes descrito por Wegener e Fürst (1999). Segundo os autores a distribuição dos tipos de uso do solo (residencial, industrial ou comercial) determinam a localização das atividades humanas. O espaço das atividades humanas demanda interação espacial com os sistemas de transportes (viagens). A infraestrutura do sistema de transportes cria as oportunidades para a interação espacial. Essa interação pode ser medida em acessibilidade, sendo que a distribuição da acessibilidade determina as decisões de localização, resultando em mudanças no uso do solo.

De acordo com Wegener (2004) são oito os tipos de subsistemas urbanos (redes, uso do solo, locais de trabalho, habitação, emprego, população, 
transporte de mercadorias e viagens) que são ordenados pela velocidade de mudança do ordenamento territorial, conforme listado abaixo:

- Mudança muito lenta: redes, uso do solo. As redes de transporte urbano, comunicações e serviços públicos bem como a distribuição do uso da terra é igualmente estável.

- Mudanças lentas: locais de trabalho, habitação. Os edifícios residenciais e os locais de trabalho (edifícios não residenciais), existem há muito mais tempo do que as empresas ou instituições que os ocupam, assim como a habitação existem a mais tempo do que as famílias que vivem nele.

- Mudança rápida: emprego, população. As empresas são estabelecidas ou fechadas, expandidas ou realocadas. Isso cria novos empregos ou torna os trabalhadores redundantes e afeta o emprego. As famílias são criadas, crescem ou diminuem e, eventualmente, são dissolvidas, e em cada etapa do ciclo de vida ajustam sua localização e motorização às suas necessidades em mudança. Isso determina a distribuição da população e de sua propriedade do carro.

- Mudança imediata: Transporte de mercadorias, viagens. A localização das atividades humanas no espaço dá origem a uma demanda de interação espacial sob a forma de transporte de mercadorias e viagens. Estes podem ajustar em minutos ou horas para mudanças no congestionamento ou flutuações na demanda.

Ainda, segundo Wegener (2004), existe um nono subsistema, o ambiente urbano. E seu comportamento temporal é extremamente complexo pois existem os impactos imediatos diretos das atividades humanas, como o ruído do transporte e a poluição do ar e os efeitos, como a contaminação da água ou do solo, que são extremamente lentos e dificilmente observáveis.

O reconhecimento de que as decisões de viagem e o planejamento de transporte e uso do solo precisa ser coordenado se espalhou rapidamente entre os pesquisadores americanos e o "land-use transport feedback cycle" ou, em português, ciclo de feedback do transporte de uso da terra, tornou-se conhecido na literatura. As relações subjacentes podem ser resumidas como segue: 


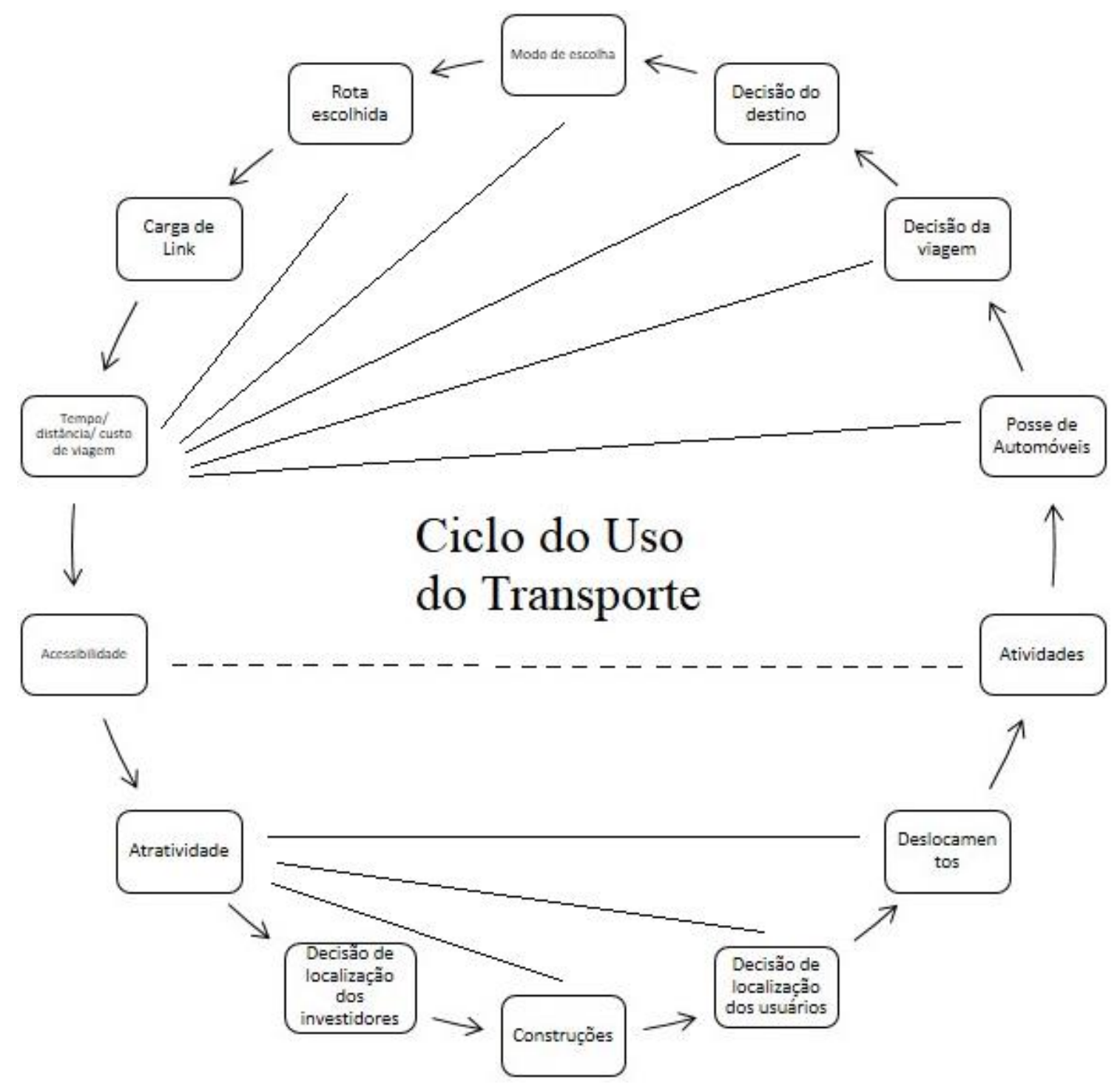

Figura 1: Ciclo de feedback do transporte de uso da terra. Fonte: Wegener, 2004. Tradução, Bacic (2017).

A Figura 1, apresenta como a acessibilidade gera a atratividade para a terra, que impulsiona investimentos, que geram mudanças no ambiente construído e por sua vez influenciam as decisões de localização dos usuários, que precisam se deslocar para suas atividades, a depender dos tempos de viagem e condições impulsionarão a aquisição de automóveis o que influenciará nas decisões de viagens e escolha dos destinos, modos e rotas, por sua vez afeta os tempos de viagens e custos que atinge a acessibilidade.

Paquette et al (1972) apresentou uma versão geral e simplificada deste ciclo (Figura 2) ressaltando que o uso da terra é o principal determinante da 
maior geração de viagem, o nível de atividade de geração de viagem e a orientação de viagens dentro da área de estudo determina as necessidades de instalações. À medida que as instalações alteram a acessibilidade da terra, esta passa a determinar o valor da terra. O valor da terra sendo o principal determinante do uso da terra, torna visível o fato que alterações em qualquer elemento causam mudanças tanto para todos os outros elementos quanto para si.

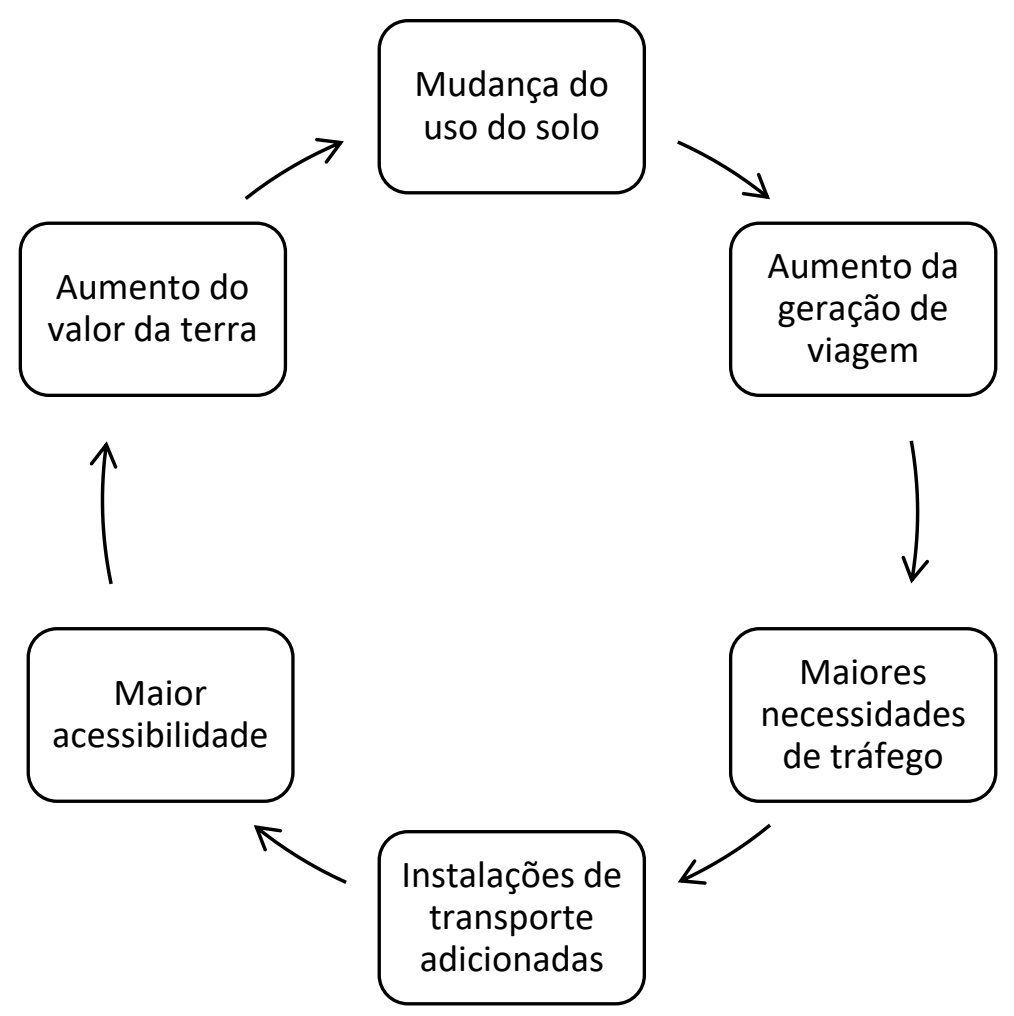
(1972).

Figura 2: Ciclo do uso do solo e transportes. Adaptado de Paquette et al

Apesar do Rodoanel ser considerado uma rodovia que se enquadra neste contexto do ciclo do transporte, possui particularidades que devem ser consideradas. Em especial, devido ao fato de um dos objetivos para sua criação foi a facilitação da circulação de veículos de carga em prol de uma melhor operação de logística urbana na RMSP, o que o configura como uma rodovia cujo potencial para promover a acessibilidade pode estar mais relacionado às viagens pendulares intermunicipais do que em relação a circulação entre as áreas subjacentes e do entorno, como será discutido na próxima seção. 


\subsubsection{Rodoanel como "beltway"}

Sendo uma via de transporte, o anel viário altera a acessibilidade e afeta o valor da terra e o seu uso (como visto na seção anterior). A conexão entre alteração na paisagem urbana e investimento em infraestrutura de transportes é uma preocupação recorrente quando se trata de planejamento urbano. Para Maciel (2011) uma grande obra de transporte é capaz de resultar em dois efeitos de longo prazo sobre o uso do solo, o primeiro é a alteração da localização das atividades econômicas no espaço urbano - realocação das firmas e das famílias - e o segundo efeito é eventual expansão da mancha urbana, isto é, a conversão do solo de uso agrícola para urbano.

Rodoanel ou anel viário é uma via em formato circular que conecta outras importantes vias de circulação, ou seja, são vias que possibilitam o redirecionamento do tráfego de passagem (pass through) de carga e/ou de passageiros na área urbana (MACIEL, 2011).

Prestes Maia (1930) subdivide os anéis viários em duas categorias, a primeira é conhecida na língua inglesa como beltway (cinturão) e corresponde aos anéis de primeira classe. Neste caso a obra constitui-se de vias expressas (pedagiadas ou não) que permitem a circulação perimetral por grande número de veículos e é capaz de suportar maiores velocidades de tráfego, o Rodoanel Mario Covas pertence a esta classe (MACIEL, 2011). A segunda categoria é chamada de ring road (via anular), corresponde aos anéis de segunda classe. A principal diferença as duas categorias se dá no porte e na forma, pois se constituem em uma interligação de vias existentes (arteriais ou não) que permitam a circulação intra urbana.

O desenvolvimento de um núcleo urbano reproduz uma pressão sobre a infraestrutura de transportes existente. O crescimento urbano a partir de uma aglomeração se expande em direção à periferia e configura um padrão radial em relação ao centro convergindo nas vias que conectam diferentes bairros (MACIEL, 2011). O eixo viário central e seus arcos de acesso (vias radiais) constituem nos principais obstáculos ao deslocamento, devido ao 
congestionamento. Os impactos que uma via pode causar são a longo prazo, dentre eles, o espraiamento urbano e a decadência das áreas centrais.

Para tanto, o anel viário é uma solução viável a fim de melhorar a circulação entre o centro e periferia, de modo que a viagem não passe necessariamente pelo centro, evitando pontos de congestionamento. Deste modo, uma via perimetral gera um ganho na acessibilidade ao desviar o tráfego da área central permitindo a conexão direta entre esses os pontos (MACIEL, 2011).

O aprimoramento da infraestrutura de transportes rodoviários não apenas consolidam o espraiamento urbano, mas permitem o desenvolvimento de subcentros de atividade econômica. Por isso não é possível afirmar que a construção de um anel viário de proporções consideráveis em nada afetaria uma região metropolitana (MACIEL, 2011).

De acordo com Volpe e Lombardo (2011) o Rodoanel acaba por induzir um efeito barreira como um inibidor da ocupação irregular e avanço da urbanização desordenada, visto que possui poucos acessos a área urbana. Machado e Waisman (2005) consideram que o Rodoanel pode dificultar a circulação em regiões adjacentes pela população ali residente, devido às suas particularidades a serem consideradas, como seu acesso restrito - só é possível entrar ou sair da rodovia nos pontos de acesso determinados. Além disso, não existem linhas de transporte público coletivo operando na rodovia, pois ele foi concebido para o tráfego de veículos particulares (automóveis, caminhões, ônibus de empresas particulares e motocicletas), no âmbito regional.

O Rodoanel não é uma opção de rota para a população da área diretamente afetada por ele, a não ser para aqueles que habitam próximo aos acessos e possuam um veículo particular (MACHADO E WAISMAN 2005). Volpe e Lombardo (2011) complementam que este processo decorre, portanto, devido ao fato da rodovia ser uma rodovia "classe 0", isto é, possui alto padrão técnico e controle total de acessos. Contudo, não se pode desprezar o efeito da conectividade entre regiões que passaram a ser melhor interligadas, em especial no contexto das viagens pendulares intermunicipais mencionadas anteriormente. 
Sendo assim, se por um lado a fundamentação teórica indica um possível aumento da acessibilidade a partir da criação do Rodanel como infraestrutura rodoviária que interliga municípios que possuem, em seu histórico de desenvolvimento urbano, uma aptidão para atuarem como cidades dormitório, por outro, características como o controle de acessos podem afetar a influência no entorno próximo desta infraestrutura rodoviária.

Para analisar como a evolução da mancha urbana se deu com a instalação do Rodoanel foram utilizadas imagens de sensoriamento remoto, baseando-se no arcabouço metodológico discutido na próxima seção.

\subsection{Sensoriamento Remoto em Áreas Urbanas}

A análise do espaço urbano pode ser realizada por meio das variáveis físico-territoriais obtidas de imagem de satélite, facilitando o monitoramento terrestre da superfície (FLORENZANO, 2011). Nesse sentido, as imagens de sensoriamento remoto têm sido utilizadas para o monitoramento da distribuição espacial urbana (HE et al., 2010).

Em especial, as imagens orbitais obtidas nas faixas do espectro eletromagnético infravermelho, são capazes de definir melhor o comportamento espectral ou sua assinatura espectral das áreas urbanizadas (LUCHIARI et al., 2011). As áreas urbanas são compostas por variados tipos de materiais incluindo os materiais impermeáveis, solos, rochas e a vegetação. Desta forma, um pixel com resolução de 30 metros ( $900 \mathrm{~m}^{2}$ no terreno) no caso do LANDSAT (Land Remote Sensing Satellite) será composto de vários materiais, o que representa um desafio na interpretação e que motivou o desenvolvimento de índices capazes de separar as áreas urbanas dentro dos pixels (WENG, 2012).

4.2.1 Aplicação dos Índices de Sensoriamento Remoto em áreas urbanas

Para Zha et al (2003) os índices para a interpretação das imagens orbitais são mais eficientes, rápidos e demandam menores intervenções humanas nos 
resultados. Assim, surgiu uma grande variedade de métodos para realizar estas interpretações, como o NDVI (Normalized Density Vegetation Index) para vegetação utilizando as bandas vermelha e infravermelho próximo, NDSI (Normalized Density Snow Index) para normalizar a presença de neve, utilizando as bandas verde e infravermelho médio, NDWI (Normalized Density Water Index) é o índice normalizado da presença de água, nas bandas verde e infravermelho próximo (ZHA et al., 2003).

Vários índices foram propostos, com diversas finalidades e aplicações em ambientes urbanos. Por exemplo Shao et al. (2014), estabelecem um índice para extrair áreas construídas de imagens orbitais de alta resolução, BASI - Built-Up Areas Saliency Index - é obtido a partir de características texturais de área construída. Chen et al (2006) e Lee et al (2010) utilizaram os índices NDVI, NDWI e NDBI, que serão detalhados a diante, para extrair as informações de uso e cobertura do solo e aplicaram também, subsequentemente, o índice NDBal (Normalized Difference Bareness Index), para separar as áreas de solo exposto.

Estoque e Murayama (2015) propõem os índices VrNIR-BI e VgNIR-BI (índices baseados nas bandas visíveis, red/green). Para a análise desses índices os autores realizaram uma comparação de vários índices espectrais em imagens LANDSAT 7 ETM+ (Enhanced Thematic Mapper Plus) e LANDSAT 8 OLI (Operational Land Image) em área urbana. Dentre os índices utilizados na comparação estão: o UI, que utilizam as bandas NIR (Near Infrared) e SWIR (Short-Wave Infrared), para explorar a relação inversa entre o brilho das áreas urbanas; o NDBI (Normalized Difference Built Index); o IBI (Index Based Built-Up Index), para classificar as áreas construídas também nas faixas NIR e SWIR e, também o NDISI. Seus resultados, mostraram que o VgNIR-BI e VrNIR-BI foram mais robustos na diferenciação dos alvos analisados.

Zhou (2014) a partir do NDBI, criou o BBI (Built-Up and Bareness Index) especificamente para o sensor OLI (LANDSAT 8) a partir de imagem binária com apenas áreas edificadas (blue-roofed, red-roofed and grey-roofed).

Xu (2008) e Balçik (2014) utilizaram o IBI para mapear os impactos da temperatura de superfície (LST). O IBI é derivado de três outros índices (SAVI Soil-Adjusted Vegetation Index, MNDWI - Modified Normalized Difference Water 
Index, e NDBI), sendo aplicado para a rápida extração de características de áreas construídas em imagens de sensoriamento remoto.

Posteriormente, Xu (2010) sugere o índice NDISI - Normalized Density Impervious Surface - para discriminar as áreas impermeáveis dentro de áreas urbanas, reduzindo o risco de mapear erroneamente áreas verdes.

A Tabela 1 apresenta a sistematização dos índices pesquisados durante a revisão bibliográfica, dando ênfase nos artigos que tinham como objetivo separar área urbana ou solo exposto visto que devido à similaridade da assinatura espectral, expressa uma das dificuldades encontradas durante a aplicação dos índices para a detecção das manchas urbanas nas imagens. A tabela contém em suas colunas os nomes dos índices utilizados ou método, o sensor, área de estudo, principais contribuições ou resultados, além de verificar se no estudo havia menção sobre a etapa de correção radiométrica durante o processamento dos dados. A discriminação das áreas de estudo é importante para o discernimento do contexto em que o método foi aplicado. A heterogeneidade nas áreas urbanas pode afetar o comportamento dos índices, devido aos diferentes fatores que influenciam como o tipo de relevo da região analisada.

Foi constatado que na literatura existe uma divergência quanto à aplicação da correção radiométrica anterior à aplicação dos índices. Nos artigos analisados, 15 realizaram algum tipo de correção radiométrica, contudo, em He et al (2010) a correção radiométrica não é utilizada nas imagens que geraram o índice proposto, BUILT-UP. Zha et al (2003) que propuseram o índice NDBI, aplica apenas a correção geométrica, conforme descrito na tabela a seguir.

\begin{tabular}{|c|c|c|c|c|c|}
\hline AUTORES & $\begin{array}{c}\text { ÍNDICES } \\
\text { UTILIZADOS } \\
\text { OU MÉTODO }\end{array}$ & SENSOR & $\begin{array}{c}\text { ÁREA DE } \\
\text { INTERESSE }\end{array}$ & $\begin{array}{c}\text { PRINCIPAIS } \\
\text { CONTRIBUIÇÕES }\end{array}$ & $\begin{array}{c}\text { CORREÇÃO } \\
\text { RADIOMÉTRICA }\end{array}$ \\
\hline $\begin{array}{l}\text { BALÇIK, } \\
\mathbf{2 0 1 4}\end{array}$ & IBI, LST & $\begin{array}{l}\text { LANDSA } \\
\text { T } 5 \text { TM } \\
\text { LANDSA } \\
\text { T } 7 \text { ETM+ }\end{array}$ & Istanbul & $\begin{array}{c}\text { Temperatura da } \\
\text { superfície, NDBI, } \\
\text { LULC }\end{array}$ & $\begin{array}{l}\text { Aplicou a correção } \\
\text { atmosférica por } \\
\text { subtração do objeto } \\
\text { escuro }\end{array}$ \\
\hline $\begin{array}{l}\text { BHATTI } \\
\text { AND } \\
\text { TRIPATHI, } \\
\mathbf{2 0 1 4}\end{array}$ & NDBI & $\begin{array}{c}\text { LANDSA } \\
\text { T } 8 \text { OLI }\end{array}$ & $\begin{array}{l}\text { Lahore, } \\
\text { Pakistan }\end{array}$ & $\begin{array}{c}\text { NDVI, NDBI, } \\
\text { BUILT-UP. NDBIoli } \\
\text { = utiliza PCA; } \\
\text { MNDWIoli; } \\
\text { BAEMoli (proposto) }\end{array}$ & $\begin{array}{l}\text { Aplicou a TOA } \\
\quad \text { (Top of } \\
\text { Atmospheric) }\end{array}$ \\
\hline
\end{tabular}




\begin{tabular}{|c|c|c|c|c|c|}
\hline $\begin{array}{l}\text { CHEN ET } \\
A L, 2006\end{array}$ & $\begin{array}{c}\text { LUCC, UHI, } \\
\text { NDWI, NDVI, } \\
\text { NDBI, NDBal, } \\
\text { PRD, } \\
\text { Vegetation } \\
\text { water content. }\end{array}$ & $\begin{array}{c}\text { Ikonos, } \\
\text { LANDSA } \\
\text { T } 7 \text { ETM+ }\end{array}$ & $\begin{array}{l}\text { Shenzhen, } \\
\text { China }\end{array}$ & Aplicação dos índices & $\begin{array}{l}\text { Aplicou um filtro } \\
\text { auto adaptativo } \\
\text { (ruído não } \\
\text { paramétrico) e } \\
\text { transformada rápida } \\
\text { de Fourier para } \\
\text { remover } \\
\text { automaticamente o } \\
\text { ruído periódico }\end{array}$ \\
\hline $\begin{array}{l}\text { CHEN ET } \\
\boldsymbol{A} \boldsymbol{L}, \mathbf{2 0 0 0}\end{array}$ & & & Shanghai & $\begin{array}{c}\text { Crescimento urbano } \\
\text { na China / conceitos } \\
\text { de áreas } \\
\text { impermeáveis e } \\
\text { crescimento urbano }\end{array}$ & $\begin{array}{l}\text { Não consta a } \\
\text { informação }\end{array}$ \\
\hline $\begin{array}{l}\text { DEHNI } \\
\text { AND } \\
\text { LOUNIS, } \\
\mathbf{2 0 1 2}\end{array}$ & $\begin{array}{l}\text { IBI e índices de } \\
\text { agricultura }\end{array}$ & $\begin{array}{l}\text { LANDSA } \\
\text { T 7, } \\
\text { ASTER }\end{array}$ & Oran, Algeria & $\begin{array}{l}\text { NDBI aplicação na } \\
\text { agricultura }\end{array}$ & $\begin{array}{l}\text { Cita a correção } \\
\text { radiométrica, mas } \\
\text { não é especifico se } \\
\text { houve a aplicação }\end{array}$ \\
\hline $\begin{array}{c}\text { HE ET } A L, \\
2010\end{array}$ & Built-Up & $\begin{array}{c}\text { LANDSA } \\
\mathbf{T}\end{array}$ & $\begin{array}{c}\text { National } \\
\text { Olympic } \\
\text { Park, Beijing }\end{array}$ & $\begin{array}{l}\text { Propôs o Built-Up } \\
\text { index }\end{array}$ & $\begin{array}{l}\text { Correção } \\
\text { radiométrica é } \\
\text { aplicada na } \\
\text { imagem de teste } \\
\text { (para comparar } \\
\text { com a imagem } \\
\text { resultante do } \\
\text { Built-Up index) }\end{array}$ \\
\hline $\begin{array}{l}\text { IM } E T A L \\
2012\end{array}$ & $\begin{array}{c}\text { Artificial } \\
\text { immune } \\
\text { network and } \\
\text { decision tree }\end{array}$ & $\begin{array}{l}\text { LANDSA } \\
\text { T TM }\end{array}$ & Syracuse, NY & $\begin{array}{l}\text { Utiliza a rede de } \\
\text { imunidade artificial } \\
\text { para extrair as } \\
\text { superfícies } \\
\text { impermeáveis }\end{array}$ & Não aplicou \\
\hline $\begin{array}{c}\text { JACOB } \\
\text { AND } \\
\text { DWARAKI } \\
\text { SH, 2015 }\end{array}$ & $\begin{array}{l}\mathrm{LU} / \mathrm{LC} \\
\text { Impervious } \\
\text { cover }\end{array}$ & $\begin{array}{l}\text { Satellite } \\
\text { imagery } \\
\text { of IRS-P6 } \\
\text { LISS-III, } \\
\text { SRTM }\end{array}$ & $\begin{array}{l}\text { Cochin, } \\
\text { Kerala }\end{array}$ & & $\begin{array}{l}\text { Não consta a } \\
\text { informação }\end{array}$ \\
\hline $\begin{array}{c}\text { LEE } \boldsymbol{E T} \\
\boldsymbol{A} \boldsymbol{L}, \mathbf{2 0 1 0}\end{array}$ & Built-Up index & $\begin{array}{l}\text { LANDSA } \\
\text { T TM } \\
\text { LANDSA } \\
\text { T ETM+ }\end{array}$ & $\begin{array}{c}\text { Cheonaran } \\
\text { City and Asan } \\
\text { City }\end{array}$ & $\begin{array}{l}\text { Re classifica o Built- } \\
\text { Up }\end{array}$ & $\begin{array}{l}\text { Não consta a } \\
\text { informação }\end{array}$ \\
\hline $\begin{array}{c}\text { LEE } \boldsymbol{E T} \\
\boldsymbol{A} \boldsymbol{L}, \mathbf{2 0 1 1}\end{array}$ & NDBI, NDBal & $\begin{array}{l}\text { LANDSA } \\
\text { T TM } \\
\text { LANDSA } \\
\text { T ETM+ }\end{array}$ & Xuzhou City & $\begin{array}{l}\text { Classifica os tipos de } \\
\text { uso e cobertura da } \\
\text { terra e compara com } \\
\text { as ilhas de calor. }\end{array}$ & Não aplicou \\
\hline $\begin{array}{l}\text { LI AND } \\
\text { YU, 2008 }\end{array}$ & NDVI, NDBI & $\begin{array}{l}\text { LANDSA } \\
\text { T ETM+ }\end{array}$ & Wuhan, China & $\begin{array}{l}\text { Compara NDVI e } \\
\text { NDBI com } \\
\text { temperatura de } \\
\text { superfície e método } \\
\text { CFD, utilizado para } \\
\text { validar a melhoria do } \\
\text { ambiente de calor } \\
\text { numa cidade por meio } \\
\text { do vento }\end{array}$ & $\begin{array}{l}\text { Não consta a } \\
\text { informação }\end{array}$ \\
\hline $\begin{array}{l}\text { ROGERS \& } \\
\text { KEARNEY, } \\
\mathbf{2 0 1 0}\end{array}$ & $\begin{array}{l}\text { Modelos de } \\
\text { misturas } \\
\text { espectrais }\end{array}$ & $\begin{array}{l}\text { LANDSA } \\
\text { T TM }\end{array}$ & & $\begin{array}{c}\text { Redução da } \\
\text { variabilidade espectral } \\
\text { nos índices }\end{array}$ & $\begin{array}{c}\text { Aplicou a correção } \\
\text { Atmosférica }\end{array}$ \\
\hline $\begin{array}{l}\text { SALLEH } \\
\text { ET AL, } \\
\mathbf{2 0 1 3}\end{array}$ & $\begin{array}{l}\text { LST, NDBI and } \\
\text { NDVI }\end{array}$ & $\begin{array}{l}\text { LANDSA } \\
\text { T ETM+ }\end{array}$ & $\begin{array}{l}\text { Putrajaya, } \\
\text { Malaysia }\end{array}$ & $\begin{array}{l}\text { Compreender os } \\
\text { fenômenos que } \\
\text { contribuem para a } \\
\text { formação da ilha de } \\
\text { calor em Putrajaya }\end{array}$ & $\begin{array}{l}\text { Aplicou a Correção } \\
\text { atmosférica por } \\
\text { subtração do objeto } \\
\text { escuro }\end{array}$ \\
\hline $\begin{array}{l}\text { SMALL ET } \\
\boldsymbol{A} \boldsymbol{L}, \mathbf{2 0 1 5}\end{array}$ & $\begin{array}{l}\text { SVD end } \\
\text { members }\end{array}$ & & São Paulo & $\begin{array}{l}\text { Solução para } \\
\text { problemas multi } \\
\text { escala para mapear } \\
\text { superfícies peri- } \\
\text { urbanas e suburbanas }\end{array}$ & $\begin{array}{l}\text { Não consta a } \\
\text { informação }\end{array}$ \\
\hline
\end{tabular}




\begin{tabular}{|c|c|c|c|c|c|}
\hline $\begin{array}{l}\text { TAUBENB } \\
\text { ÖCK } \boldsymbol{E T} \\
\boldsymbol{A} \boldsymbol{L}, \mathbf{2 0 0 9}\end{array}$ & $\begin{array}{l}\text { Area, Built-Up } \\
\text { density, LSI, } \\
\text { LPI, NP, PD... }\end{array}$ & $\begin{array}{l}\text { LANDSA } \\
\mathrm{T}\end{array}$ & $\begin{array}{l}\text { India: } 12 \\
\text { cidades }\end{array}$ & $\begin{array}{l}\text { Multi-escala de } \\
\text { análise temporal na } \\
\text { densidade de área } \\
\text { construída }\end{array}$ & $\begin{array}{c}\text { Aplicou a Correção } \\
\text { Atmosférica }\end{array}$ \\
\hline $\begin{array}{l}\text { VARSHNE } \\
\text { Y } 2013\end{array}$ & $\begin{array}{l}\text { Improved NDBI } \\
\text { (abordagem } \\
\text { automática) }\end{array}$ & $\begin{array}{l}\text { LANDSA } \\
\text { T TM }\end{array}$ & Delhi, Índia & $\begin{array}{c}\text { Propõe uma } \\
\text { abordagem } \\
\text { automática para o } \\
\text { NDBI proposto por } \\
\text { He et al (2010) }\end{array}$ & $\begin{array}{c}\text { Realizou a } \\
\text { conversão do } \\
\text { número digital de } \\
\text { pixels para reflexão } \\
\text { espectral }\end{array}$ \\
\hline $\begin{array}{l}\text { WANG } E T \\
A L, 2015\end{array}$ & $\begin{array}{l}\text { LST, NDVI, } \\
\text { NDBI }\end{array}$ & $\begin{array}{l}\text { MODIS, } \\
\text { ASTER }\end{array}$ & Washington & $\begin{array}{c}\text { Compõe os índices } \\
\text { para os dois satélites e } \\
\text { compara }\end{array}$ & $\begin{array}{l}\text { Aplicou a correção } \\
\text { atmosférica apenas } \\
\text { para gerar o NDVI }\end{array}$ \\
\hline $\begin{array}{l}\text { WENG, } \\
\mathbf{2 0 1 2}\end{array}$ & $\begin{array}{l}\text { Revisão de } \\
\text { índices e } \\
\text { métodos }\end{array}$ & & & $\begin{array}{c}\text { Revisão dos índices, } \\
\text { métodos e aplicações } \\
\text { para a extração das } \\
\text { superfícies } \\
\text { impermeáveis nas } \\
\text { áreas urbanas }\end{array}$ & \\
\hline XU, 2008 & IBI & $\begin{array}{l}\text { LANDSA } \\
\text { T ETM+ }\end{array}$ & Fuzhou, China & $\begin{array}{l}\text { Propõe o IBI (Index- } \\
\text { based Built-Up } \\
\text { index), através dos } \\
\text { índices SAVI, } \\
\text { MNDWI, NDBI. }\end{array}$ & $\begin{array}{c}\text { Aplicou a correção } \\
\text { atmosférica }\end{array}$ \\
\hline XU, 2010 & NDIDI & $\begin{array}{l}\text { LANDSA } \\
\text { T ETM+ }\end{array}$ & Fuzhou, China & $\begin{array}{l}\text { Propõe o NDISI } \\
\text { (Normalized } \\
\text { Difference } \\
\text { Impervious Surface } \\
\text { Index) }\end{array}$ & $\begin{array}{l}\text { Aplicou a correção } \\
\text { atmosférica }\end{array}$ \\
\hline $\begin{array}{l}\text { YANG } \\
\text { AND LIU, } \\
\mathbf{2 0 0 5}\end{array}$ & $\begin{array}{l}\text { Imperviousness } \\
\text { Index }\end{array}$ & $\begin{array}{l}\text { LANDSA } \\
\text { T TM } \\
\text { LANDSA } \\
\text { T ETM+ } \\
\text { SPOT }\end{array}$ & $\begin{array}{l}\text { Pensacola } \\
\text { Metropolitan } \\
\text { Statistical } \\
\text { Area, USA }\end{array}$ & $\begin{array}{l}\text { Propõe o índice para } \\
\text { capturar as áreas de } \\
\text { superfície } \\
\text { impermeáveis. }\end{array}$ & $\begin{array}{l}\text { Aplicou a correção } \\
\text { radiométrica }\end{array}$ \\
\hline $\begin{array}{l}\text { ZHA } E T \\
A L, 2003\end{array}$ & NDBI & $\begin{array}{c}\text { LANDSA } \\
\mathbf{T}\end{array}$ & $\begin{array}{c}\text { Nanjing, } \\
\text { China }\end{array}$ & $\begin{array}{c}\text { Propõe o índice } \\
\text { NDBI }\end{array}$ & Não aplica \\
\hline $\begin{array}{l}\text { ZHANG } E T \\
A L, 2009\end{array}$ & $\begin{array}{l}\text { NDVI e NDBI } \\
\text { LST, e ISA }\end{array}$ & $\begin{array}{l}\text { IKONOS, } \\
\text { LANDSA } \\
\quad \mathrm{T}\end{array}$ & & $\begin{array}{l}\text { Utiliza o NDVI e o } \\
\text { NDBI para calcular } \\
\text { áreas impermeáveis e } \\
\text { também imagem de } \\
\text { alta resolução Ikonos } \\
\text { para extrair o ISA }\end{array}$ & $\begin{array}{l}\text { Aplicou a correção } \\
\text { radiométrica (TOA) }\end{array}$ \\
\hline $\begin{array}{l}\text { ZHAO } \\
\text { AND } \\
\text { CHEN, } \\
\mathbf{2 0 0 9}\end{array}$ & $\begin{array}{l}\text { NDBI (Bareness } \\
\text { Index); NDSI; } \\
\text { BI; NDBal }\end{array}$ & $\begin{array}{l}\text { LANDSA } \\
\text { T ETM+ }\end{array}$ & $\begin{array}{l}\text { Yellow River } \\
\text { Delta (YRD), } \\
\text { China }\end{array}$ & $\begin{array}{c}\text { Utiliza os índices } \\
\text { como base para } \\
\text { propor o NDBal } \\
\text { (Normalized, } \\
\text { Difference Bareness } \\
\text { Index). }\end{array}$ & $\begin{array}{c}\text { Realizou a redução } \\
\text { de ruídos }\end{array}$ \\
\hline $\begin{array}{c}\text { ZHOU ET } \\
A L, 2014\end{array}$ & $\begin{array}{l}\text { NDBI for OLI } \\
\text { data }\end{array}$ & $\begin{array}{l}\text { LANDSA } \\
\text { T } 8 \text { OLI }\end{array}$ & $\begin{array}{l}\text { Zhengzhou, } \\
\text { China }\end{array}$ & $\begin{array}{c}\text { Propõe adequações } \\
\text { para aplicação do } \\
\text { índice NDBI nas } \\
\text { imagens LANDSAT } 8 \\
\text { OLI }\end{array}$ & $\begin{array}{c}\text { Aplicou a correção } \\
\text { atmosférica } \\
\text { (FLAASH) }\end{array}$ \\
\hline
\end{tabular}

Dos 25 artigos descritos na Tabela 2, 17 utilizam o índice NDBI ou derivados deste como o BUILT-UP, IBI, NDBI for OLI data, BUILT UP DENSITY e em 20, utilizam a série de sensores LANDSAT (variando entre os sensores TM, ETM+ e OLI), o que parece razoável dado que sensores desta série possuem 
faixas no SWIR e NIR, que são essenciais para a aplicação do NDBI, além da grande oferta de imagens gratuitas e sua série temporal com imagens desde a década de 1970.

\subsection{Definição dos Índices NDBI, NDVI e BUILT-UP}

O índice denominado NDBI, combina as faixas do espectro eletromagnético relativas ao infravermelho próximo e ao infravermelho médio, para analisar o crescimento de áreas construídas, auxiliar na classificação do uso e ocupação da superfície do ambiente urbano (ESTOQUE E MURAYAMA, 2015). Esta técnica tem larga aplicação (LI et al, 2008; COSTĂCHIOIU e DATCU, 2010; SALLEH et al, 2013; WANG et al, 2015;) e demostra boa acurácia quando comparada com outros índices de identificação do crescimento urbano (CHEN et al, 2006; MENG et al, 2009).

Proposto por Zha et al, (2003) o NDBI é a diferença normalizada para áreas construídas, com a finalidade de incrementar o número digital destas respectivas áreas nos intervalos das bandas do infravermelho próximo (NIR) e infravermelho médio (SWIR). O NDBI é construído a partir da Fórmula 1:

$$
N D B I=\frac{(S W I R-N I R)}{(S W I R+N I R)}
$$

Conforme Xu (2008), é possível que o NDBI se misture com o ruído nas imagens e outras classes de uso como solo exposto, porque os valores de refletância são próximos aos valores das áreas urbanas. Dessa forma, o índice proposto por He et al (2010), denominado Built-Up Index, pode ser utilizado para evidenciar áreas impermeabilizadas e a vegetação de ambientes urbanos, pois considera a relação entre o índice NDBI e o NDVI. O Built-Up Index foi escolhido para a extração da superfície construída por sua precisão na separação de área urbana com o solo exposto (HE et al., 2010). 
Os estudos apresentados por Im et al. (2012), Lee et al. (2010) e Varshney (2013), comprovam, o Built-Up Index é capaz de separar a superfície urbana e mostram métodos para aperfeiçoar a identificação do crescimento urbano.

O NDVI - Normalized Density Vegetation Index - é o índice que permite a análise e separação de tipos e densidade de cobertura vegetal, um dos primeiros estudos foi realizado pelo Dr. John Rouse (ROUSE, 1973) quando o LANDSAT 1 foi lançado. É obtido a partir dos comprimentos de onda em que a vegetação tem alta refletância, o infravermelho próximo (NIR) e a banda do visível de baixa reflectância, vermelho (RED) (HE et al., 2010).

O cálculo do índice NDVI, é dado pela diferença normalizada da vegetação, foi realizado conforme apresentado pela Formula 2:

$$
N D V I=\frac{(N I R-R E D)}{(N I R+R E D)}
$$

O BUILT-UP é um índice proposto por He et al. (2010) a fim de aperfeiçoar a separação de áreas construídas (superfícies impermeáveis) de áreas não construídas (superfícies permeáveis). É derivado de imagens binárias dos índices NDBI e NDVI. Nestas imagens binárias os valores positivos de NDVI indicam áreas permeáveis, vegetação, e os valores positivos de NDBI indicam as áreas impermeáveis, ocupação urbana. A partir das imagens binárias geradas obtém-se o Built-Up através da equação descrita na fórmula 3 (HE et al, 2010):

$$
\text { Built_Up } p^{b}=N D B I^{b}-N D V I^{b}
$$

O resultado do índice Built-Up é uma imagem binária, onde as áreas urbanas devem ter valor de 1 e as áreas não urbanas valor 0 (HE et al., 2010).

\subsection{Técnica de Votação}

A técnica de votação de maioria simples (Majority Voting) é um método de nível abstrato oriundo da regra de votos ("vote rules"). Tem sido amplamente utilizada em classificações provando ser uma estratégia eficaz (MANFRÉ et al., 
2016) por determinar as classes pelo resultado da maioria simples de votos, a classe que irá permanecer é aquela mais recorrente entre os resultados dos classificadores (Campos et al. 2016).

Kittler (1998) apresenta a fórmula para a regra do método de votação. Esta regra é obtida a partir da regra de soma, sendo menos susceptível a erros, reduzindo o efeito da variabilidade. Em Xu et al. (1992) uma análise de votação foi realizada para calcular a classificação de cada algoritmo e a classe mais recorrente k é atribuída ao pixel j analisado.

Devido ao seu princípio básico de determinar as classes pelo resultado da maioria simples de votos, prevalece a classe mais recorrente entre os vários classificadores utilizados. Quando os votos são iguais, os rótulos de classe são obtidos aplicando o seletor de valor máximo às somas de classe (ou médias) (LIU et al., 2014).

Kittler (1998) traz uma extensa revisão dos algoritmos aplicados em regras de produto, soma, mínimo e majoritário, o autor afirma que a regra de votos majoritários é obtida a partir da regra de soma sob o pressuposto de que todas as classes são a priori equiprováveis e as saídas de peritos individuais são endurecidas nas saídas e zero, caso contrário. Como as estratégias de combinação, a regra máxima e o voto estão relacionados à regra de soma, eles são menos sensíveis aos erros de estimação e, portanto, são susceptíveis de apresentar melhor desempenho do que a regra de mínimos, que pode ser derivado da regra do produto.

A Figura 3 apresenta um fluxograma explicativo para a melhor compreensão da técnica de votação. Nela se encontram 5 quadrados que representam os resultados do mapeamento do Built-Up para o mesmo ano e no pixel destacado, em cinza seriam os pixels mapeados como área construída e os pixels em branco, mapeados como área não construída. De acordo com a regra de votação de maioria simples, aquela classe que houve maior incidência é a classe vencedora, portanto neste caso é expressa por área construída. 


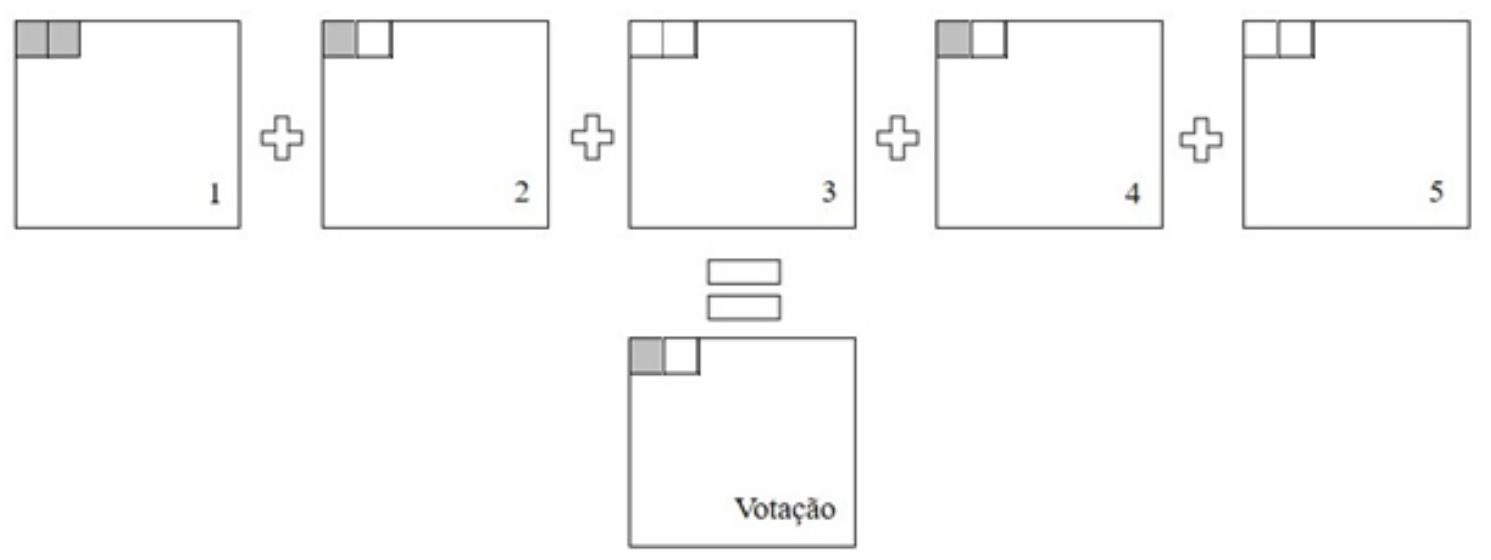

Figura 3: Fluxograma do funcionamento da técnica de votação. Elaboração: Bacic, 2017.

Manfré et al (2016) utilizou o método de votação juntamente com a análise contextual e métodos de seleção aleatória e a precisão foi avaliada para cada conjunto de classificação, sendo que um aumento progressivo na precisão do conjunto foi observado como os classificadores menos precisos foram removidos.

Para Campos et al. (2016) a precisão de uma classificação pode ser aprimorada ao utilizar uma combinação de classificadores, que potencializem a tomada de decisão, ou pela seleção do classificador com melhor desempenho. Manfré et al. (2016) mostra que a técnica de votação, vem sendo empregada para trazer um resultado mais acurado as classificações.

Angeli et al (2012) utiliza a rotulação dos neurônios do mapa de Kohonen, de modo que o algoritmo MTM rotula automaticamente cada neurônio por maioria de votos. O autor referenciado, reitera que na fase de pós processamento não se utilizou imagens de satélite, mas se houvesse utilizado o valor radiométrico do pixel seria substituído pelo valor de peso do neurônio vencedor antes de executar o esquema de processamento de imagem para simplificar o problema.

Gislason et al. (2006) utiliza a maioria de votação para auxiliar na classificação das áreas de florestas. Grinand et al. (2013) também faz a classificação de florestas aleatórias. Emprega árvores de decisão (classificação) e uma a regra de voto majoritário é aplicada para determinar a categoria final. 
Neste trabalho, foi desenvolvido modelos que utilizam as bandas e índices refletidos tal qual como o NDVI e NIRI para cada data analisada.

Campos et al. (2016) avalia oito classificadores através da técnica de votação para representar seis classes de cobertura do solo. A técnica foi selecionada para avaliar o desempenho de classificadores, onde um pixel é efetivamente atribuído à classe que a sua probabilidade de pertinência seja maior na maioria dos classificadores utilizados.

Patel et al. (2015) utilizou imagens LANDSAT para extração de áreas urbanas, em seguida, combinar com os mapas resultantes por maioria de votos. Da mesma forma, as coletas de três anos foram subdivididas em terços (uma por ano) e depois combinadas por maioria de votos. Para comprovar a eficácia da técnica de mapeamento de áreas urbanas e a contagem de população ao longo de vários anos, o último teste repete a abordagem do terceiro, mas usa dados LANDSAT coletados dois anos depois.

Du et al. (2014) exploraram o desempenho de três classificadores em uma primeira fase e oito na fase subsequente. $O$ voto de maioria melhorou a precisão em $93,49 \%$.

Waske e Braun (2009) trazem uma revisão a respeito das possíveis aplicações em redes neurais (ANN), árvores de decisão (DT) e support vector machine (SVM) por exemplo. Os autores tem o foco de seu estudo no treinamento do classificador de base em dados de entrada modificados (amostras de treinamento ou recursos de entrada), gerando um conjunto de classificadores independentes, esses resultados são então combinados ao resultado final por meio da técnica de votação. O modo de voto por maioria simples, pode ser mais eficaz do que estratégias de votação mais complexas. $O$ conceito geral baseia-se no pressuposto de que classificadores independentes produzem erros individuais, que não são produzidos pela maioria dos outros classificadores.

BREIMAN (2001) utiliza vários classificadores e depois fez a votação dos pixels, explicando detalhadamente as fórmulas utilizadas. Onde a técnica de votação, foi aplicada em uma análise multitemporal de índices de sensoriamento remoto para a determinação da mancha urbana, com isso ao invés de mapear 
várias classes apenas foram mapeadas as áreas construídas e não construídas. Mais aplicações podem ser encontradas em GIACINTO \& ROLI (2001), GARCÍAGUTIÉRREZ et al. (2005), BAGAN et al. (2015).

Waske e Braun (2009) afirmam que apesar de comumente a técnica de votação ser utilizada na combinação de vários classificadores, ela pode ser aplicada na combinação de vários resultados de um mesmo classificador.

Neste trabalho o método de votação é aplicado visando melhorar o mapeamento da mancha urbana, base para a análise sobre o impacto do Rodoanel.

\section{MATERIAIS E MÉTODOS}

Nas seções abaixo estão descritos os pontos referentes a área de estudo, materiais e métodos.

\section{1 Área De Estudo}

A área de estudo está localizada na RMSP e abrange a microrregião de Osasco, composta pelos municípios de Barueri, Carapicuíba, Cotia, Embu, Osasco e Santana de Parnaíba que compreendem parte do Rodoanel (Trecho Oeste).

\subsubsection{Rodoanel}

O Rodoanel Mário Covas (SP-21) foi idealizado para oferecer alternativa aos veículos, especialmente de carga, desviando a rota das Marginais Tietê e Pinheiros, para minimizar o congestionamento urbano e é considerado um instrumento de desenvolvimento urbano, preservação ambiental, racionalização do transporte e promoção da integração regional (DERSA, 1997). A rodovia é 
concessionada pela Companhia de Concessões Rodoviárias (CCR-Rodoanel) e recebe cerca de 240 mil veículos por dia (CCR-Rodoanel, 2016).

O trecho de interesse é localizado na porção oeste, foi inaugurado em 11 de outubro de 2002, o marco zero é localizado na Avenida Raimundo Pereira de Magalhães (Bairro Perus, São Paulo) e possui 32 quilômetros de extensão, intersecta as rodovias Anhanguera (SP-330), Bandeirantes (SP-348), Castelo Branco (SP-280), Raposo Tavares (SP-270) e Régis Bittencourt (BR-116). Os acessos urbanos no trecho Oeste se dão nas cidades de Osasco (Jardim Padroeira) e em Carapicuíba (Parque Jandaia).

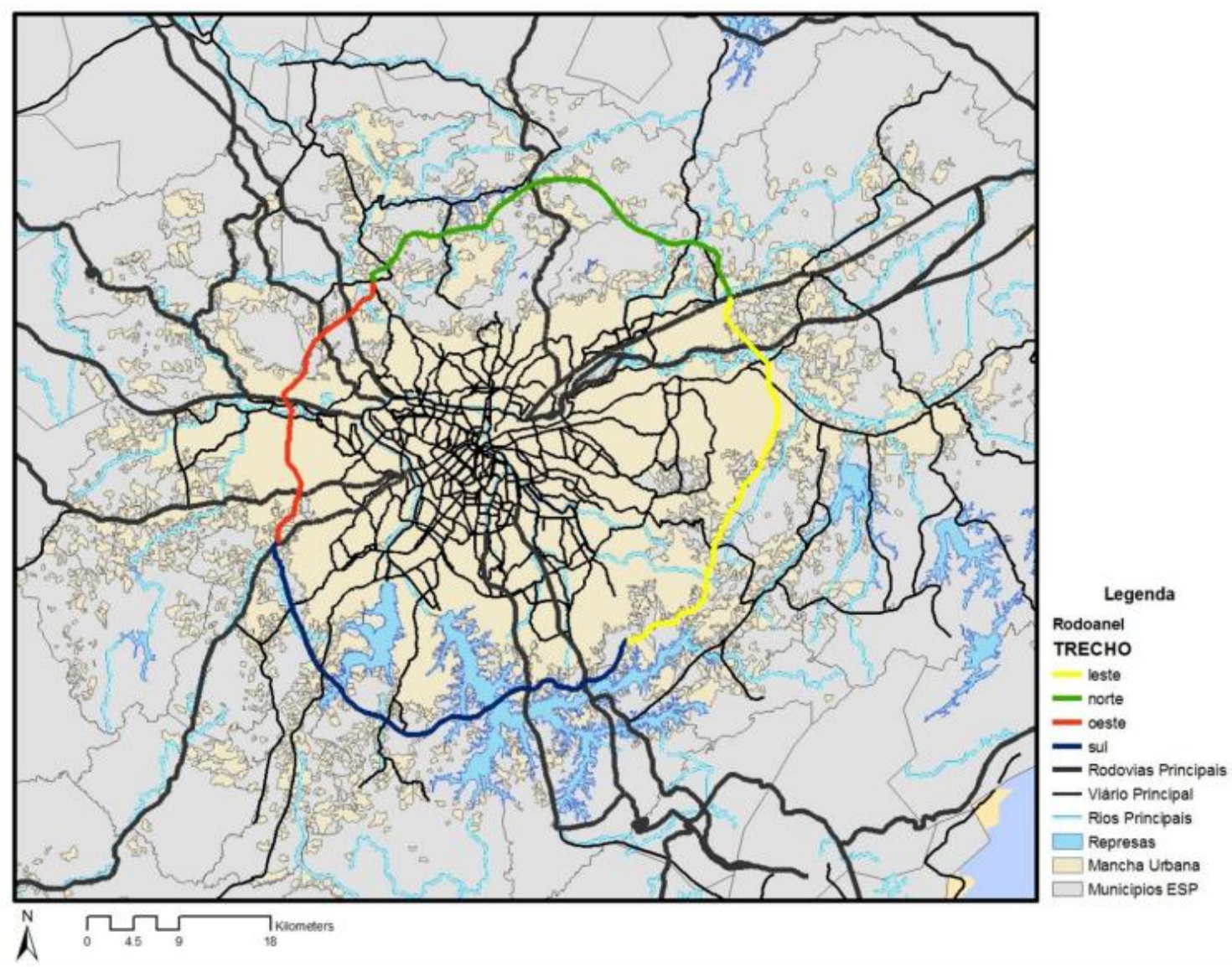

Figura 4: Mapa de Localização do Rodoanel. Fonte: Maciel 2011. 


\subsubsection{Municípios da Microrregião de Osasco}

A Tabela 2, abaixo é composta pelas informações geográficas dos municípios, tais como habitantes, tamanho territorial, densidade demográfica e as respectivas coordenadas UTM.

\begin{tabular}{|c|c|c|c|c|}
\hline Municípios & Habitantes & $\begin{array}{c}\text { Unidade } \\
\text { territorial } \\
\left(\mathbf{k m}^{2}\right)\end{array}$ & $\begin{array}{c}\text { Densidade } \\
\text { demográfica } \\
(\text { hab./km²) }\end{array}$ & $\begin{array}{c}\text { Coordenadas } \\
\text { UTM }\end{array}$ \\
\hline Barueri & 240.749 & 65,701 & $3.665,21$ & $\begin{array}{l}23^{\circ} 30^{\prime} 38^{\prime \prime} \mathrm{S} \\
46^{\circ} 52^{\prime} 34^{\prime \prime} \mathrm{O}\end{array}$ \\
\hline Carapicuíba & 369.584 & 34,546 & $10.698,32$ & $\begin{array}{l}23^{\circ} 31^{\prime} 21^{\prime \prime} \mathrm{S} \\
46^{\circ} 50^{\prime} 08^{\prime \prime} \mathrm{O}\end{array}$ \\
\hline Cotia & 201.150 & 323,994 & 620,81 & $\begin{array}{l}23^{\circ} 36^{\prime} 14^{\prime \prime} \mathrm{S} \\
46^{\circ} 55^{\prime} 09^{\prime \prime} \mathrm{O}\end{array}$ \\
\hline Embu & 240.230 & 70,398 & $3.412,89$ & $\begin{array}{l}23^{\circ} 38^{\prime} 56^{\prime \prime} \mathrm{S} \\
46^{\circ} 51^{\prime} 07^{\prime \prime} \mathrm{O}\end{array}$ \\
\hline Osasco & 666.740 & 64,954 & $10.264,80$ & $\begin{array}{l}23^{\circ} 31^{\prime} 57^{\prime \prime} \mathrm{S} \\
46^{\circ} 47^{\prime} 30^{\prime \prime} \mathrm{O}\end{array}$ \\
\hline $\begin{array}{c}\text { Santana de } \\
\text { Parnaíba }\end{array}$ & 108.813 & 179,949 & 604,74 & $\begin{array}{l}23^{\circ} 26^{\prime} 39^{\prime}, \mathrm{S} \\
46^{\circ} 55^{\prime} 04^{\prime}, \mathrm{O}\end{array}$ \\
\hline
\end{tabular}

Tabela 2: Dados dos municípios. Fonte: IBGE 2010.

A Figura 5 abaixo mostra a localização dos municípios da micro região de Osasco, o município de São Paulo ao lado, bem como o Rodoanel em vermelho e as rodovias que o interceptam representadas na cor preta. 


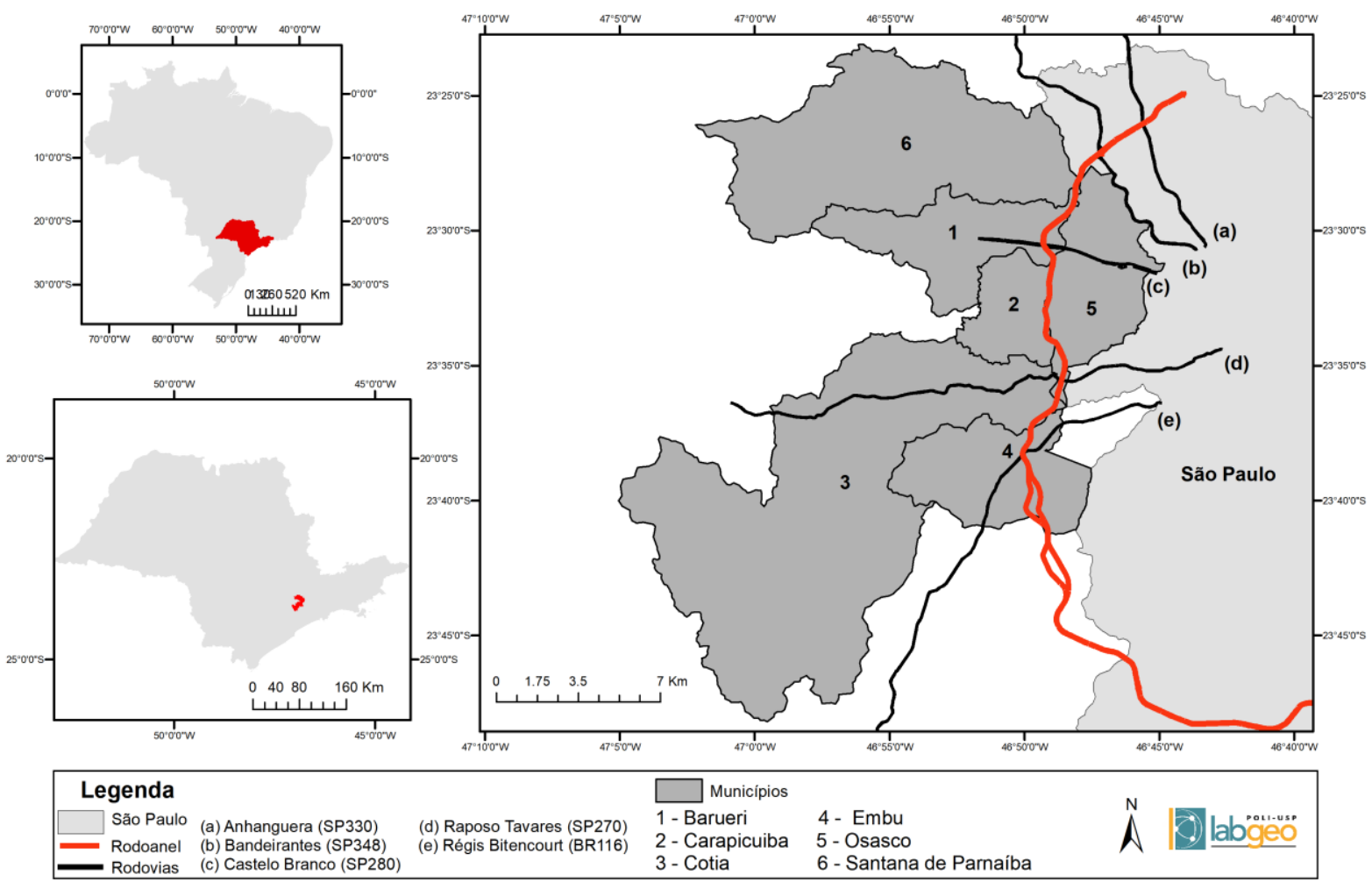

Figura 5: Mapa de localização dos municípios.

Os municípios da área de estudo, são de grande importância no contexto da região metropolitana devido à busca da população por morar próximo a capital do estado e ter a possibilidade de maior qualidade de vida nos municípios menores. A Tabela 3, apresenta o crescimento absoluto da população nos municípios, bem como o percentual de aumento da população em cada um destes. O município de São Paulo obteve um aumento populacional de $8 \%$ e somente dois municípios da área de estudo apontaram um incremento inferior a este, são Carapicuíba e Osasco, enquanto Embu e Barueri marcaram um crescimento de $16 \%$, Cotia se destacou com 35\% e Santana de Parnaíba com $45 \%$. 


\begin{tabular}{ccccc}
\hline & \multicolumn{4}{c}{ Aumento da população nos municípios do Trecho Oeste } \\
\hline & Municípios & $\mathbf{2 0 0 0}$ & $\mathbf{2 0 1 0}$ & Aumento \\
\hline \multirow{2}{*}{ Trecho } & Barueri & 208.281 & 240.749 & $16 \%$ \\
\cline { 2 - 5 } Oeste & Carapicuíba & 344.596 & 369.584 & $7 \%$ \\
\cline { 2 - 5 } & Cotia & 148.987 & 201.150 & $35 \%$ \\
\cline { 2 - 5 } & Embu & 207.663 & 240.230 & $16 \%$ \\
\cline { 2 - 5 } & Osasco & 652.593 & 666.740 & $2 \%$ \\
\hline & Santana de Parnaíba & 74.828 & 108.813 & $45 \%$ \\
\hline
\end{tabular}

Tabela 3: Aumento da população nos municípios da área de estudo. Fonte: IBGE: Dados censitários 2000 e 2010.

A Tabela 4 que foi desenvolvida por Aranha (2011), mostra os municípios de interesse e São Paulo (como base comparativa), o campo Entrada (A) referese a quantidade de pessoas maiores de 15 anos que entram no município com motivo trabalho ou estudo e residem em outro município dentro da RMSP. O campo Saída (B) resume a quantidade de pessoas, maiores de 15 anos que, saem do município com destino a outro dentro da RMSP por motivo trabalho e ou estudo. A coluna de Diferença (A-B) é a subtração entre a quantidade de pessoas que entram e saem dos municípios referentes ás linhas.

\begin{tabular}{lccc}
\hline Municípios & Entrada (A) & Saída (B) & Diferença (A-B) \\
\hline Barueri & 43.018 & 20.981 & 22.037 \\
\hline Carapicuíba & 6.111 & 63.908 & -57.797 \\
\hline Cotia & 10.781 & 14.820 & -4.039 \\
\hline Embu & 4.886 & 29.189 & -24.303 \\
\hline Osasco & 35.113 & 102.600 & -67.487 \\
\hline Santana de Parnaíba & 4.319 & 10.533 & -6.214 \\
\hline São Paulo & $\mathbf{5 9 1 . 0 4 2}$ & $\mathbf{8 2 . 4 1 5}$ & $\mathbf{5 0 8 . 6 2 7}$ \\
\hline
\end{tabular}

Tabela 4: Fluxo de pessoas nos Municípios da RMSP em 2000. Adaptado de: Aranha, 2005. Dados: Censo 2000. Reorganização: Bacic (2018)

O município de Barueri originou-se das aldeias de índios que resistiram aos ataques dos bandeirantes com a ajuda de padres jesuítas, sendo elevada à 
categoria de freguesia em 1809. Em 1875 foi inaugurada a estação ferroviária da Estrada de Ferro Sorocabana e apenas em 1948 tornou-se um município. O desenvolvimento econômico foi impulsionado em 1973 quando a Lei de Zoneamento Industrial aprovou a instalação de polos empresariais, como os de Alphaville (composto por um grupo de condomínios residenciais de alto padrão, centro industrial e empresarial), Tamboré, Jardim Califórnia e Votupóca (PREFEITURA DE BARUERI, 2016).

Carapicuíba é o município com maior densidade demográfica da área de estudo. Foi uma aldeia fundada pelo padre José de Anchieta e apenas em 1965 tornou-se um município (PREFEITURA DE CARAPICUÍBA, 2016). Sua economia é composta pelo comércio local e sua ocupação foi marcada pela implantação do Conjunto Habitacional Castelo Branco com 14 mil unidades habitacionais em 1972, o que acarretou em uma forte influência da migração intra metropolitana na microrregião de Osasco (MEYER, 2004).

O município de Cotia foi estabelecido em 1906, é majoritariamente residencial e a maior parte dos residentes trabalham em São Paulo (PREFEITURA DE COTIA, 2016), o que gera um grande volume de tráfego entre os municípios.

Embu, também conhecido como Embu das Artes, possui a Feira de Artes e Artesanato desde 31 de Janeiro de 1969 e foi instituído como estância turística (PREFEITURA DE EMBU, 2016).

Osasco a princípio era um bairro de São Paulo, emancipado em 1962, possui a segunda maior densidade demográfica entre os municípios de interesse além de apresentar o segundo maior PIB do estado de São Paulo em 2015 (IBGE, 2016). Sua atividade econômica está concentrada nos setores de serviços, comércio e indústria. A ocupação de Osasco teve forte influência dos imigrantes da Itália, França, Espanha, Portugal, Alemanha, Irlanda e Nordeste do Brasil. O serviço de trem da CPTM oferece parada em 5 estações no município.

Santana de Parnaíba apresenta a menor densidade demográfica entre os municípios em 2010 (Tabela 2). Assim como os outros municípios, sua origem está ligada as expedições dos Bandeirantes, mas, de fato só recebeu 
investimentos econômicos a partir da década de 1980 com a instalação da usina hidrelétrica (IBGE, 2016).

\subsection{Materiais}

Os dados utilizados para a elaboração do banco de dados estão descritos na tabela abaixo:

\begin{tabular}{|c|c|c|}
\hline Natureza/ Fonte & 2000 & 2010 \\
\hline \multirow{5}{*}{$\begin{array}{l}\text { Dados de } \\
\text { Sensoriamento Remoto: } \\
\text { Imagens LANDSAT }\end{array}$} & 26/08/1999 & $18 / 04 / 2010$ \\
\hline & $16 / 12 / 1999$ & $04 / 05 / 2010$ \\
\hline & $17 / 01 / 2000$ & 07/07/2010 \\
\hline & $24 / 05 / 2000$ & $24 / 08 / 2010$ \\
\hline & $25 / 06 / 2000$ & $28 / 11 / 2010$ \\
\hline \multirow{3}{*}{$\begin{array}{c}\text { Dados Populacionais. } \\
\text { Fonte: IBGE }\end{array}$} & Limites municipais & \\
\hline & Setores censitários & \\
\hline & $\begin{array}{c}\text { Tabela geral de } \\
\text { população }\end{array}$ & \\
\hline \multirow{3}{*}{$\begin{array}{l}\text { Dados Populacionais. } \\
\text { Fonte: CEM (IBGE) }\end{array}$} & & Limites municipais \\
\hline & & Setores censitários \\
\hline & & $\begin{array}{l}\text { Tabela geral de } \\
\text { população }\end{array}$ \\
\hline
\end{tabular}

As imagens foram adquiridas gratuitamente através da plataforma da Divisão de Serviço Geológico dos Estados Unidos (USGS) - GLOVIS, ortorretificadas. Os dados do Censo de 2000 foram adquiridos gratuitamente no site do IBGE e os dados de 2010, extraídos do CEM (Centro de Estudos da Metrópole - CEPID).

As imagens foram adquiridas de acordo com a disponibilidade no site e sua qualidade, visto que imagens com extensa cobertura de nuvens atrapalham muito o resultado por encobrir a presença de ocupação urbana, o que dificultaria ainda mais a aplicação dos índices. Sendo assim, houve a necessidade de buscar duas imagens no ano de 1999 para compor os dados referentes à 
primeira época de análise. Parte-se do pressuposto que as mudanças de cobertura do solo nesse intervalo curto entre as imagens dentro do período de um mesmo ano, afetam de forma pouco significativa a análise.

Para a validação dos índices foram utilizadas imagens de alta resolução disponíveis através da ferramenta de WMS do software Arcgis, Imagens Ikonos 2002 com resolução espacial de 4 metros para a validação dos dados de 2000 e imagens do levantamento aerofotogramétrico realizado pela EMPLASA em 2010, com resolução espacial de 1 metro para a validação das imagens de 2010.

Para os dados populacionais, utilizou-se os dados do Censo populacional Brasileiro realizado pelo IBGE. O Censo é uma pesquisa realizada a cada 10 anos e reúne informações acerca da população brasileira. O Censo compreende dois levantamentos, sobre o Universo e sobre uma Amostra. Os dados do Universo são disponibilizados de forma agregada por setores censitários, sendo que cada setor possui um código único e abrange uma área composta de $250 \mathrm{a}$ 300 domicílios. Os dados da Amostra são agregados por área de ponderação, um outro recorte espacial em um nível mais agregado que os setores (IBGE, 2016). Na amostra, o questionário é aplicado em $10 \%$ da população. Nesta, encontram-se os micro dados, que possuem maior detalhamento das variáveis.

Para armazenar, preparar, organizar, analisar e produzir mapas dos dados e resultados dos estudos de área urbana foram utilizados Sistemas de Informações Geográficas (SIG):

\begin{tabular}{c}
\hline Software llwis 3.0 (Open Source) \\
\hline Software ArcGIS 10.4 (Trial License - Student) \\
Software RStudio \\
\hline Google Earth para verificação das áreas desconhecidas \\
Software Envi 5.3
\end{tabular}

Tabela 6: Softwares utilizados.

$$
\text { Software Envi } 5.3
$$

\subsection{Métodos}

Para o desenvolvimento desta pesquisa, foram cumpridas sequências de três etapas encadeadas, a primeira é relativa a elaboração do mapa de uso do 
solo urbano através da aplicação do Built-Up Index e a segunda é referente a aplicação da técnica de votação e a terceira, pertinente a elaboração do mapa coroplético da variável de população total dos dados do censo para 2000 e 2010, como expresso pelo fluxograma na Figura 6, abaixo.

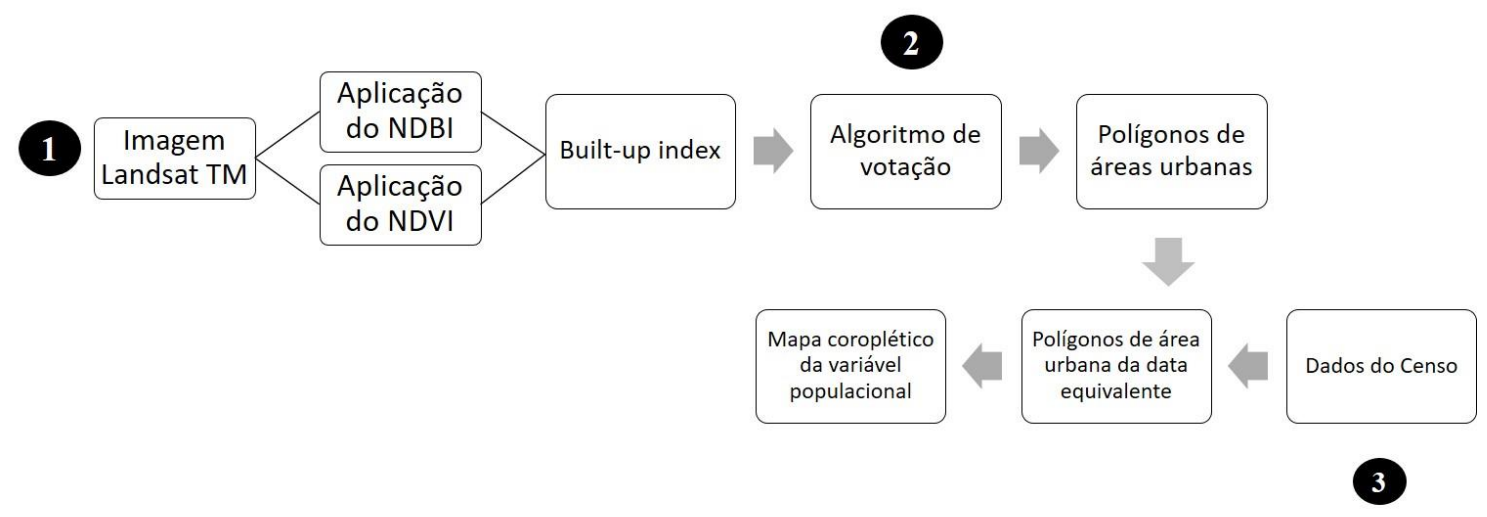

Figura 6: Fluxograma metodológico.

\subsubsection{Mapeamento do uso do solo urbano}

As imagens baixadas no catálogo de imagens GLOVIS - USGS já vêm corrigidas geometricamente. $O$ único processo necessário foi a reprojeção para o hemisfério sul.

Para a organização dos dados optou-se pela criação de dois bancos de dados separados para as datas de 2000 e 2010, a fim de facilitar o manuseio das imagens. O Sistemas de Coordenadas adotado, foi o UTM e Datum SAD69, Fuso 23 Sul, mesmo sistema de coordenadas adotado nos dados do Censo.

Após a re-projeção das imagens adquiridas no GLOVIS para o hemisfério Sul, foram desenvolvidos os índices NDBI, NDVI e Built-Up para cada imagem. O índice Built-Up foi escolhido para realizar a extração da superfície impermeável por sua capacidade de separação de área urbana e solo exposto (HE et al., 2010). Após a finalização de todo o processo, a imagem raster composta por pixels de áreas construídas e não construídas foi convertida em polígonos.

Conforme mencionado anteriormente o índice Built Up é um índice binário, para tal, é necessário transformar os índices NDBI e NDVI em imagens binárias 
para então realizar a subtração das mesmas. Esta transformação foi realizada de modo simples através da aplicação de contraste no histograma da imagem $\mathrm{NDBI}$, onde os valores inicialmente variavam de -1 (não construídos) a 1 (construídos). Todos os valores negativos receberam o valor de 0 e todos os positivos o valor 1 , através do streach do histograma. Com isso, tudo aquilo que não era área construída deveria valer 0 e tudo aquilo que fosse área construída deveria equivaler a 1.

Contudo, observou-se que as áreas construídas não iniciavam em 0 , mas em alguns casos em 0,01 ou até 0,3 fator este que era variável dentre a mesma imagem. Realizou-se vários testes para cada imagem para então definir o limiar de ajuste necessário para cada uma, de modo a separar ao máximo a classe de solo exposto da classe construída. Para as imagens obtidas em épocas do ano chuvosas este limiar de ajuste foi menor e havia menor confusão entre as classes. Nas imagens obtidas em épocas mais secas do ano o equívoco entre o solo exposto e a área construída era significativamente maior, influenciando o limiar de ajuste. Esta confusão se dá devido à proximidade da assinatura espectral de cada alvo, sendo que mais informações acerca da assinatura espectral dos alvos podem ser encontradas em Florenzano (2011).

Para a validação dos índices foi elaborada uma matriz de confusão, composta por uma tabela que compara os resultados, obtidos a partir do processamento dos índices, com pontos aleatórios de referência informados a partir da interpretação de imagens de melhor resolução espacial. A validação dos índices é descrita na seção 5.4 deste documento.

O classificador de Máxima Verossimilhança considera a ponderação das distâncias entre a média dos níveis de cinza de cada classe, os parâmetros estatísticos utilizados são representados pelo vetor de média e pela matriz de covariância que descreve a variabilidade das classes. Seu algoritmo, parte do princípio que todas as amostras selecionadas possuem uma distribuição normal (Gaussiana) ou próxima da normal q a probabilidade de um pixel pertencer a uma classe depende de sua posição na função de densidade de probabilidade (FDP) construído a partir de parâmetros da amostragem (Paola \& Schowengerd, 1995; Qian et al, 2007) sem considerar textura ou informação contextual (Qian et al, 2007). 


\subsection{Validação das imagens}

Comumente um mapeamento resultante do processamento de imagens orbitais precisa ser avaliada quanto à sua qualidade, como é o caso dos mapeamentos gerados a partir dos índices e métodos aplicados neste trabalho.

Garantir a utilização de um conjunto de dados independentes para a avaliação e treinamento do algoritmo evita a superestimação da precisão de sua classificação (CONGALTON, 1991). Ainda conforme Congalton (1991) a forma mais comum de representar a precisão da classificação é através da matriz de erros (ou de confusão).

A matriz de confusão é uma matriz estabelecida em linhas e colunas que expressam a amostra coletada, neste caso, pixels. As colunas referem-se à verdade terrestre, ao passo que as linhas expressam pela classificação dos dados que se pretende avaliar. Uma matriz de confusão é a forma mais eficiente para simbolizar a precisão de como cada classe é descrita, gerando a exatidão global (acurácia geral), erros de tipo um (omissão) e erros de tipo dois (comissão presentes nas classificações (CONGALTON, 1991).

Para se calcular a exatidão global realiza-se a operação de divisão da soma do total de pixels corretamente classificados (expressos na diagonal principal) pelo número total de pixels da amostra (CONGALTON, 1991). A precisão dos erros de omissão e de comissão, são calculadas de formas similares, estes são os pixels erradamente excluídos da sua classe verdadeira a que pertencem e os pixels incluídos erroneamente em uma classe particular (IWAI; QUINTANILHA, 2005).

A partir do total de pixels corretamente classificados em uma classe, divide-se pelo total de pixels da classe em questão proveniente dos dados de referência (coluna), tem-se então a medida da probabilidade dos pixels estarem corretamente classificados, esta é a acurácia do produtor (erro de omissão), o número total dos pixels classificados (linha) oferece o resultado da acurácia do usuário, relacionada à probabilidade de um indivíduo pertencer a classe representada, sendo uma medida do valor do erro de comissão (CONGALTON, 1991). 
Foram gerados 500 pontos aleatórios para o recorte da imagem LANDSAT da área da RMSP. Os pontos que incidiram sobre o oceano foram descartados da análise, mas as áreas de rios e represas dentro da RMSP foram mantidas na amostra.

Como os recortes das imagens utilizadas como verdade terrestre de alta resolução eram diferentes, foi necessário aceitar quantidades diferentes desses pontos, ou seja, a imagem tida como amostras de referência para 2000 é a Ikonos tem seu recorte os limites municipais da RMSP, com isso, os pontos que caíram fora dos limites municipais foram descartados. O total de pontos considerados foi de 325 , respeitando o mínimo de 50 pontos em cada classe proposto por Congalton (1991).

Para a imagem de verdade terrestre de 2010, as Ortofotos do voo da EMPLASA, a área imageada não se restringia aos limites municipais e uma vez que o cálculo dos índices já haviam sido feitos para o recorte todo, foram considerados 468 , excluídos apenas os pontos que coincidem com o oceano, os pontos podem ser observados na Figura 7 .

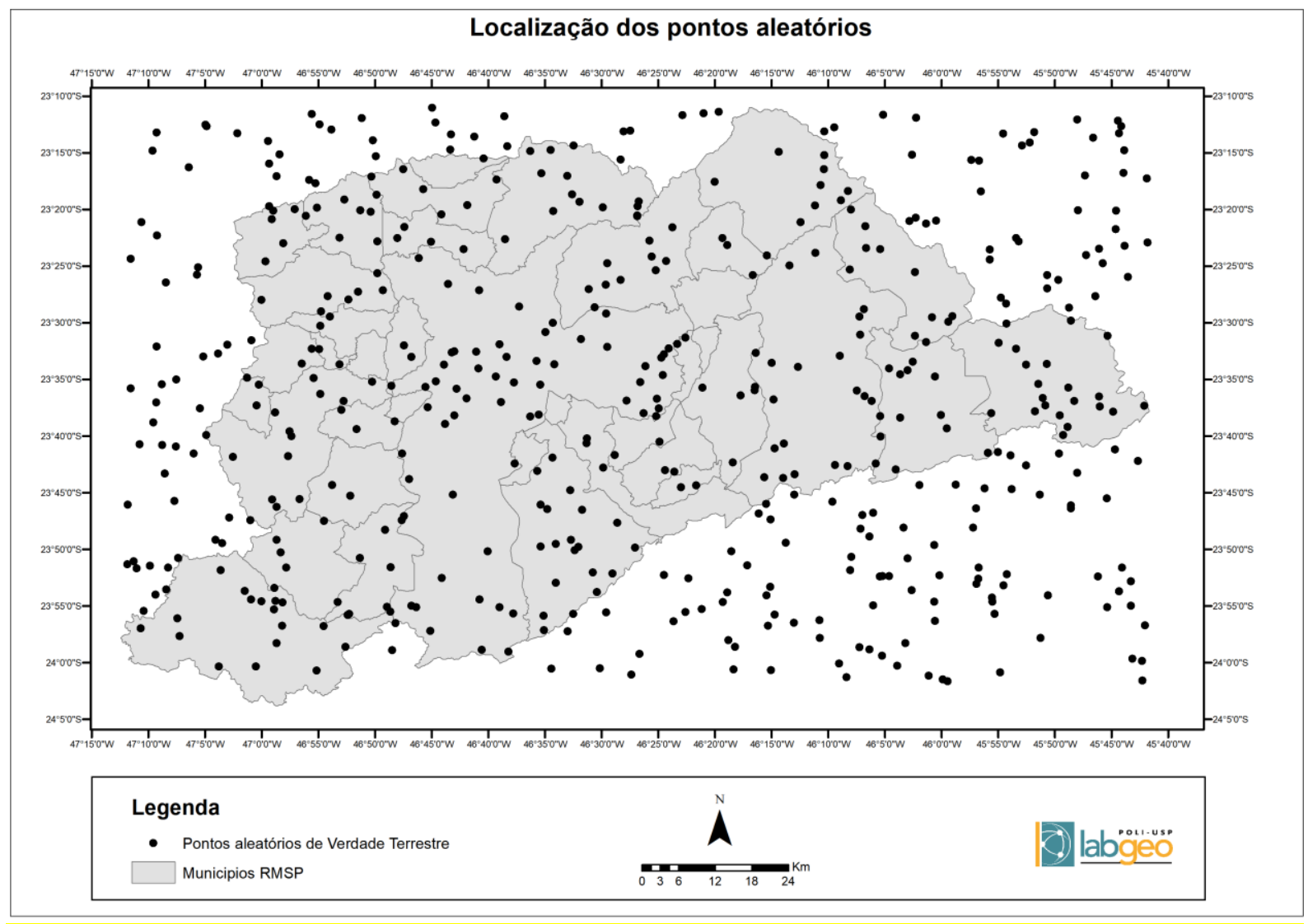

Figura 7: Localização dos Pontos de controle de verdade terrestre. 


\section{RESULTADOS E DISCUSSÕES}

\subsection{Aplicação da Correção Radiométrica no mapa de área construída}

Conforme apresentado na revisão bibliográfica na seção 4, existe uma divergência muito grande quando à recomendação de aplicar a correção radiométrica ou correção atmosférica na literatura.

Para a elaboração do índice Built-Up, utiliza-se a composição dos índices NDVI e NDBI. Para a construção do índice NDVI, em grande parte de suas aplicações utiliza-se algum tipo de correção radiométrica. Isto é necessário devido à sua interação com as bandas infravermelho próximo e vermelho. Entretanto no índice NDBI, esta correção não se faz necessária devido a utilização de bandas fora da faixa do visível, infravermelho próximo e médio.

Zha et al (2003), ao proporem o índice Built-Up não mencionam a utilização de nenhum tipo de correção radiométrica, nem de filtragem, anteriormente às etapas da construção do índice. Os autores aplicam apenas a filtragem majoritária $(5 \times 5)$ para suavizar o efeito de sal e pimenta dos resultados, como último passo a ser seguido. He et al (2010) ao proporem uma abordagem semiautomática para a construção do índice mencionam a correção radiométrica apenas em uma imagem de alta qualidade utilizada para testes e não nas imagens em que o índice foi aplicado.

Mesmo com estas referências, nesta dissertação teve-se o cuidado de testar a correção radiométrica para verificar se esta poderia melhorar o resultado do mapeamento de áreas construídas. Foi escolhido então, o método DOS (dark object subtraction), consolidado na literatura (CHAVEZ, 1989; BALÇIK, 2014; SALLEH et al, 2013;)

O método de subtração dos objetos escuros (DOS) estima a interferência atmosférica diretamente da imagem. Considera que existem alvos escuros na imagem (como sombras oriundas da topografia ou nuvens) que apresentam valores muito baixo de número digital na imagem (CHAVEZ, 1989). Este método necessita inicialmente do valor do pixel escuro da banda de menor comprimento de onda. Este valor é então utilizado para identificar a condição atmosférica no 
momento da obtenção da imagem e a partir do modelo de espalhamento relativo, calcular o espalhamento em cada banda espectral (CHAVEZ, 1989).

Após a aplicação do método DOS em todas as imagens adquiridas para compor o conjunto de 2000 e o conjunto de 2010, aplicou-se os índices NDVI e NDBI para então gerar o índice Built-Up de cada imagem. Posteriormente, a técnica de votação foi aplicada no conjunto de imagens de 2000 (resultado na Figura 8), do mesmo modo no conjunto de imagens de 2010 (resultado na Figura 9).

A avaliação dos resultados visualmente é limitada, visto que na Figura 8 referente ao resultado da técnica de votação de 2000 com correção $(A)$ e sem correção (B), poucos pixels são diferentes.

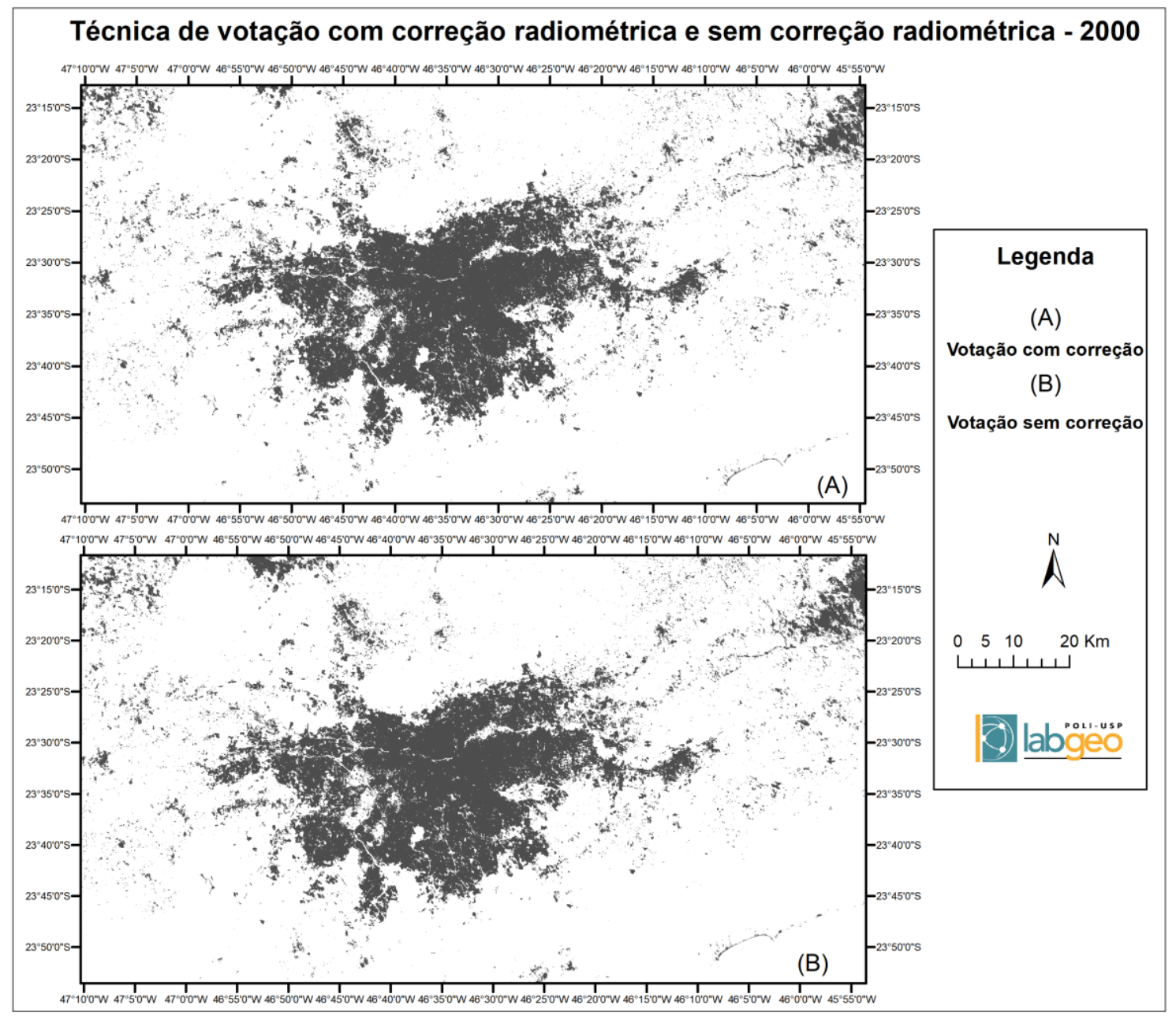

Figura 8: Mapeamento da Área Construída na RMSP utilizando a Técnica de votação aplicada nas imagens com e sem correção radiométrica - 2000. 
Com isso a matriz de confusão foi elaborada com os mesmos pontos delimitados anteriormente e constatou-se que a votação com correção radiométrica atingiu o índice Kappa de 90,09\% e exatidão global de 90,15\% ( Tabela 7), enquanto a votação sem correção atingiu índice Kappa de 91,33\% e exatidão global de $91,38 \%$ (Tabela 8 ).

$\mathrm{Na}$ Tabela 8 tem-se a matriz de confusão da técnica de votação com correção para 2000, com os respectivos valore de índice Kappa, Exatidão global, erros de omissão e comissão de cada classe.

\begin{tabular}{|c|c|c|c|c|}
\hline \multicolumn{5}{|c|}{ Matriz de confusão da Votação com Correção (2000) } \\
\hline \multicolumn{5}{|c|}{ Classificado } \\
\hline Verdade & Construído & Não construído & & Total \\
\hline Construído & 44 & 15 & & 59 \\
\hline Não construído & 17 & 249 & & 266 \\
\hline & 61 & 264 & & 325 \\
\hline Kappa & $90,09 \%$ & Exatidão global & $90,15 \%$ & \\
\hline $\begin{array}{l}\text { Erro de omissão } \\
\text { construído }\end{array}$ & 0,72 & $\begin{array}{l}\text { Erro de comissão } \\
\text { construído }\end{array}$ & 0,75 & \\
\hline $\begin{array}{c}\text { Erro de omissão não } \\
\text { construído }\end{array}$ & 0,94 & $\begin{array}{l}\text { Erro de comissão não } \\
\text { construído }\end{array}$ & 0,94 & \\
\hline
\end{tabular}

Abaixo, tem-se a tabela da matriz de confusão da votação sem correção radiométrica para 2000.

\begin{tabular}{ccccc}
\hline \multicolumn{5}{c}{ Matriz de confusão da votação de 2000 } \\
\hline & \multicolumn{2}{c}{ Classificado } & Notal \\
\hline Verdade & Construído & Não construído & 61 \\
\hline Construído & 47 & 14 & 264 \\
\hline Não construído & 14 & 250 & 325 \\
\hline Kappa & 61 & 264 & \\
\hline & $91,33 \%$ & Exatidão global & $91,38 \%$ & \\
\hline $\begin{array}{c}\text { Erro de omissão } \\
\text { construído }\end{array}$ & 0,77 & $\begin{array}{c}\text { Erro de comissão } \\
\text { construído }\end{array}$ & 0,77 \\
\hline $\begin{array}{c}\text { Erro de omissão não } \\
\text { construído }\end{array}$ & 0,95 & $\begin{array}{c}\text { Erro de comissão não } \\
\text { construído }\end{array}$ & 0,95 & \\
\hline
\end{tabular}

Tabela 8: Matriz de confusão da técnica de votação - 2000.

A Figura 9, apresenta maiores diferenças entre os resultados da aplicação 
e não aplicação da correção radiométrica. Em (a) tem-se o resultado da técnica de votação aplicada em imagens com a correção DOS e em (b) em imagens sem alterações no valor do número digital do pixel. Observa-se que em (b) há uma subestimação de áreas construídas no ano de 2010, quando comparadas com uma composição colorida RGB datada de 2010 ou mesmo com as imagens de 2000.

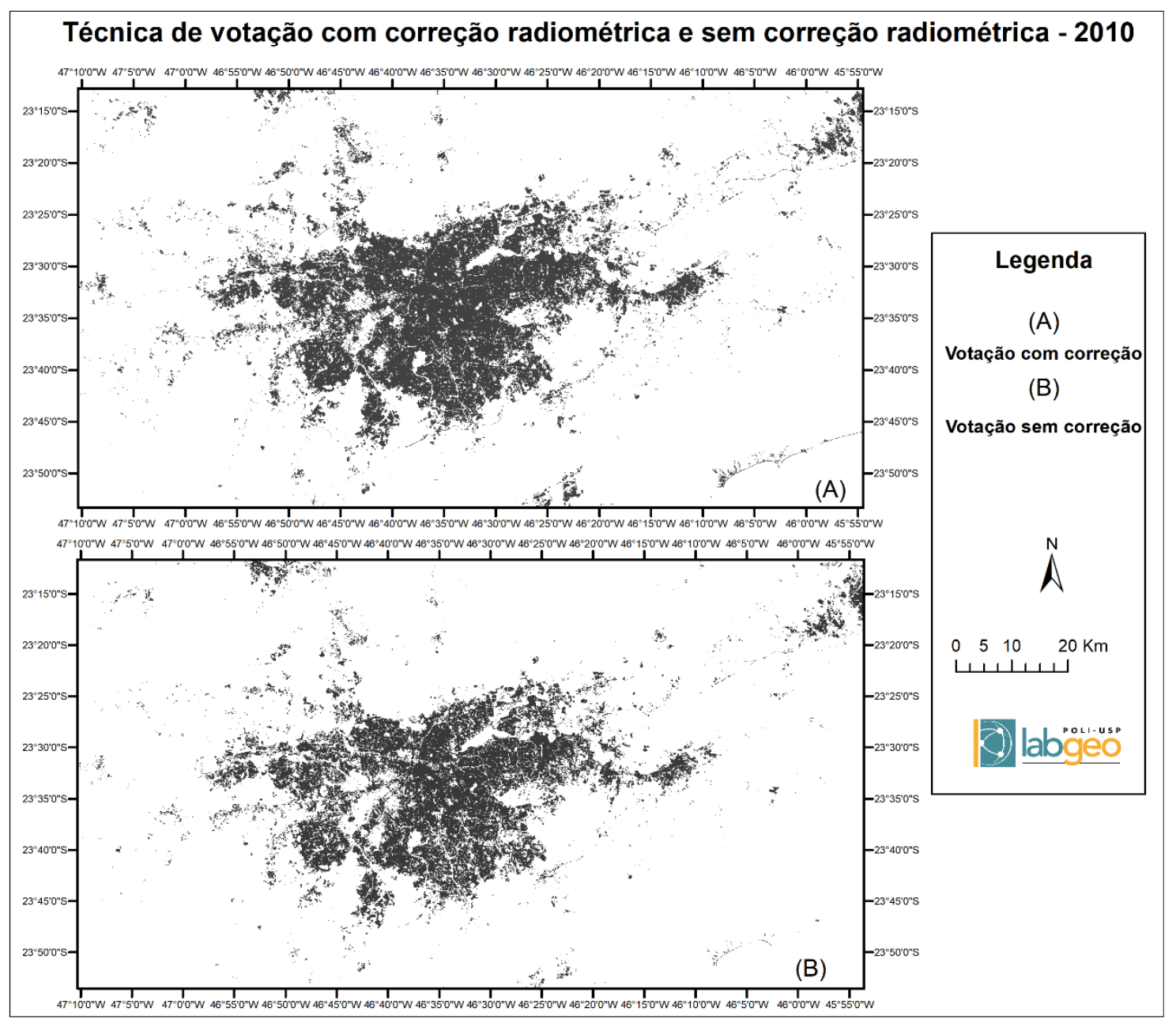

Figura 9: Mapeamento da Área Construída na RMSP utilizando a Técnica de votação aplicada nas imagens com e sem correção radiométrica - 2010.

A matriz de confusão da votação com correção de 2010 obteve os resultados, Kappa de 90,42\% e exatidão global de 94,44\% (Tabela 9), enquanto a votação sem correção atingiu de índice Kappa de 88,41 e exatidão global de $88,46 \%$, vide tabela (Tabela 10). 


\begin{tabular}{|c|c|c|c|c|}
\hline \multicolumn{5}{|c|}{ Matriz de Confusão da Votação com correção Radiométrica (2010 } \\
\hline \multicolumn{5}{|c|}{ Classificado } \\
\hline Verdade & Construído & Não construído & & Total \\
\hline Construído & 46 & 9 & & 55 \\
\hline Não construído & 17 & 396 & & 413 \\
\hline & 63 & 405 & & 468 \\
\hline Kappa & $94,42 \%$ & Exatidão global & $94,44 \%$ & \\
\hline $\begin{array}{l}\text { Erro de omissão } \\
\text { Construído }\end{array}$ & 0,73 & $\begin{array}{l}\text { Erro de comissão } \\
\text { Construído }\end{array}$ & 0,84 & \\
\hline $\begin{array}{l}\text { Erro de omissão } \\
\text { Não Construído }\end{array}$ & 0,98 & $\begin{array}{l}\text { Erro de comissão } \\
\text { Não Construído }\end{array}$ & 0,96 & \\
\hline
\end{tabular}
2010.

Tabela 9: Matriz de confusão da votação com correção radiométrica -

Abaixo, tem-se a tabela da matriz de confusão da votação sem correção radiométrica para 2010 .

\begin{tabular}{|c|c|c|c|c|}
\hline \multicolumn{5}{|c|}{ Matriz de confusão da votação de 2010} \\
\hline & & Classificado & & \\
\hline Verdade & Construído & Não Construído & & Total (linha) \\
\hline Construído & 39 & 49 & & 88 \\
\hline Não Construído & 5 & 375 & & 380 \\
\hline Total (coluna) & 44 & 424 & & 468 \\
\hline Kappa & $88,41 \%$ & Exatidão Global & $88,46 \%$ & \\
\hline $\begin{array}{l}\text { Erro De Omissão } \\
\text { Construído }\end{array}$ & 0,89 & $\begin{array}{l}\text { Erro De Comissão } \\
\text { Construído }\end{array}$ & 0,44 & \\
\hline $\begin{array}{l}\text { Erro De Omissão } \\
\text { Não Construído }\end{array}$ & 0,88 & $\begin{array}{c}\text { Erro De Comissão Não } \\
\text { Construído }\end{array}$ & 0,99 & \\
\hline
\end{tabular}

Tabela 10: Matriz de confusão da técnica de votação - 2010.

\subsection{Aplicação da técnica de votação}

A técnica de votação foi aplicada em todas as imagens selecionadas para compor o conjunto referente a 2000 e o conjunto referente a 2010, sendo que para realizar a avaliação de cada imagem Built-Up foi elaborada uma matriz de confusão. Foram utilizados 325 pontos, definidos pelos critérios na seção 5.4 que trata a avaliação das classificações.

Para dezembro (1999) o índice Kappa obtido foi de 89.78\%, conforme a Tabela 11 onde 30 pontos foram classificados corretamente como construído e 
apenas 9 pontos eram na verdade edificados porém o índice marcou como não construídos. O índice Built-Up desta imagem foi o que produziu melhores resultados comparado a todo o conjunto de imagens de 2000 em que o índice foi aplicado.

\begin{tabular}{ccccc}
\hline & \multicolumn{2}{c}{ Dezembro } & \\
\hline Verdade & Construído & Classificado & Não construído & Total \\
\hline Construído & 30 & 9 & 39 \\
\hline Não construído & 24 & 262 & 286 \\
\hline & 54 & 271 & 325 \\
\hline Kappa & $89,78 \%$ & Exatidão global & $89,85 \%$ \\
\hline $\begin{array}{c}\text { Erro de omissão } \\
\text { construído }\end{array}$ & 0,56 & $\begin{array}{c}\text { Erro de comissão } \\
\text { construído }\end{array}$ & 0,77 \\
\hline $\begin{array}{c}\text { Erro de omissão não } \\
\text { construído }\end{array}$ & 0,97 & $\begin{array}{c}\text { Erro de comissão não } \\
\text { construído }\end{array}$ & 0,92 \\
\hline \begin{tabular}{c} 
Tabela 11: \\
\hline
\end{tabular} & & \begin{tabular}{c} 
\\
\hline
\end{tabular} & & \\
\hline
\end{tabular}

Tabela 11: Matriz de confusão do índice Built-Up de Dezembro (1999) referente ao conjunto de 2000.

A matriz de confusão referente ao índice Built-Up de Janeiro teve índice Kappa similar ao resultado de Maio e de Agosto, todos com $87 \%$. Os resultados de pixels mapeados corretamente e com erro são idênticos como pode ser observado na

\begin{tabular}{cccc}
\hline & \multicolumn{3}{c}{ Janeiro } \\
\hline & \multicolumn{2}{c}{ Classificado } & Total \\
\hline Verdade & Construído & Não construído & 54 \\
\hline Construído & 33 & 21 & 271 \\
\hline Não construído & 21 & 250 & 325 \\
\hline & 54 & 271 & $87,08 \%$ \\
\hline Kappa & $87,00 \%$ & Exatidão global & 0,61 \\
\hline $\begin{array}{c}\text { Erro de omissão } \\
\text { construído }\end{array}$ & 0,61 & $\begin{array}{c}\text { Erro de comissão } \\
\text { construído }\end{array}$ \\
$\begin{array}{c}\text { Erro de omissão não } \\
\text { construído }\end{array}$ & 0,92 & $\begin{array}{c}\text { Erro de comissão não } \\
\text { construído }\end{array}$ & 0,92 \\
\hline
\end{tabular}

Tabela 12 e Tabela 13.

\begin{tabular}{cccc}
\hline & \multicolumn{3}{c}{ Janeiro } \\
\hline & \multicolumn{3}{c}{ Classificado } \\
\hline Verdade & Construído & Não construído & Total \\
\hline Construído & 33 & 21 & 54 \\
\hline Não construído & 21 & 250 & 271 \\
\hline & 54 & 271 & 325 \\
\hline
\end{tabular}




\begin{tabular}{|c|c|c|c|}
\hline Kappa & $87,00 \%$ & Exatidão global & $87,08 \%$ \\
\hline $\begin{array}{l}\text { Erro de omissão } \\
\text { construído }\end{array}$ & 0,61 & $\begin{array}{l}\text { Erro de comissão } \\
\text { construído }\end{array}$ & 0,61 \\
\hline $\begin{array}{l}\text { Erro de omissão não } \\
\text { construído }\end{array}$ & 0,92 & $\begin{array}{l}\text { Erro de comissão não } \\
\text { construído }\end{array}$ & 0,92 \\
\hline
\end{tabular}

As matrizes foram geradas novamente várias vezes para checar se não havia erro de processamento, mas foi obtido sempre o mesmo resultado.

\begin{tabular}{|c|c|c|c|c|}
\hline \multicolumn{5}{|c|}{ Maio } \\
\hline \multicolumn{5}{|c|}{ Classificado } \\
\hline Verdade & Construído & Não construído & & Total \\
\hline Construído & 33 & 21 & & 54 \\
\hline \multirow[t]{2}{*}{ Não construído } & 21 & 250 & & 271 \\
\hline & 54 & 271 & & 325 \\
\hline Kappa & $87,00 \%$ & Exatidão global & $87,08 \%$ & \\
\hline $\begin{array}{l}\text { Erro de omissão } \\
\text { construído }\end{array}$ & 0,61 & $\begin{array}{l}\text { Erro de comissão } \\
\text { construído }\end{array}$ & 0,61 & \\
\hline $\begin{array}{l}\text { Erro de omissão não } \\
\text { construído }\end{array}$ & 0,92 & $\begin{array}{l}\text { Erro de comissão não } \\
\text { construído }\end{array}$ & 0,92 & \\
\hline
\end{tabular}

Tabela 13: Matriz de confusão do índice Built-Up de Maio (2000).

O índice Built-Up de Junho, aferiu o menor índice Kappa de todo o conjunto, com apenas $\mathbf{8 6 . 9 6 \%}$ e os maiores erros de classificação (Tabela 14). Esta imagem, capturada no período de outono/inverno no Brasil onde comumente são as épocas mais secas do ano, sendo passível de maiores presenças de solo exposto ou vegetação extremamente seca o que pode ocasionar em maiores erros no produto gerado pelo índice.

\begin{tabular}{cccc}
\hline & \multicolumn{3}{c}{ Junho } \\
\hline & \multicolumn{3}{c}{ Classificado } \\
\hline Verdade & Construído & Não construído & Total \\
\hline Construído & 39 & 28 & 67 \\
\hline Não construído & 14 & 243 & 257 \\
\hline & 53 & 271 & 324 \\
\hline Kappa & $86,96 \%$ & Exatidão global & $87,04 \%$ \\
\hline
\end{tabular}




\begin{tabular}{cccc}
\hline $\begin{array}{c}\text { Erro de omissão } \\
\text { construído }\end{array}$ & 0,74 & $\begin{array}{c}\text { Erro de comissão } \\
\text { construído }\end{array}$ & 0,58 \\
\hline $\begin{array}{c}\text { Erro de omissão não } \\
\text { construído }\end{array}$ & 0,90 & $\begin{array}{c}\text { Erro de comissão não } \\
\text { construído }\end{array}$ & 0,95 \\
\hline Tabela & &
\end{tabular}

Tabela 14: Matriz de confusão do índice Built-Up de Junho (2000).

O resultado de Built-Up gerado a partir da imagem datada de Agosto, obteve resultados similares à Janeiro e Maio, com índice Kappa de 87\% conforme a Tabela 15, comprovando que a similaridade espectral entre as imagens traz resultados semelhantes.

\begin{tabular}{|c|c|c|c|c|}
\hline \multicolumn{5}{|c|}{ Agosto } \\
\hline \multicolumn{5}{|c|}{ Classificado } \\
\hline Verdade & Construído & Não construído & & Total \\
\hline Construído & 33 & 21 & & 54 \\
\hline \multirow[t]{2}{*}{ Não construído } & 21 & 250 & & 271 \\
\hline & 54 & 271 & & 325 \\
\hline Kappa & $87,00 \%$ & Exatidão global & $87,08 \%$ & \\
\hline $\begin{array}{l}\text { Erro de omissão } \\
\text { construído }\end{array}$ & 0,61 & $\begin{array}{l}\text { Erro de comissão } \\
\text { construído }\end{array}$ & 0,61 & \\
\hline $\begin{array}{c}\text { Erro de omissão não } \\
\text { construído }\end{array}$ & 0,92 & $\begin{array}{c}\text { Erro de comissão não } \\
\text { construído }\end{array}$ & 0,92 & \\
\hline
\end{tabular}

O resultado da técnica de votação foi considerado satisfatório para este aglomerado de imagens, pois o índice Kappa alcançado foi de $91.33 \%$ como mostrado na Tabela 8. Os erros foram reduzidos e os acertos aumentados.

Abaixo, na Figura 10, têm-se o recorte da área de interesse para facilitar a visualização do resultado e seguindo a comparação visual com a composição colorida RGB das bandas vermelho, verde e azul respectivamente, é possível observar que as áreas edificadas representadas na cor roxa na imagem LANDSAT foram marcadas como área construída após a aplicação da técnica de votação. 


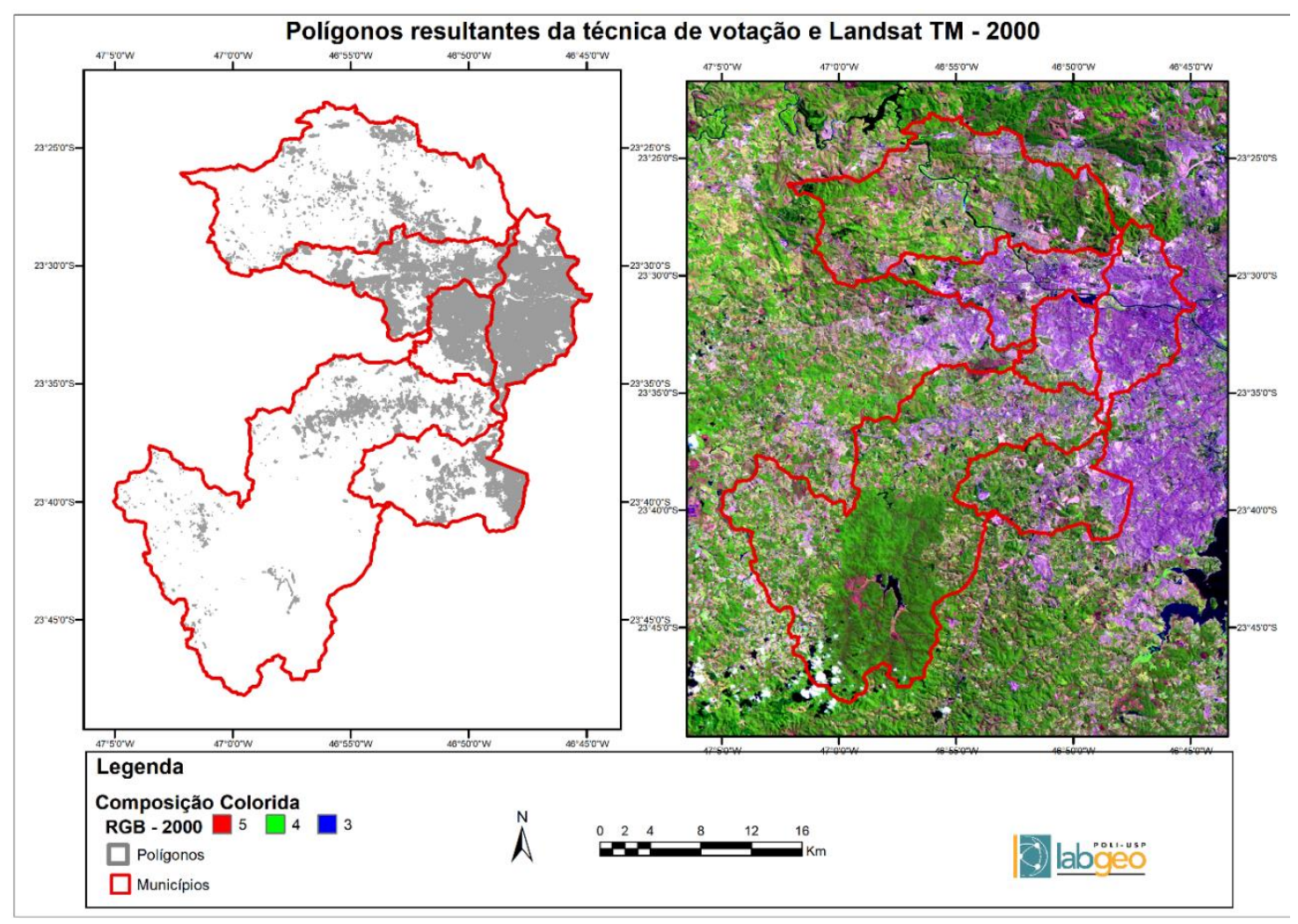

Figura 10: Mapeamento das áreas construídas a partir da técnica de votação 2000.

As imagens que constituem o conjunto para aplicar a técnica de votação para 2010, obtiveram resultados similares na elaboração do índice Built-Up. Acredita-se que devido à homogeneidade das imagens, pouca ou nenhuma presença de nuvens, isso tenha gerado um resultado mais uniforme, somente a imagem de Novembro possuía bastante nuvens.

A imagem referente ao mês de Abril (2010), resultou no índice Kappa de $87,61 \%$ (Tabela 16). É importante salientar que, os pontos de verdade terrestre para compor a matriz de confusão do conjunto de 2010 foram aferidos em imagens de 1 metro de resolução, enquanto o índice foi elaborado a partir de imagens LANDSAT com 30 metros de resolução. Com isso, muitos pontos na área de borda ou transição entre áreas construídas e vegetadas foram mapeadas erroneamente ( 53 pontos de controle) 


\begin{tabular}{cccc}
\hline \multicolumn{5}{c}{ Abril } \\
\hline Verdade & Construído & $\begin{array}{c}\text { Classificado } \\
\text { Não construído }\end{array}$ & Total \\
\hline Construído & 35 & 53 & 88 \\
\hline Não construído & 5 & 377 & 382 \\
\hline \multicolumn{5}{c}{40} & 430 & 468 \\
\hline Kappa & 40 & Exatidão global & $87,66 \%$ \\
\hline $\begin{array}{c}\text { Erro de omissão } \\
\text { Construído }\end{array}$ & 0,88 & $\begin{array}{c}\text { Erro de comissão } \\
\text { Construído }\end{array}$ & 0,40 \\
\hline $\begin{array}{c}\text { Erro de omissão } \\
\text { Não Construído }\end{array}$ & 0,88 & $\begin{array}{c}\text { Erro de comissão } \\
\text { Não Construído }\end{array}$ & 0,99 \\
\hline
\end{tabular}

Tabela 16: Matriz de confusão do índice Built-Up de Abril (2010).

O índice Built-Up gerado a partir da imagem de Maio, obteve um resultado bom, o maior entre o conjunto de analisado, com índice Kappa de 90,13\% (Tabela 17). Esta imagem também não possuía muitas nuvens, mas cinco pontos foram classificados como não construídos quando na verdade eram construídos.

\begin{tabular}{|c|c|c|c|c|}
\hline \multicolumn{5}{|c|}{ Maio } \\
\hline \multicolumn{5}{|c|}{ Classificado } \\
\hline Verdade & Construído & Não construído & & Total \\
\hline Construído & 42 & 5 & & 47 \\
\hline Não construído & 41 & 380 & & 421 \\
\hline & 83 & 385 & & 468 \\
\hline Kappa & $90,13 \%$ & Exatidão global & $90,17 \%$ & \\
\hline $\begin{array}{l}\text { Erro de omissão } \\
\text { construído }\end{array}$ & 0,51 & $\begin{array}{l}\text { Erro de comissão } \\
\text { construído }\end{array}$ & 0,89 & \\
\hline $\begin{array}{l}\text { Erro de omissão } \\
\text { não construído }\end{array}$ & 0,99 & $\begin{array}{l}\text { Erro de comissão } \\
\text { não construído }\end{array}$ & 0,90 & \\
\hline
\end{tabular}

Tabela 17: Matriz de confusão do índice Built-Up de Maio (2010).

Abaixo, tem-se a Tabela 18 referente ao índice Built-Up de Julho de 2010, com índice Kappa de 86,48\%. Nesta imagem, 26 pontos de controle eram construídos e foram mapeados como não construído pelo índice. 


\begin{tabular}{ccccc}
\hline & \multicolumn{2}{c}{ Julho } & \\
\hline & \multicolumn{2}{c}{ Classificado } & Total \\
\hline Verdade & Construído & Não construído & 88 \\
\hline Construído & 62 & 26 & 380 \\
\hline Não construído & 37 & 341 & 468 \\
\hline Kappa & 83 & Exatidão global & $86,54 \%$ \\
\hline $\begin{array}{c}\text { Erro de omissão } \\
\text { construído }\end{array}$ & $86,48 \%$ & $\begin{array}{c}\text { Erro de comissão } \\
\text { construído }\end{array}$ & 0,70 \\
\hline $\begin{array}{c}\text { Erro de omissão } \\
\text { não construído }\end{array}$ & 0,63 & $\begin{array}{c}\text { Erro de comissão } \\
\text { não construído }\end{array}$ & 0,90 \\
\hline \begin{tabular}{c} 
Tabela \\
\hline
\end{tabular} & 0,93 & & \\
\hline
\end{tabular}

Tabela 18: Matriz de confusão do índice Built-Up de Julho (2010).

A imagem de Agosto originou o índice Built-Up com índice Kappa de 89,91\%. A Tabela 19 mostra a matriz de confusão para esta data e observa-se que apenas seis pontos foram mapeados como não construídos, quando na verdade estes eram construídos.

\begin{tabular}{|c|c|c|c|c|}
\hline \multicolumn{5}{|c|}{ Agosto } \\
\hline \multicolumn{5}{|c|}{ Classificado } \\
\hline Verdade & Construído & Não construído & & Total \\
\hline Construído & 42 & 6 & & 48 \\
\hline Não construído & 41 & 379 & & 420 \\
\hline & 83 & 385 & & 468 \\
\hline Kappa & $89,91 \%$ & Exatidão global & $89,96 \%$ & \\
\hline $\begin{array}{l}\text { Erro de omissão } \\
\text { construído }\end{array}$ & 0,51 & $\begin{array}{l}\text { Erro de comissão } \\
\text { construído }\end{array}$ & 0,88 & \\
\hline $\begin{array}{l}\text { Erro de omissão } \\
\text { não construído }\end{array}$ & 0,98 & $\begin{array}{l}\text { Erro de comissão } \\
\text { não construído }\end{array}$ & 0,90 & \\
\hline
\end{tabular}

Abaixo, tem-se a Tabela 20 referente ao índice Built-Up de Novembro de 2010, com índice Kappa de 79,18\%, este foi o pior resultado dentro das imagens analisadas em 2010 devido a presença de nuvens superior ás demais. 


\begin{tabular}{ccccc}
\hline & \multicolumn{2}{c}{ Novembro } & \\
\hline \multicolumn{4}{c}{ Classificado } & Total \\
\hline Verdade & Construído & Não construído & 88 \\
\hline Construído & 47 & 41 & 380 \\
\hline Não construído & 56 & 324 & 468 \\
\hline Kappa & 103 & 365 & $79,27 \%$ \\
\hline $\begin{array}{c}\text { Erro de omissão } \\
\text { construído }\end{array}$ & $79,18 \%$ & Exatidão global & \\
\hline $\begin{array}{c}\text { Erro de omissão } \\
\text { não construído }\end{array}$ & 0,46 & $\begin{array}{c}\text { Erro de comissão } \\
\text { construído }\end{array}$ & 0,53 \\
\hline Tabela 20: & 0,89 & $\begin{array}{c}\text { Erro de comissão } \\
\text { não construído }\end{array}$ & 0,85 \\
\hline
\end{tabular}

Tabela 20: Matriz de confusão do índice Built-Up de Novembro (2010).

Observou-se que no resultado de 2010 a área construída sofreu uma pequena subestimação reproduzindo o padrão dos índices que foram utilizados. O índice Kappa da técnica de votação foi de $88,41 \%$ e seguiu o mesmo padrão de erros e acertos, total de 49 pontos mapeados erroneamente como área construída, os demais erros são possíveis de serem observados na Tabela 10, exposta anteriormente.

A Figura 11 traz o resultado da técnica de votação no recorte dos municípios de interesse e apesar da subestimação de área construída, este resultado apresentou menor confusão com a classe de solo exposto do que o conjunto 2000, principalmente na faixa de solo ao redor da represa do Alto Cotia. 


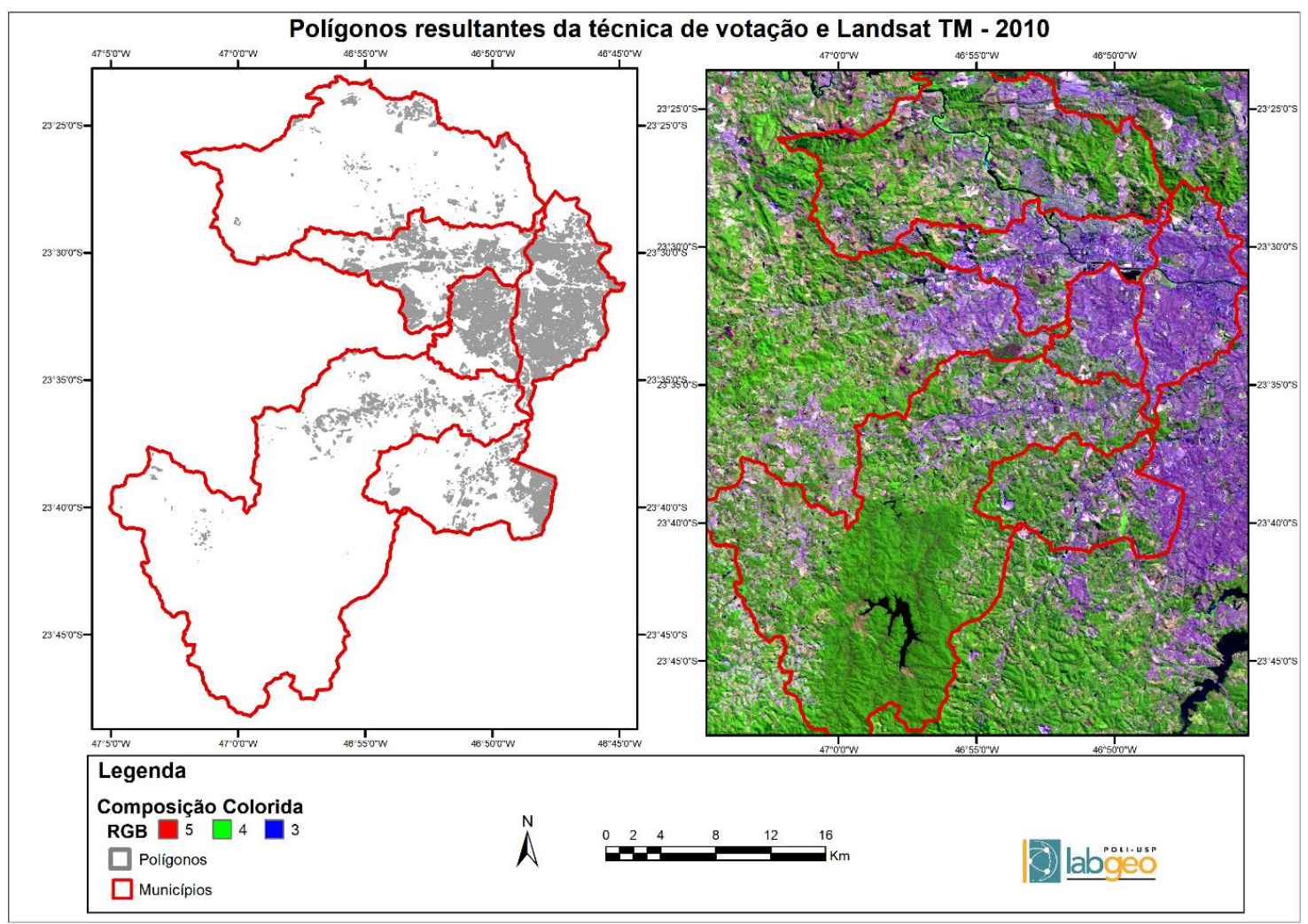

Figura 11: Mapa dos polígonos resultantes da aplicação da técnica de votação $-2010$.

Ao comparar os resultados obtidos pela técnica de votação para 2000 e 2010 (expresso na Figura 12), é seguro dizer que a heterogeneidade das imagens, não somente compostas por nuvens mas por imagens de períodos secos e úmidos onde a confusão com solo exposto é menor, apresenta resultados benéficos a técnica apresentada pois a regra de majoritariedade funciona de forma a minimizar as diferenças decorrentes de presença de nuvens e influência da época do ano nos valores de reflectância capturados pelos sensores e subsequente cálculo dos índices.

No conjunto de 2010, as imagens eram mais similares e com isso gerou um mapa da técnica de votação similar aos anteriores, pois cada imagem exerceu menor influência sobre o resultado final. Enquanto a heterogeneidade das imagens de 2000 mostrou grande diferença e ganhos com a técnica de votação, pois mesmo com os erros obtidos é possível compreender que imagens distintas trazem um ganho maior no resultado ao aplicar o algoritmo de votação.

No município de Barueri (1), nota-se que os polígonos em 2000 são 
maiores e a cidade mais adensada do que mostra em 2010, o mesmo ocorre em Carapicuíba (2) e Osasco (5) que apresentam espaços vazios no interior das cidades, em trechos que são extremamente consolidados e serão discorridos adiante.

Cotia (3), apresenta uma área erroneamente mapeada, as margens da Represa Auto Cotia em 2000 o que não ocorre em 2010, similarmente as áreas de chácaras em Cotia são mapeadas em 2000 e com uma subestimação em 2010. Embu (4), apesar de em 2000 os polígonos parecerem mais densos, não é possível identificar a primeiro momento, estas diferenças serão abordadas posteriormente na análise individual de cada município.

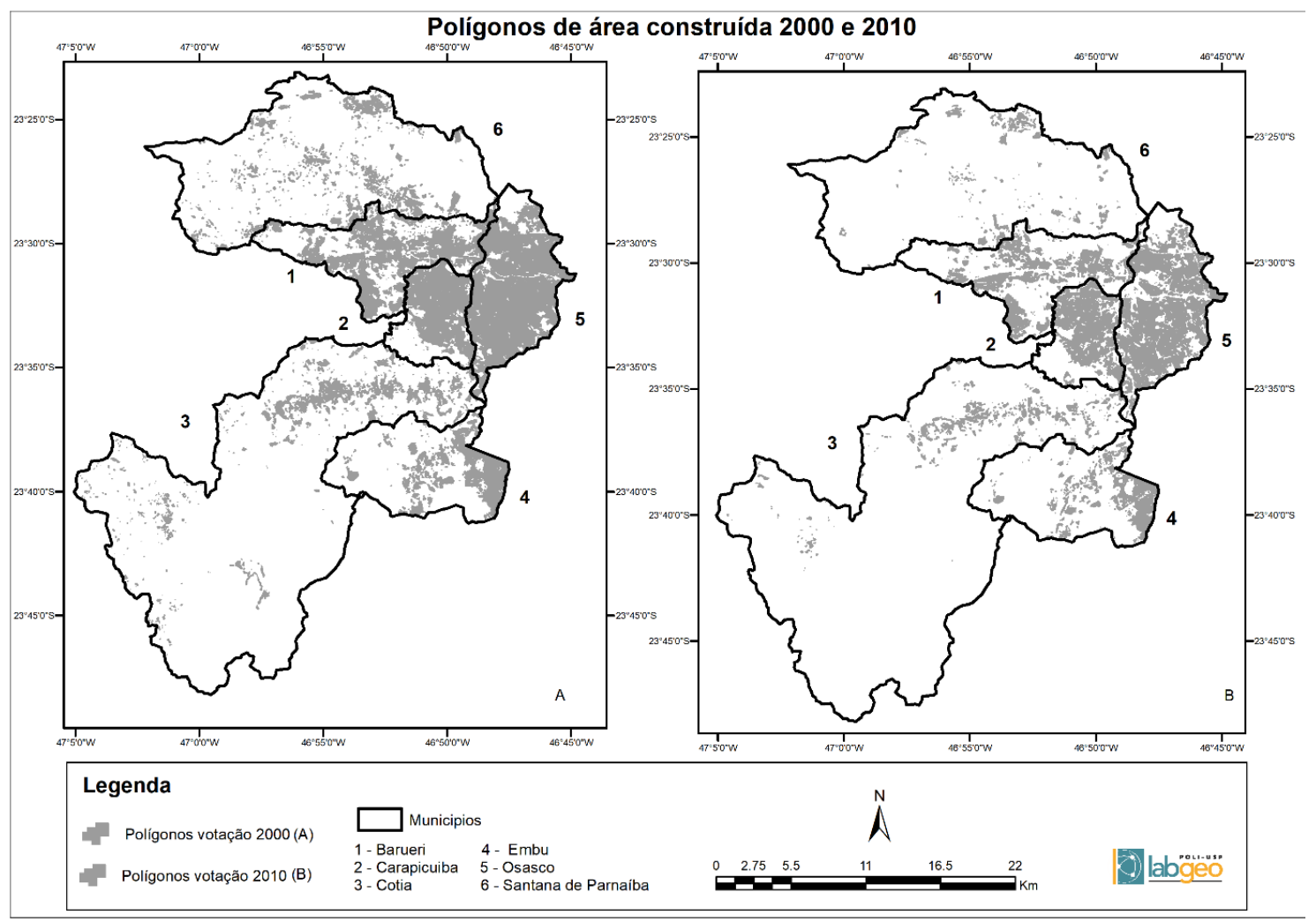

Figura 12: Polígonos da técnica de votação 2000 (A) e 2010 (B).

\subsection{Mapa de área construída de 2000 e 2010}

Para facilitar a interpretação dos resultados da técnica de votação no mapeamento da área construída através do índice Built-Up sobre a área de estudo, a análise será feita individualmente por município, em ordem alfabética. 
O município de Barueri, é atravessado pelo Rodoanel Mário Covas próximo à sua divisa com Osasco e também pela rodovia Castello Branco (SP280) que liga São Paulo ao centro-oeste paulista, é uma rodovia bastante importante para o estado. O Rodoanel não possui acesso urbano neste ponto da rodovia, porém possui interligação com a rodovia Castello Branco.

Como se pode constatar na Figura 13, Barueri é um município bastante adensado nas divisas com seus vizinhos, Carapicuíba a leste e Jandira a oeste (que não faz parte da área de estudo). Possui área militar bem extensa, na porção sudeste e na porção noroeste uma grande área não construída composta por vegetação. $\mathrm{Na}$ imagem de 2000, o mapeamento segue as mesmas áreas expostas como construída na composição colorida LANDSAT (2010), com poucas áreas diferentes. Acredita-se que em 2000 as construções ainda não estavam consolidadas. Já em 2010, devido a depreciação já mencionada causada pelo índice Built-Up algumas áreas foram excluídas, principalmente aquelas que são compostas por condomínios arborizados onde é comum que o índice cause erro.

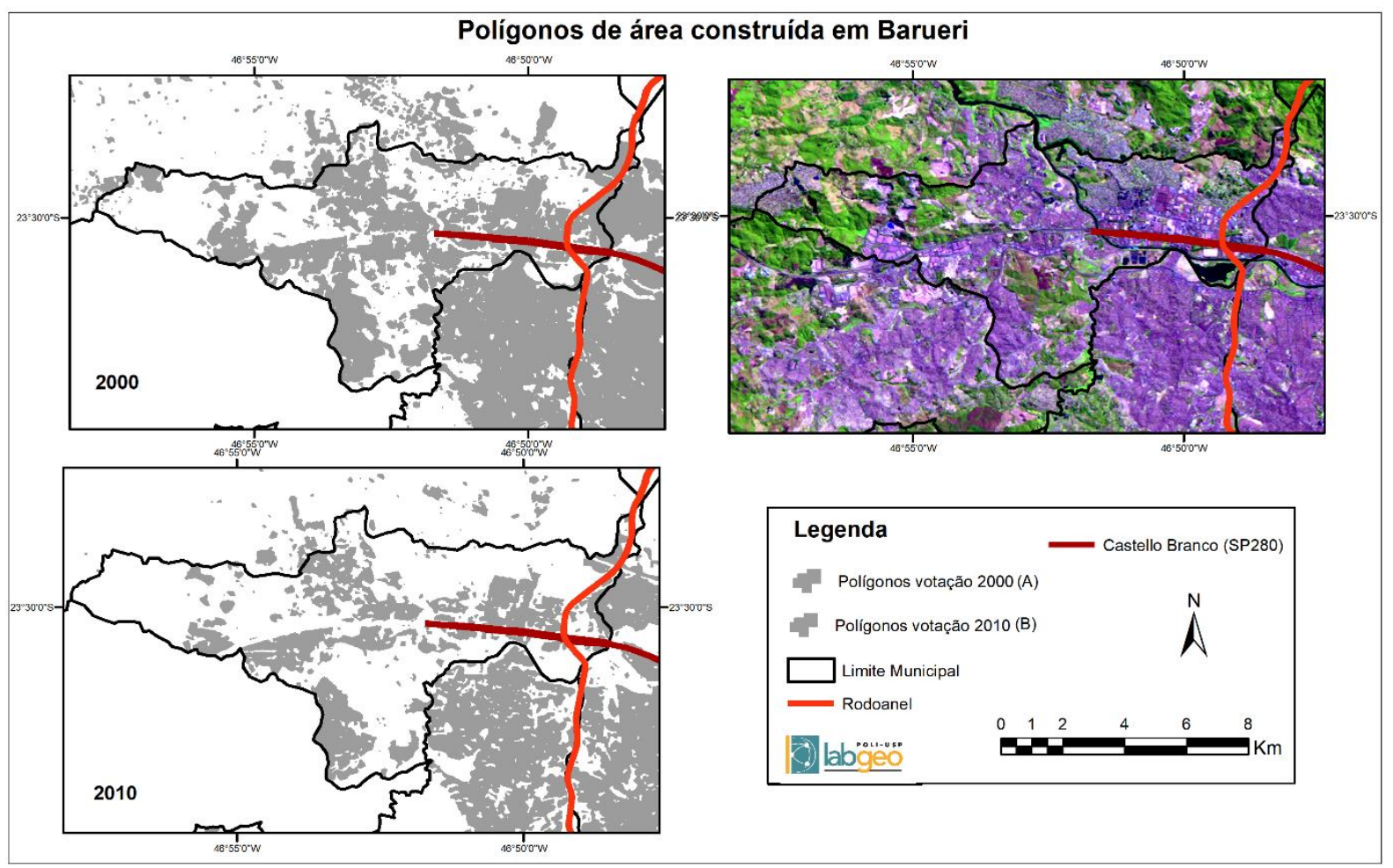

Figura 13: Polígonos de área construída gerado pela votação de 2000 e 2010 em Barueri - SP. 
Carapicuíba, possui acesso urbano do Rodoanel na porção sul do município, no mesmo complexo viário (viaduto das Bandeiras) que conecta 0 município de Osasco ao Rodoanel, estes municípios são extremamente próximos e interligados, mas não chegam ao conceito completo de conurbação (quando duas cidades crescem tanto sua área urbana que, é difícil in loco distinguir qual é cada) como se pode observar na Figura 14. É uma cidade bastante adensada, com a maior parte do município coberto por áreas construídas e o restante, composto por área de chácaras, condomínios de padrão mais elevado e ruas muito arborizadas. Nestas áreas o índice Built-Up não consegue mapear as construções devido à grande mistura espectral nos pixels e também à resolução espacial do pixel (30 metros), que aumenta essa confusão.

Como a urbanização deste município e seu adensamento não é recente, de acordo com as referências bibliográficas pesquisadas (MEYER, 2004; DAMIANI, 2010), sabe-se então que pouco mudou nas áreas edificadas. Com isso, em 2000 nota-se que o mapeamento segue com bons resultados e em 2010, os polígonos são menores ou menos adensados, o que neste caso não representa em uma diminuição de área construída e sim um erro do índice BuiltUp.

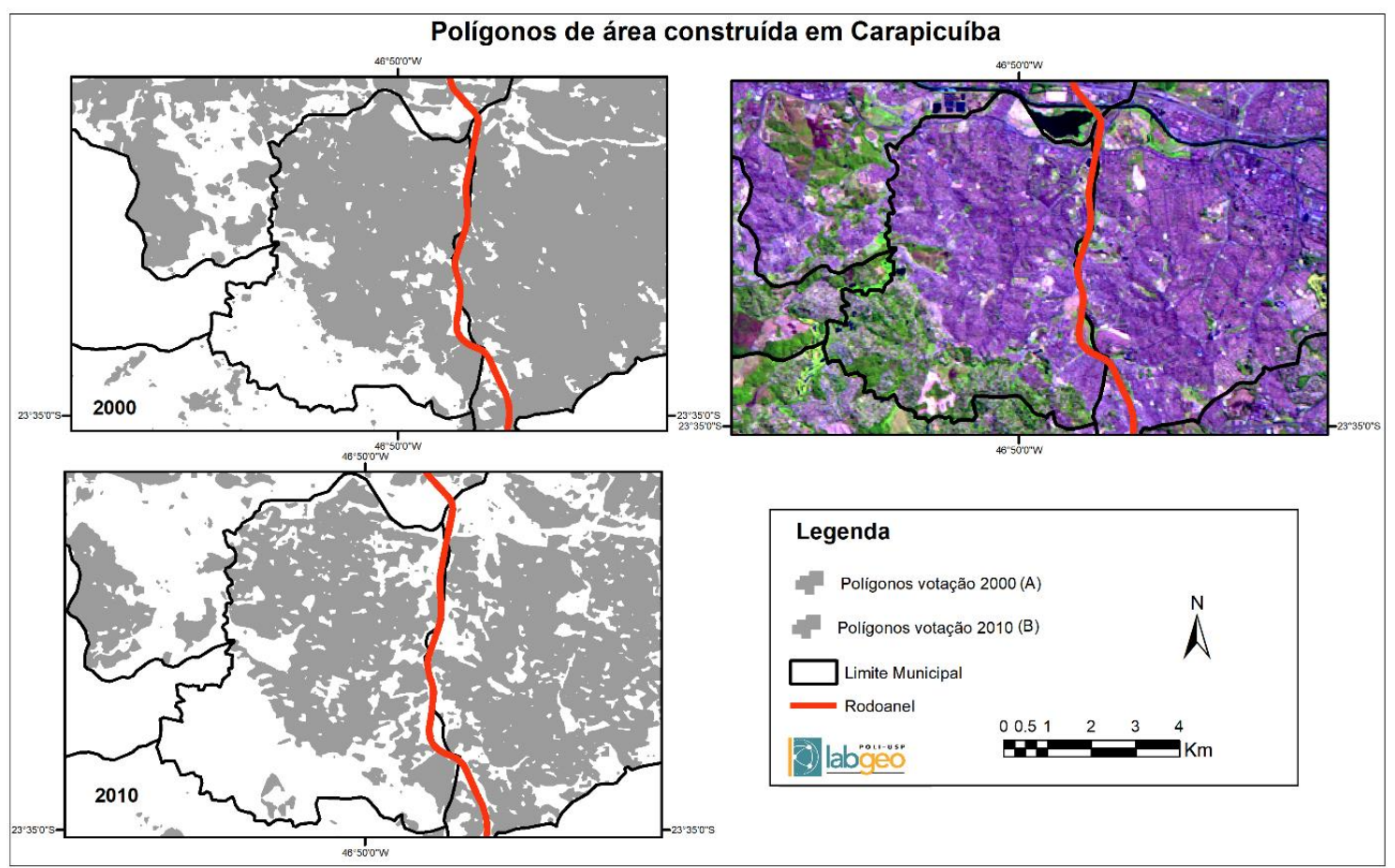


Figura 14: Polígonos de área construída gerado pela votação de 2000 e 2010 em Carapicuíba - SP.

Cotia também não possui acesso em área urbana do Rodoanel, porém, este município tem conexão com a rodovia Raposo Tavares (SP270) que conecta São Paulo à divisa com Mato Grosso do Sul. É um município que possui grandes áreas vegetadas destinadas a parques e fazendas e também a represa Pedro Beicht que compõe o sistema Alto Cotia, que pode ser observada na Figura 15.

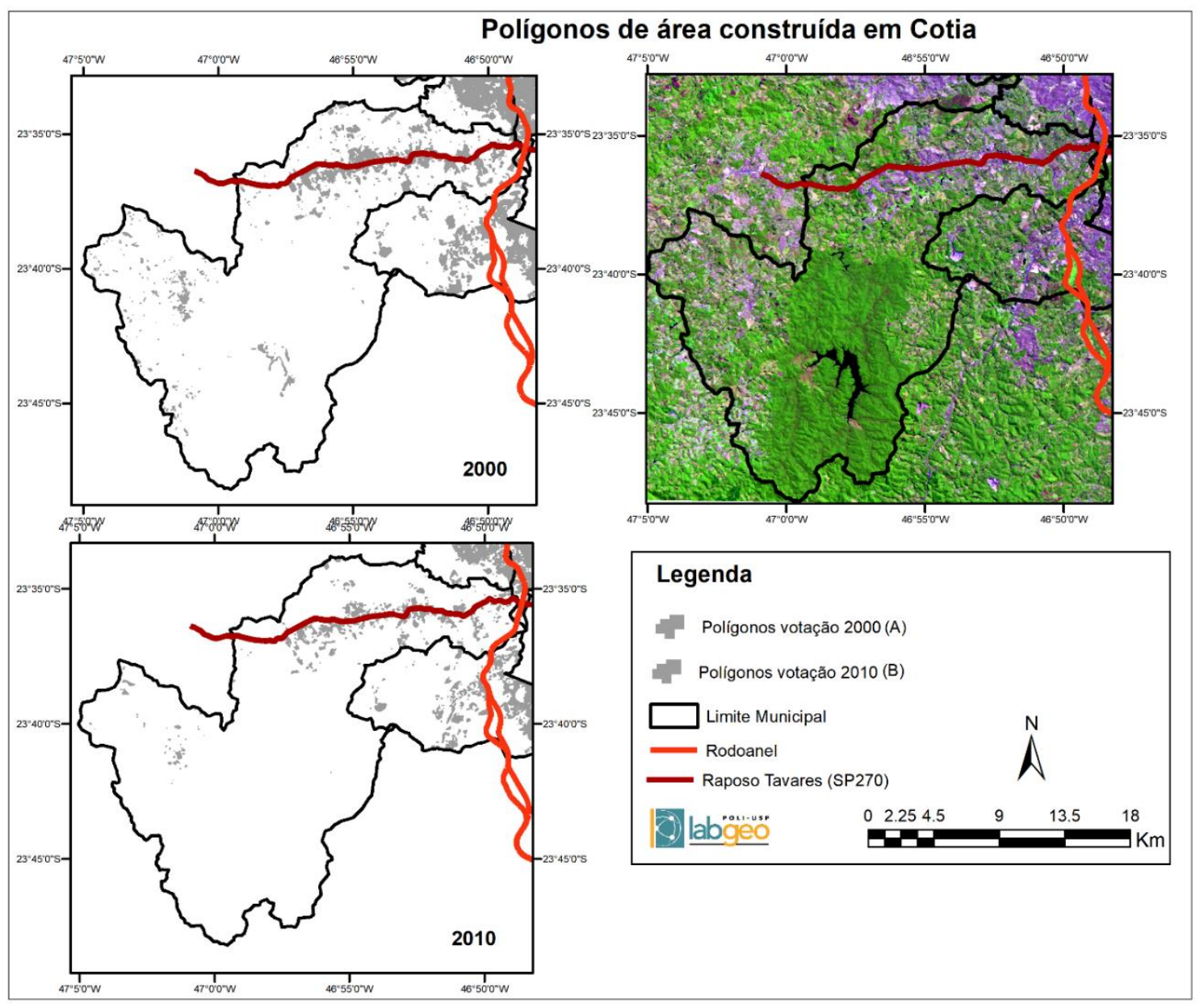

Figura 15: Polígonos de área construída gerado pela votação de 2000 e 2010 em Cotia - SP.

A área em volta da represa foi mapeada erroneamente em 2000 como área construída devido a confusão com o solo exposto do índice Built-Up na maioria das imagens geradas previamente a técnica de votação, que por sua vez 
não foi capaz de subtrair este erro visto que seus elementos de entrada 0 condicionaram para o mesmo. Entretanto, este erro não ocorre no resultado de 2010 pois o trecho em questão não é mais caracterizado como solo exposto extremamente seco e sim, possui uma vegetação instalada o que tem uma diferença na assinatura espectral para com a área construída grande e não é apontado erroneamente.

O município tem sua expansão fortemente conectada à rodovia Raposo Tavares, por toda a sua extensão observa-se um adensamento de alvos urbanos (Figura 15). As demais áreas ocupadas do município são compostas por áreas de uso misto (agrícola e urbano), chácaras, condomínios de alto padrão e bastante vegetados, sendo áreas propensas a adensamento no futuro. Estas regiões não são facilmente mapeáveis na escala de resolução espacial de 30 metros, com isso é natural que haja uma subestimação das mesmas, consequentemente os dados de densidade demográfica nestas regiões também serão afetados.

O município de Embu, é atravessado pelo Rodoanel, porém sem acessos urbanos diretos, somente com a rodovia Régis Bittencout (BR116) que conecta São Paulo ao sul do país (até Porto Alegre - RS). Embu é um município novo e classificado pelo IBGE como estância turística, seu maior adensamento urbano se dá na porção leste, no limite com São Paulo (especificamente o bairro de Capão Redondo) e também no município de Taboão da Serra (nordeste). 


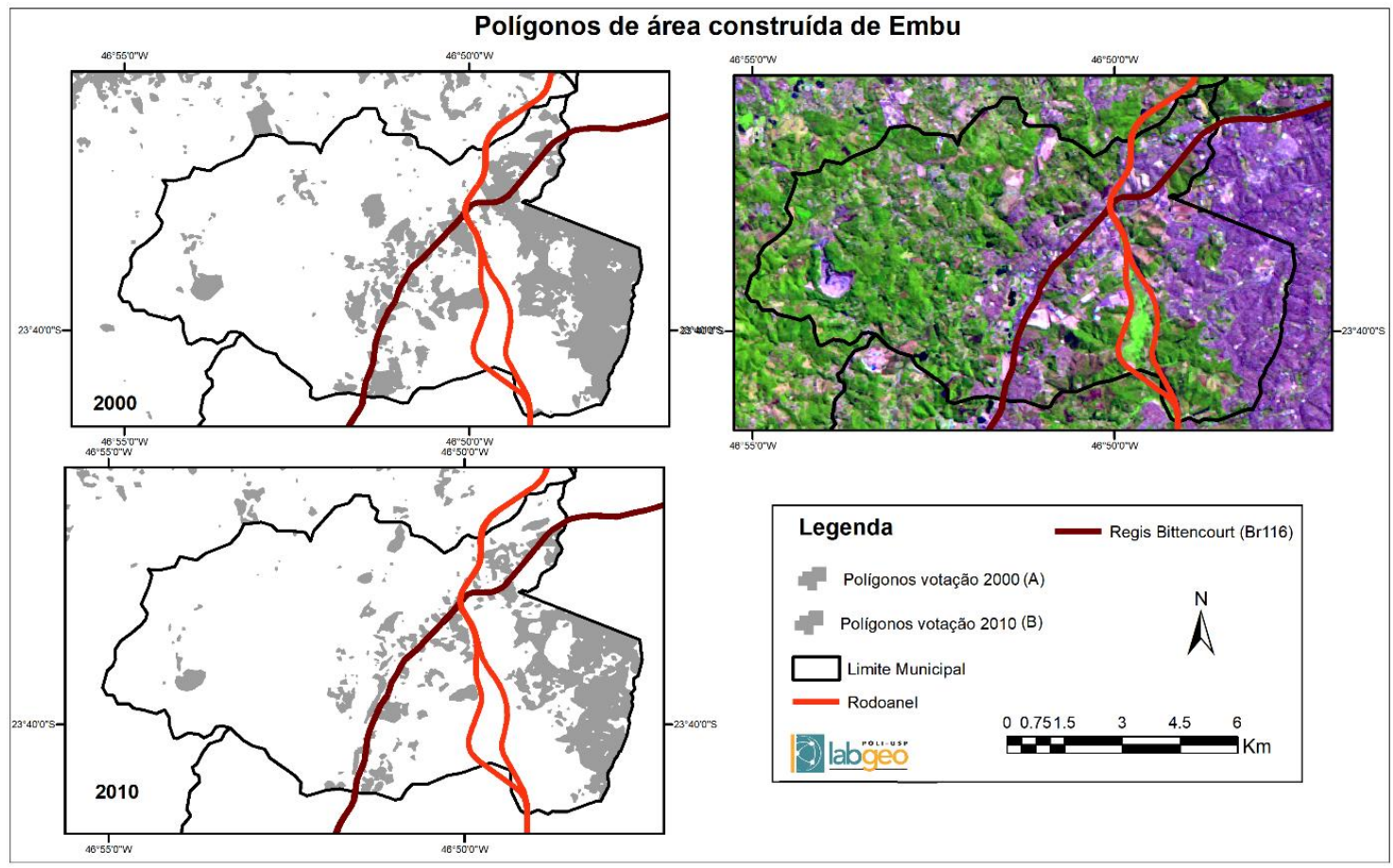

Figura 16: Polígonos de área construída gerado pela votação de 2000 e 2010 em Embu - SP.

Assim como acontece em Cotia, o adensamento urbano de Embu (Figura 16) segue outra rodovia, que não o Rodoanel, no caso a Régis Bittencourt, que é anterior ao Rodoanel. As demais áreas do município também são compostas por vegetação e áreas residenciais com vegetação no entorno, tornando dificultoso o mapeamento pelo índice Built-Up das áreas construídas pois são rarefeitas e em parte coberta pela copa das árvores. Embu possui uma pedreira na porção oeste do município que, foi erroneamente mapeada como área construída nos dois anos. Porém este erro é perfeitamente comum visto que a pedreira produz matéria prima para os materiais de construção das edificações.

Osasco possui um acesso urbano do Rodoanel ao sul do município, na região do Parque Jandaia. Osasco está representado na Figura 17, com base nesta é propicio dizer que é um município quase que completamente ocupado e edificado e sem alterações significativas na área construída entre 2000 e 2010, o que provavelmente indicaria uma maior verticalização, porém os métodos empregados aqui não são capazes de mapear esse processo. 


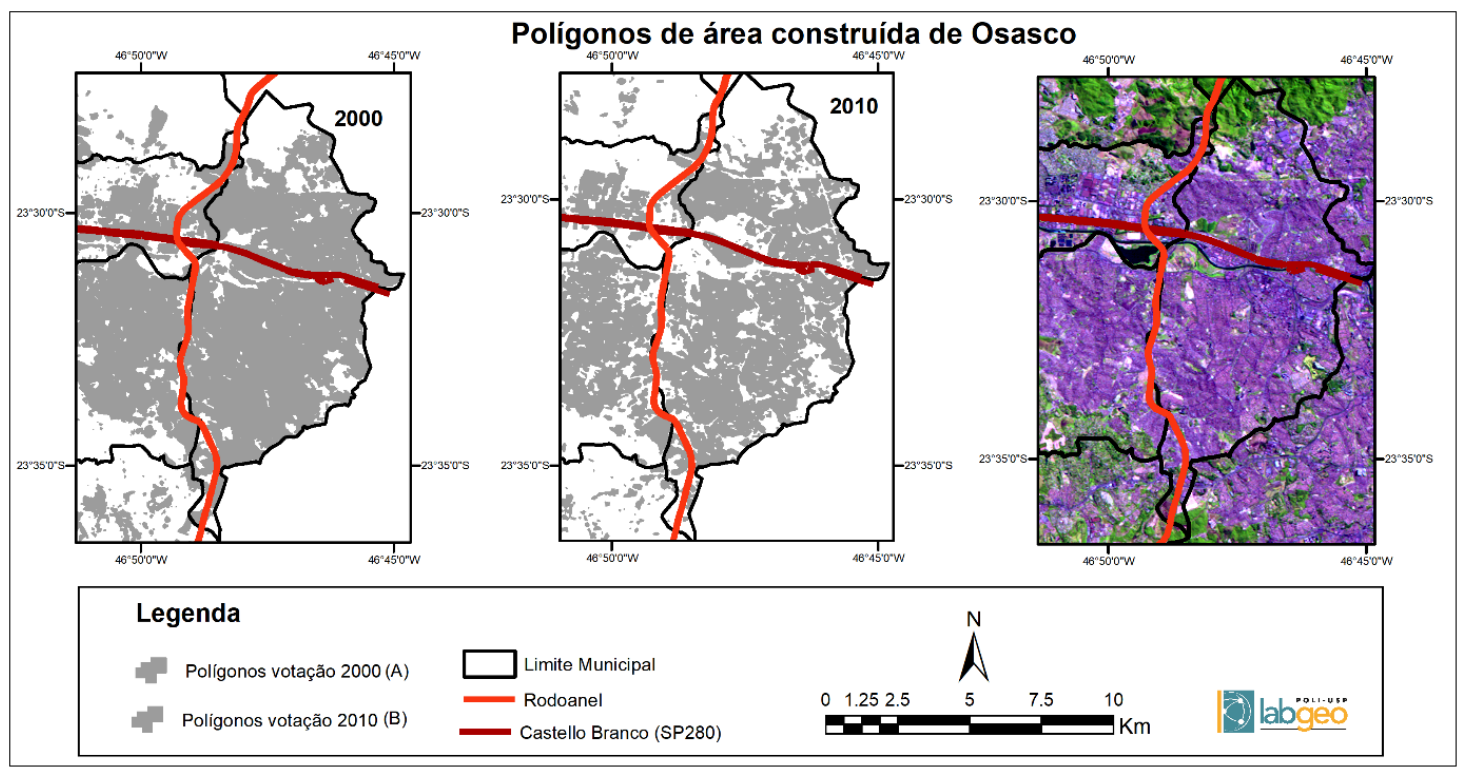

Figura 17: Polígonos de área construída gerado pela votação de 2000 e 2010 em Osasco - SP.

Novamente nota-se a subestimação de área construída causada pelo Built-Up do conjunto de dados de 2010.

Outra rodovia que corta o municpioio é a Castello Branco (SP-280) e sua vizinhança também é bastante ocupada, porém não se pode afirmar que esta rodovia causou um adensamento, já que o município é conurbado ao município de São Paulo (zona Oeste), fato este muito propicio ao crescimento de Osasco ainda mais levando em consideração que não existem barreiras geográficas (tal como serras), além do rio Tietê entre estes.

Santana de Parnaíba é o município que sofre menor influência do Rodoanel, este corta o município em um pequeno trecho não habitado, onde encontram-se fazendas e estradas rurais. É um município importante na região por abrigar condomínios residenciais de alto padrão e também condomínios industriais/comerciais. Há doze residenciais Alphaville além de outros condomínios horizontais de chácaras e sítios.

Como se pode observar na Figura 18, devido ao tamanho do pixel e a grande cobertura de vegetação a redor das residências tornam-se áreas são mais complicadas para o índice Built-Up, logo, passível de maiores erros. Acredita-se que os resultados em 2000 foram mais condizentes com a realidade 
do município do que em 2010, que foram subestimados devidos aos erros já mencionados anteriormente.

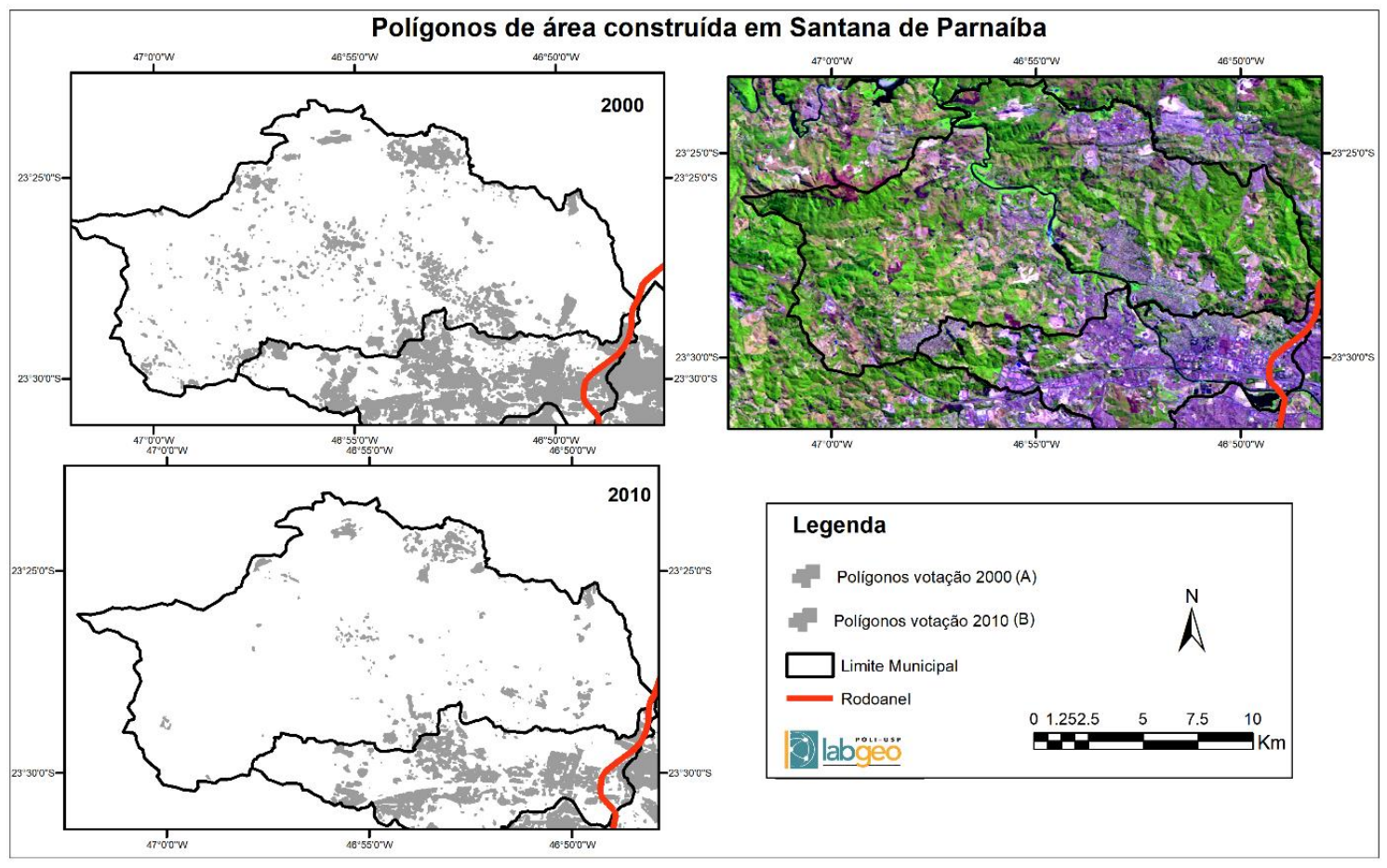

Figura 18: Polígonos de área construída gerado pela votação de 2000 e 2010 em Santana de Parnaíba - SP.

Observou-se a necessidade de comparar os resultados dos polígonos do Built Up mesmo após a técnica de votação com uma classificação supervisionada a fim de identificar o problema anteriormente mencionado de confusão dos polígonos de área construída com o solo exposto.

A Figura 19 expressa um mapa comparativo da área de teste referente a região da represa do sistema Auto Cotia, em $(A)$ têm-se os polígonos de área construídas oriundo da técnica de votação do conjunto de dados de 2000 , em (B) os polígonos de área construída de 2010, em (C) a composição colorida RGB nas bandas 543 falsa cor (imagem pertencente ao conjunto de imagens de 2010), em (D) está representada a classificação de Máxima Verossimilhança de 2000 e em (E) a classificação de 2010. 


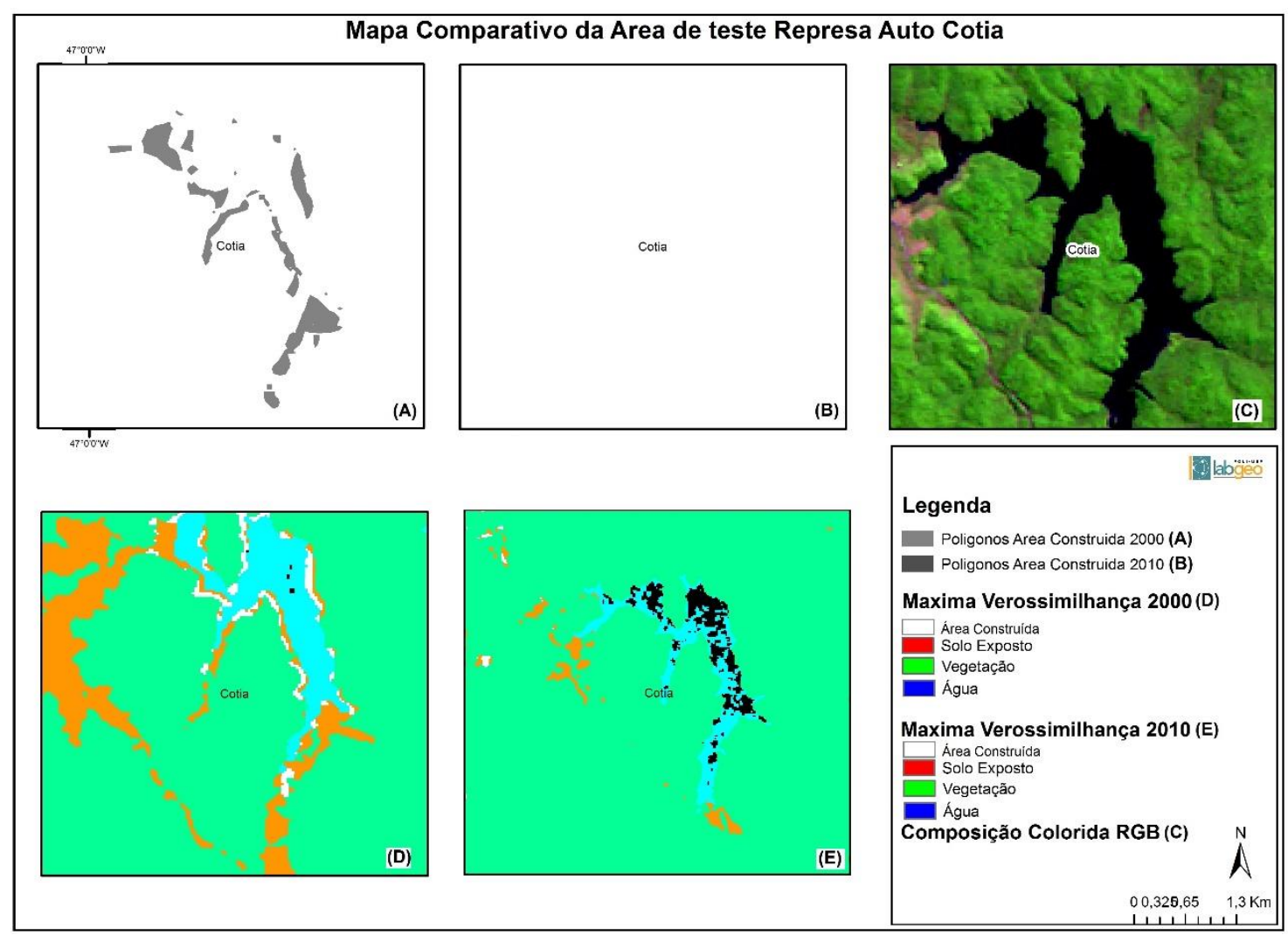

Figura 19: Mapa da área de Teste: Represa Auto Cotia.

A classificação de 2000 (D) apresenta extensa área de Solo exposto, marcado em vermelho, pequenos trechos apontados como área construída, e os pontos em preto são ruídos que não foram classificados em nenhuma classe. Em (E), a classificação mostra a área de água em azul e pequenos trechos classificados como solo exposto, entretanto existe bastante ruído. Ao comparar visualmente os recortes $(A)$ e $(D)$ observa-se que as áreas classificadas como solo exposto próximas a represa foram mapeadas como construída pelo índice Built Up que manteve-se no resultado da técnica de votação, devido à pouca presença de água no solo no momento de aquisição das imagens, tornando a assinatura espectral semelhante (entre áreas construídas e solo exposto). Neste caso então, a confusão de solo exposto com área construída foi identificada e mesmo com a técnica de votação aplicada nas cinco imagens do índice Built Up (2000), foi capaz de eliminar o erro.

Ao contrapor os recortes $(B)$ e (E) observa-se que o índice Built Up através do resultado da técnica de votação foi capaz de culminar com a incerteza mapeada no conjunto de dados anterior, conforme observa-se na composição 
colorida (C) existe uma área pequena de solo exposto no canto esquerdo da imagem que neste caso, não resultou na confusão. Entretanto a classificação de uma imagem que compôs o conjunto de imagens de 2010, mapeou uma extensa área de ruídos na água, e parte de solo exposto nas bordas da represa.

A Figura 20 representa os mesmos dados da anterior para o recorte da região entre Barueri e Santana de Parnaíba. Em (A) têm-se os polígonos de área construídas oriundo da técnica de votação do conjunto de dados de 2000, em (B) os polígonos de área construída de 2010, em (C) a composição colorida RGB nas bandas 543 falsa cor (imagem pertencente ao conjunto de imagens de 2010), em (D) está representada a classificação de Máxima Verossimilhança de 2000 e em (E) a classificação de 2010.

Os trechos expressos nesta imagem foram mencionados anteriormente pela dificuldade de mapeamento do índice Built Up devido à falta de homogeneidade na cobertura do solo. Este trecho representado é composto por área de prédios (Barueri) que causam sombra e por isso impede o imageamento do satélite no momento da aquisição da imagem acarretando na baixa qualidade do resultado do índice Built Up, loteamentos residenciais do tipo Alphaville já consolidados (no canto esquerdo superior) e loteamentos industriais no centro e direita superior da imagem. 


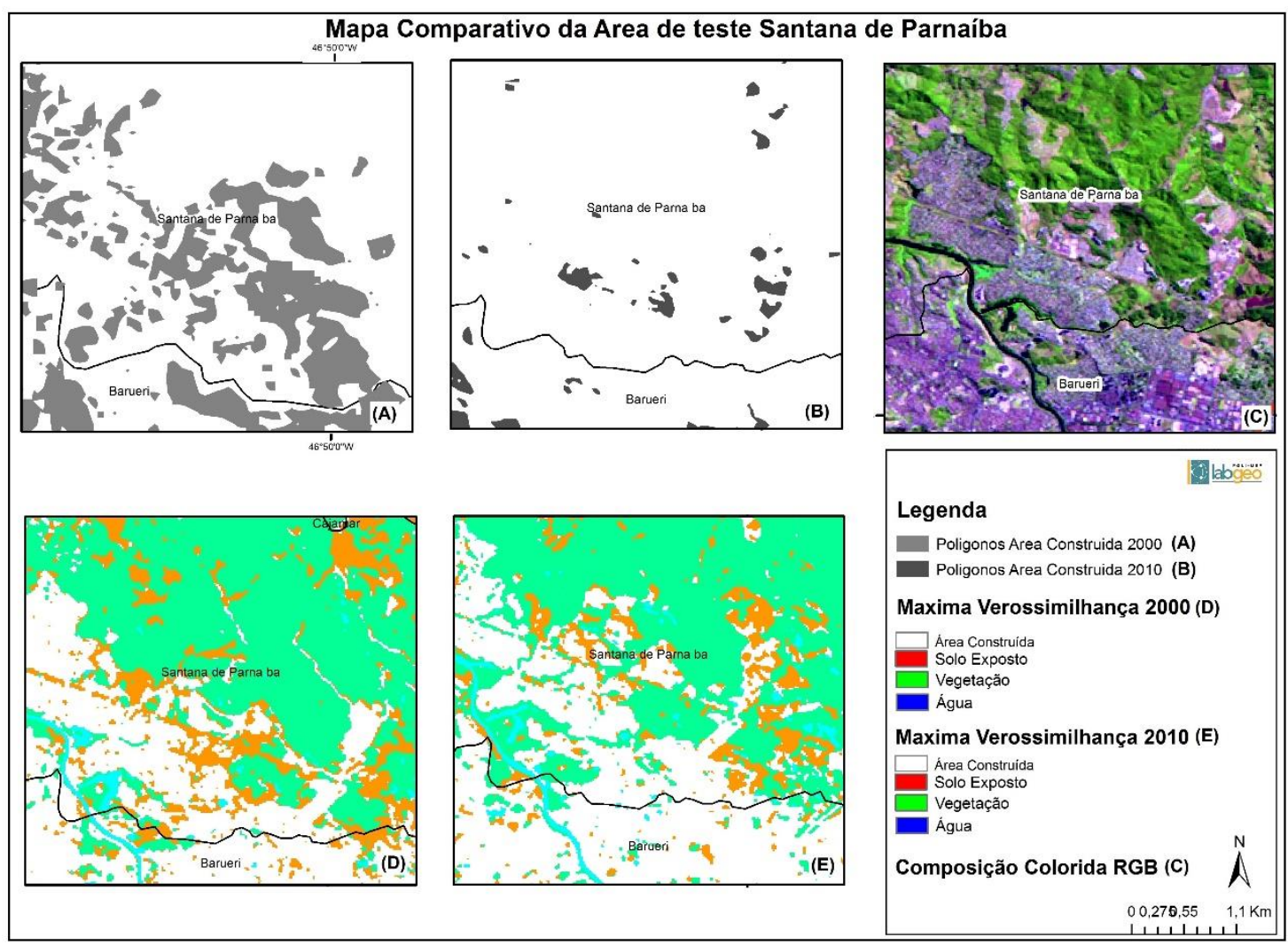

Figura 20: Mapa da área de Teste: Santana de Parnaíba

No trecho onde observa-se a presença de prédios, o índice Built Up não foi capaz de realizar o mapeamento nas duas datas analisadas 2000 (A) e 2010 (B). A área em que se encontram no canto superior esquerdo em (C) refere-se a loteamentos Alphaville, observa-se que em (A) 2000 o índice atingiu resultados mais próximos para com a realidade expressa em (C), ainda que não fielmente. Ao inserir a imagem (D) na análise nota-se que a faixa de terra de linha de transmissão que permeia o rio Tietê foi classificada como solo exposto, além das áreas construídas mencionadas anteriormente possuírem maior correspondência com (C) as áreas de água são mapeadas como água.

Em (B) é evidente a subestimação causada pelo índice Built Up pois quase não foi mapeado os trechos de áreas construídas, com apenas alguns fragmentos de áreas construídas não é possível identificar ao menos um recorte similar a realidade $(C)$ ou a classificação $(E)$, embora também não tenha ocorrido muitos trechos de confusão com solo exposto é valido afirmar que, neste trecho de teste o Built Up não trouxe resultados satisfatórios. 
Quanto ao trecho de loteamentos industriais, na porção centro e direita superior da imagem, observa-se uma superestimação em (A) que, mapeou áreas construídas maiores do que a realidade, perante $(B)$ que possui polígonos mais próximos a real representação exposta em (C). A classificação de máxima verossimilhança em $(D)$ e $(E)$ foram mais fidedigno a composição colorida $(C)$, mostrando em 2010 a presença de áreas de solo exposto dentro ou próximo aos loteamentos industriais.

\subsection{Mapeamento coroplético da população total}

Para a análise do adensamento populacional nos municípios após a implantação do Rodoanel, é necessário a compreensão da dinâmica de ocupação da população nos municípios, bem como o conhecimento de sua concentração para então avaliar se tal processo ocorreu.

Elaborou-se então, um mapa coroplético utilizando, ao invés do recorte espacial do setor censitário IBGE, o recorte espacial dos polígonos de área construída resultantes da técnica de votação para ambos os conjuntos de datas analisadas a variável de população total. Tal processo unicamente especializou a variável de população total no espaço do polígono de área construída. Não aplicou-se nenhum tipo de conta de densidade populacional (onde a população é dividida pela área) pois a inconsistência no tamanho dos polígonos era grande, ocorreram polígonos de áreas construídas extremamente pequenos que agrupavam a população de uma região muito grande.

Na Figura 21, têm-se a concentração de população por cores que variam do amarelo ao vermelho escuro. A mesma figura é dividida em pequenos mapas numerados, de 1 a 6 referente a cada município da área de interesse, que serão analisados separadamente. 


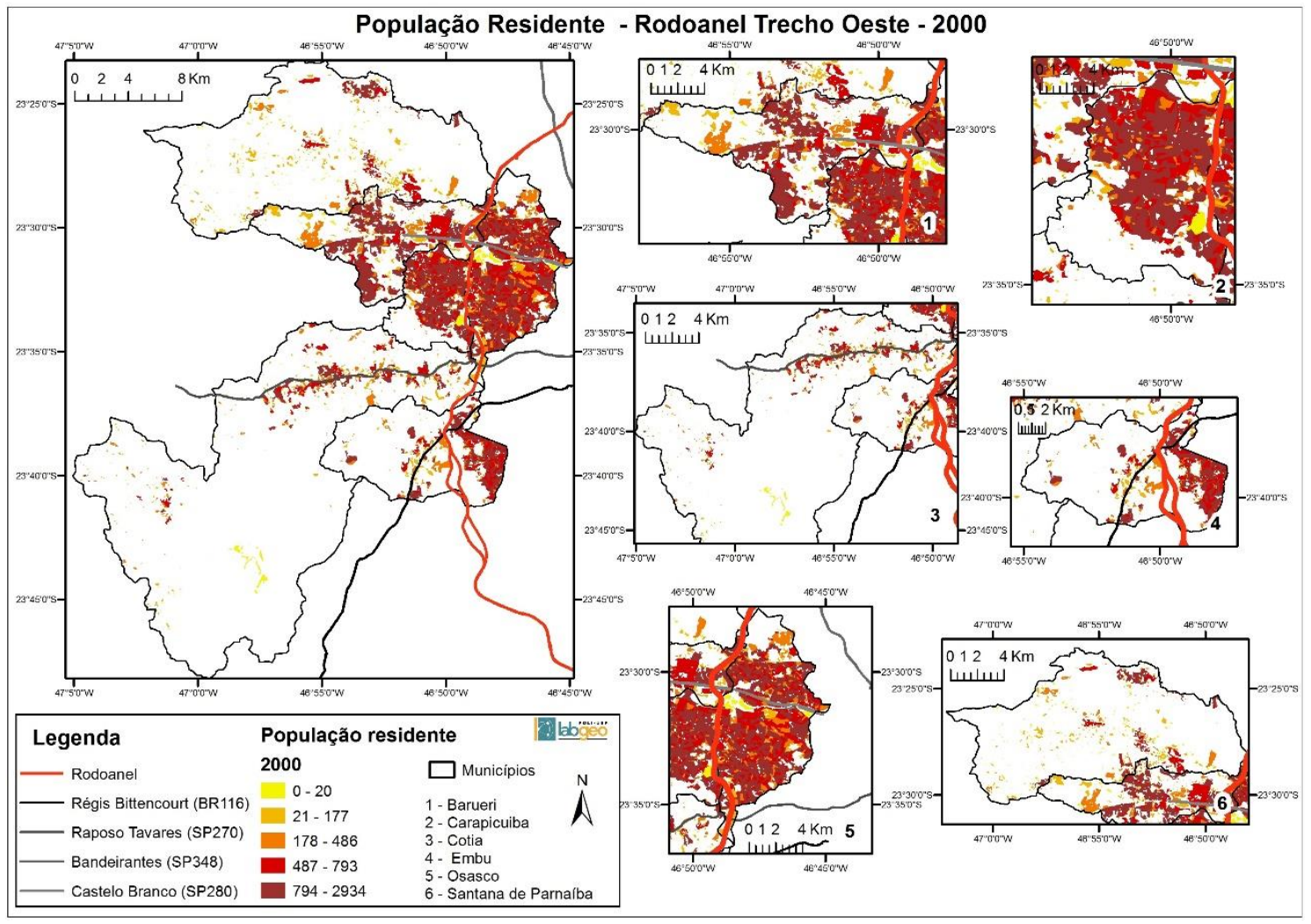

Figura 21: Mapa coroplético de População total (v249) em cada polígono 2000.

1. Barueri: município atravessado pela rodovia Castello Branco e sua população agrupa-se longo desta rodovia e na divisa com os municípios a oeste (Jandira e Cajamar, ambos fora da área de estudo).

2. Carapicuíba: é um município bastante povoado, principalmente próximo ao acesso urbano do rodoanel, no trecho norte.

3. Cotia: não é um município muito povoado em toda a sua extensão (devido as áreas não ocupadas já mencionadas, de parques, fazendas e represas) e sua maior concentração se dá ao longo da rodovia Raposo Tavares.

4. Embu: tem sua concentração de habitantes ao longo da rodovia Regis Bittencourt e próximo à divisa com o município de São Paulo.

5. Osasco: é o município com maior concentração de habitantes, e apenas as áreas militares e montanhosas (ao norte) não são ocupadas. 
6. Santana de Parnaíba: possui poucas concentrações de habitantes.

Para o mapa coroplético referente ao ano de 2010, utilizou-se a variável de População residente do respectivo censo e também utilizou-se o novo setor calculado a partir da intersecção do mapa de área construída com o setor censitário original.

Diante da Figura 22, é possível observar que aparentemente não houve mudança no padrão espacial da população, ou seja, não houve um espraiamento dos municípios (em parte porque os mais populosos não têm mais espaço horizontal para crescer e em parte, pode ter havido uma influência das limitações do método para gerar o mapa de área construída de 2010).

Mesmo com os polígonos não sendo os mesmos, acredita-se que houve uma concentração da população nas áreas onde já eram habitadas anteriormente, a destacar o município de Cotia, ao longo da rodovia Raposo Tavares e Santana de Parnaíba.

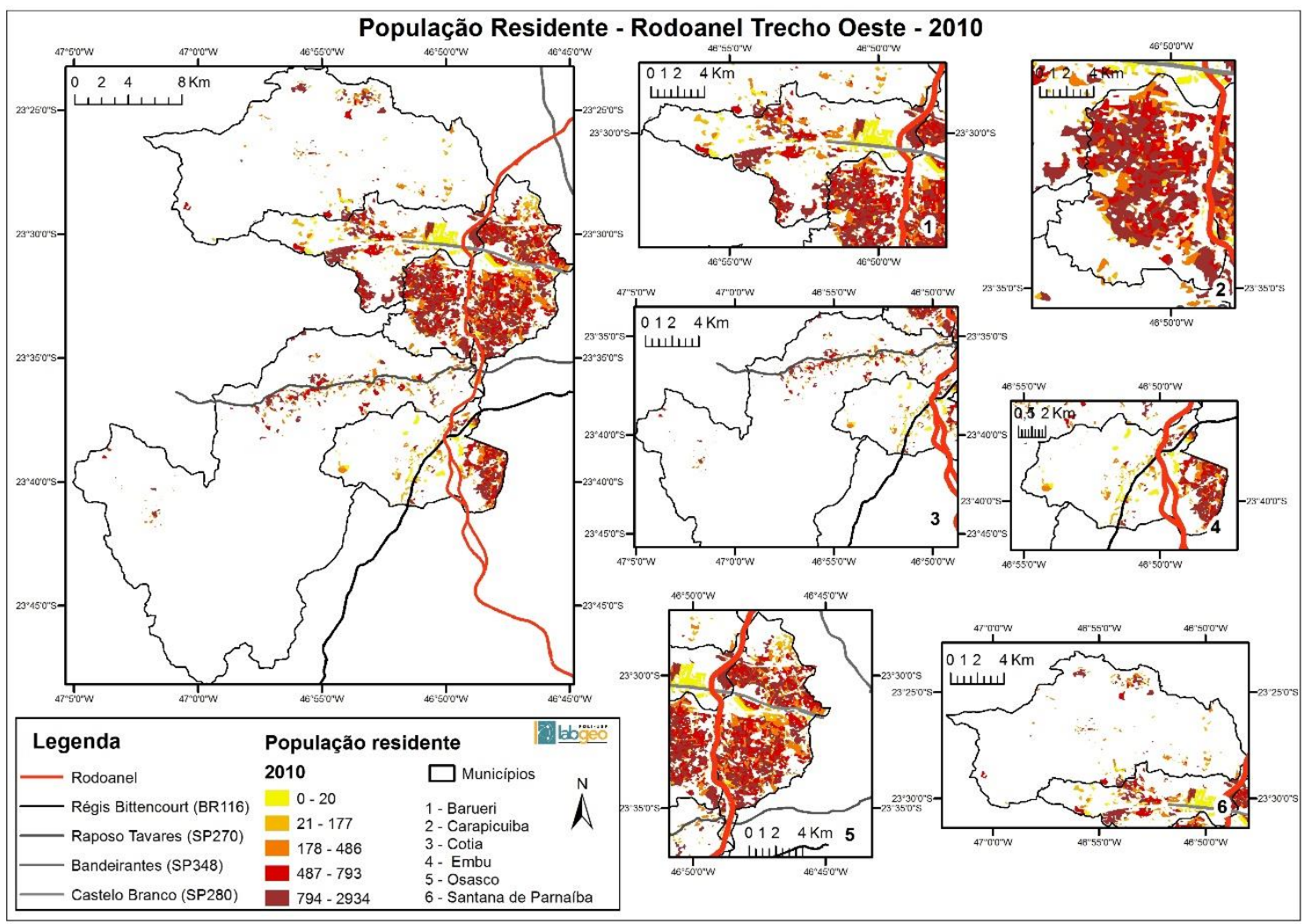

Figura 22: Mapa coroplético da população total residente em cada polígono da técnica de votação - 2010. 


\section{CONCLUSÕES E RECOMENDAÇÕES}

O índice Built-Up apresentou falhas no mapeamento que foram ocorridas devido ao período de aquisição das imagens, pois as imagens adquiridas nos períodos não chuvosos (especialmente nos meses entre maio a setembro) tem uma proximidade grande entre as assinaturas espectrais do solo exposto e coberturas de solo de áreas urbanas, especificamente as construídas. Este fator implicou diretamente no limiar de corte para a transformação das imagens NDBI e NDVI em imagem binária (2 bits) através da aplicação de streach no histograma.

Observou-se ainda a necessidade de se estudar mecanismos para automatizar a etapa de transformação das imagens em binárias de modo que não se obtenha tantas perdas de áreas construídas devido a confusão com outros tipos de cobertura do solo, especialmente o solo exposto.

É fato que o índice é um modo de automatizar o processo de mapeamento de áreas construídas porém, o método de transformação aplicado para transformar em imagem binária, trouxe um tempo de processamento e de testes maior do que o esperado para a elaboração dos resultados. Acredita-se também que este fator tenha implicado diretamente nas imagens em que houve uma subestimação nas áreas construídas pois, em muitos casos para separar a área construída do solo exposto, houve a necessidade de diminuir os valores enquadrados como áreas construídas e do mesmo modo ocorre o fator inverso.

Constatou-se também que em áreas de extração de pedras (pedreiras) sempre haverá uma incerteza no mapeamento que é marcado como área construída, devido ao fato de ser uma das matérias primas para a construção das edificações.

Embora as recomendações do autor que propôs o índice Built-Up sejam para não utilizar a correção radiométrica, realizou-se o teste da mesma a fim de confirmar a ausência de resultados positivos. Não foram observada melhoras significativas que justifiquem o uso da técnica pois, acrescenta um passo desnecessário na construção dos índices que tem o objetivo de tornarem o 
mapeamento mais automatizado e rápido, nos resultados de 2000 não houve melhora e em 2010 o benefício foi baixo.

A aplicação da técnica de votação com imagens Built-Up foi eficaz em melhorar os resultados de mapeamento das áreas construídas e para que o seu resultado seja melhor depende diretamente da qualidade das imagens de entrada Built-Up. Uma recomendação para trabalhos futuros seria realizar a votação combinada a classificações de imagens, como por exemplo a máxima verossimilhança em apenas duas classes construído e não construído para mesclar o resultado e então tentar melhorar os resultados da técnica.

O mapa coroplético da população absoluta mostra um adensamento da população nas áreas indicadas anteriormente como já adensadas, isto pode significar um processo de verticalização que o índice não é capaz de apontar devido ao tamanho do pixel de entrada da imagem LANDSAT e também a presença de sombras, além de não ser mapeável a altura da edificação.

Acredita-se então que, para responder a questão proposta anteriormente na justificativa quanto a influência do Rodoanel no crescimento da mancha urbana dos municípios e consequentemente um incremento na população absoluta seja necessária a utilização de mais dados pois não foi possível afirmar esta relação.

A condição do Rodoanel como uma rodovia de classe zero onde possui alto padrão técnico e controle total dos acessos com somente dois em Carapicuíba e Osasco (onde na realidade é um viaduto que interliga ambos os municípios ao rodoanel nos sentidos norte e sul), mostra que este pode não ser um indutor de expansão para os municípios que o permeiam. Entretanto é capaz de gerar uma maior acessibilidade as rodovias a quem ele dá acesso, como por exemplo o caso da Raposo Tavares em Cotia que apresentou números mais elevados de população residente ao longo de seu percurso.

Considerando que o Rodoanel foi projetado como uma via que tem como finalidade a melhor circulação de veículos de carga para uma operação logística mais eficaz, especialmente na RMSP, pode-se constatar que o mesmo cumpre seu papel de auxilio no trecho logístico e inibidor da expansão urbana conforme levantado pela bibliografia discutida anteriormente. 
Sugere-se em estudos futuros uma análise aprofundada neste tema, tendo outros dados, especialmente de circulação de veículos no trecho para compreender se realmente este não favorece a acessibilidade da população 0 que vai de encontro a teoria exposta, o Ciclo do uso do Solo e Transportes, dado que em geral estes municípios são "dormitórios" onde a maior parte de sua população precisa se deslocar aos vizinhos (especialmente São Paulo) para ofertas de trabalho e educação.

Ainda propõem-se como trabalhos futuros a utilização de imagens de alta resolução para compor as imagens utilizadas como insumo para a técnica de votação e outros tipos de classificação, onde o solo exposto seria atribuído valor baixo no algoritmo, para então obter uma maior eficiência na separação dos mesmos. 


\section{REFERÊNCIAS BIBLIOGRÁFICAS}

AMARAL, Silvana; GAVLAK, A. A.; Escada, M. I. S.; Monteiro, A. M. V. Using remote sensing and censos tract data to improve representation of population spatial distribution: case studies in the Brazilian Amazon. Population and Environment: A Journal of Interdisciplinary Studies. 2012.

ANDRADE, Thompson Almeida e Serra, R. V. O recente desempenho das cidades médias no crescimento populacional urbano brasileiro. Revista Brasileira de Estudos da População. v. 16, n.1/2. 1999

ANGIELI, SUZANNE. QUESNEY, ARNAUD. GROSS, L. Image Simplification Using Kohonen Maps: Application to Satellite Data for Cloud Detection and Land Cover Mapping. INTECH.Chapter 14. 2012. Disponível em: https://www.intechopen.com/books/applications-of-self-organizing-maps/imagesimplification-using-kohonen-maps-application-to-satellite-data-for-clouddetection-and-land-c

ARANHA, Valmir. Mobilidade pendular na metrópole paulista. São Paulo em perspectiva, v. 19, n. 4, p. 96-109, out./dez. 2005

ARRUDA, Fabiana de. Aplicação de um modelo baseado em atividades para análise da relação uso do solo e transportes no contexto brasileiro. Tese (Doutorado) Escola de Engenharia de São Carlos/USP. 2005

BAGAN, HASI. WANG, Q.; WATANABE, M.; YANG, Y.; MA, J.; Land cover classification from MODIS EVI times-series data using SOM neural network. International Journal of Remote Sensing. 26:22, 4999-5012, DOI: 10.1080/01431160500206650. 2005.

BALÇIK, F. B. Determining the impact of urban components on land surface temperature of Istanbul by using remote sensing indices. Environ Monit Assess. 186: 859-872. 2014

BARROZO, L.V.; MACHADO, R.P.P.; Luchiari, A.; Queiroz Filho, A.P. Dasymetric mapping of socioeconomic data of the city of Sao Paulo: First Approach. In: Conferência Geográfica Regional. 2011. Anais. Santiago, Chile, UGI. 2011.

BARROZO, Ligia Vizeu; PÉREZ-MACHADO, R. P.; Small, C.; Cabral-Miranda, W. Changing spatial perception: dasymetric mapping to improve analysis of health outcomes in a megacity. Journal of Maps. DOI: 10.1080/17445647.2015.1101403. 2015.

BATTHI, S. S.; TRIPATHI, N. K.; Built-Up Area Extraction Using LANDSAT 8 OLI Imagery. 51(4). 445-467. GIScience \& Remote Sensing. 2014

BIELECKA, E. A dasymetric population density map of Poland. In: Internacional Cartographic Conference. 22. 2005. Anais. Coruña, Espanha. 2005.

BRUZZONE, Lorenzo; COSSU, R.; Combining parametric and non-parametric algorithms for a partially unsupervised classification of multitemporal remotesensing images. Information Fusion. 289-197. 2002. 
CAMPOS, WALDIR WAGNER. GASPAR, JULIO. LAGE, M. O.; KAWASHIMA, R. S.; GIANNOTTI, M. A.; QUINTANILHA, J.A. avaliação de classificadores de imagem de satélite a partir do uso de uma técnica de votação. Revista Brasileira de Cartografia. No 68/8: 1653-1664 Sociedade Brasileira de Cartografia, Geodésia, Fotogrametria e Sensoriamento Remoto ISSN: 1808-0936. 2016.

CCR RODOANEL. Companhia de Consorcio Rodoviário. Disponível em: http://www.rodoaneloeste.com.br/institucional/ Acesso em: 14/09/2016

CCR RODOANEL. Concessionária do Rodoanel Oeste S.A. RELATÓRIO DA ADMINISTRAÇÃO. Disponível em: http://www.rodoaneloeste.com.br/resources/files/misc/b5fe3b092f7e4fdd8f398fc 5fc5bf540_CCR\%20RodoAnel_2012-2011.pdf Acesso em: 14/09/2016

Censo Demográfico. Instituto Brasileiro de Geografia e Estatística. Disponível em: <http://7a12.ibge.gov.br/sobre-o-ibge/o-que-e-censo.html> Acesso em: 10/06/2016

CHAVEZ Jr., P.S. An improved dark-object subtraction technique for atmospheric scattering correction of multispectral data. Remote Sensing of Environment. v. 24, p. 459-479, 1988.

CHEN, SHUPENG; ZENG, SHAN; XLE. CHUANGJLE; Remote Sensing and Gls for Urban Growth Analysis in China. Photogrammetric Engineering \& Remote Sensing. 66, 5. 593-598. 2000.

CHEN, XIAO-LING; ZHAO, Hong-Mei; Li, Ping-Xiang, Yin, Zhi-Young. Remote sensing image-based analysis of the relationship between urban heat island and land use/cover changes. Remote Sensing of Environment. 104. 133-146. 2006

CONGALTON, RUSSELL G. A review of assessing the accuracy of classifications of remotely sensed data. Remote Sensing of Environment. Vol.37, Issue 1, Pages 35-46. July 1991.

CORREA, Roberto Lobato. O Espaço urbano. Editora Ática, Série Princípios, 3a. edição, n. 174, 1995. p.1-16.

DAMIANI, AMÉLIA LUISA. A urbanização crítica na metrópole de São Paulo, a partir de fundamentos da geografia urbana. Revista De Geografia Norte Grande. n.46, p.29-43, 2010

DAVIS, Clodoveu. Projeto OMT-G. Disponível em http://homepages.dcc.ufmg.br/ clodoveu/DocuWiki/doku.php?id=omtg\#object_ modeling_technique_for_geographic_applications_-_omt-g. Acesso em 06/10/2016.

DEHNI, ABDELLATIF; LOUNI, MOURAD. Remote Sensing Techniques for Salt Affected Soil Mapping: Application to the Oran Region of Algeria. Procedia Engineering. 33. 188 - 198. 2012

Desenvolvimento Rodoviário (DERSA) Rodoanel Metropolitano de São Paulo. São Paulo. Fev. 1997. 39p.

DNIT. Departamento Nacional de Infraestrutura de Transportes. Rodoanel, a maior obra viária do Brasil. Disponível em: http://www.dnit.gov.br/noticias/rodoanel-a-maior-obra-viaria-do-brasil Acesso em 13/09/2016 
DU, P.; LIU, S.; XIA, J.; ZHAO, Y.; Information fusion techniques for change detection from multi-temporal remote sensing images. Information Fusion. 14. 19-27. 2013.

ESTOQUE, RONALD C. MURAYAMA, YUJI. Classification and change detection of built up lands from Landsat-7 ETM+ and Landsat-8 OLI/TIRS imageries: A comparative assessment of various spectral indices. Ecological Indicators. 56. 205 - 217. 2015.

FLORENZANO, T. G. Iniciação em sensoriamento remoto /Tereza Gallotti Florenzano.3 ed. ampl. e atual. São Paulo: Oficina de Textos, p, 71-79, 2011.

GARCÍA-GUTIÉRREZ, Jorge. MATEOS-GARCÍA, D.; GARCIA, M.; Neurocomputing an evolutionary-weighted majority voting and support vector machines applied to contextual classification of LiDAR and imagery data fusion. Neurocomputing. 163. 17-24. 2015.

GIACINTO, Giorgio; ROLI, F. An approach to the automatic design of multiple classifier systems. Pattern Recognition Letters. 22. 25-33. 2001.

GISLASON, PALL OSKAR.; BENEDIKTSSON, JON ATLI.; SVEINSSON, J. R. Random Forests for land cover classification. Pattern Recognition Letters. 27. 294 - 300. 2006.

HE, Chuyang; SHI, Peijun; XIE, D; ZHAO, Y. Improving the normalized difference Built-Up index to map urban Built-Up areas using a semiautomatic segmentation approach. Remote Sensing Letters, 1: 4, 213 -221, First published on: 26 April 2010.

IBGE. Censo Demográfico 2000, Instituto Brasileiro de Geografia e Estatística, 2000.

IBGE. Censo Demográfico 2010, Instituto Brasileiro de Geografia e Estatística, 2010.

IBGE. Instituto Brasileiro de Geografia e Estatística. Sinopse do Censo Demográfico $2010 . \quad$ Disponível em: http://www.censo2010.ibge.gov.br/sinopse/index.php?dados=29\&uf=35. Acesso em: 05/08/2016.

IGBE. Introdução ao Processamento Digital de Imagens. Manuais Técnicos em geociências - número 9. 2001.

IM, JUNGHO. LU, Z.; RHEE, J.; QUACKENBUSH, L. J. Impervious surface quantification using a synthesis of artificial immune networks and decision/regression trees from multi-sensor data. Remote Sensing of Environment. 117. p. 102 - 113. 2012

IWAI, O. K.; QUINTANILHA, J. A. Utilização de imagens de satélite como ferramenta de auxílio ao planejamento urbano. In: Revista de Geografía, Norte Grande, ํo 34, Pontificia Universidad Católica de Chile, Santiago, Chile, p. 65 82. 2005.

J.D. PAOLA ; R.A. SCHOWENGERDT. A detailed comparison of backpropagation neural network and maximum-likelihood classifiers for urban land use classification. IEEE. Transactions on Geoscience and Remote Sensing. Vol. 33, Issue: 4, Jul 1995. 
JACOB, PREETI. DWARAKISH, G. S.; Temporal Analysis of Spatial Distribution of Built-Up Area in PeriUrban Areas of Cochin, Kerala: Case Study of SubWatershed in Periyar River. Aquatic Procedia. 4. 1445 - 1451. 2015.

KAMPEL, S.A. Geoinformação para Estudos Demográficos: Representação Espacial de Dados de População na Amazônia Brasileira. São Paulo, Escola Politécnica da Universidade de São Paulo. 2003.

KAWAKUBO, F. S.; MORATO, R. G.; LUCHIARI, A. Use of fraction imagery, segmentation and masking techniques to classify land-use and land-cover types in the Brazilian Amazon. International Journal of Remote Sensing. 34:15, 5452-5467. 2013

KITTLER, J. Combining Classifiers: A Theoretical Framework. Pattern Analysis \& Applic. 1: 18 - 27. Springer - Verlag London Limited. 1998.

LEE, J.A; LEE, S. S.; CHI, K. H. Development of an urban classification method using a Built-Up index. Selected Topics in Power Systems and Remote Sensing. 2010.

LEE, LONG; CHEN, LONGQIAN; WANG, Xinxin; ZHAO, J. Use of LANDSAT $\mathrm{TM} / \mathrm{ETM}+$ Data to Analyze Urban Heat Island and Its Relationship with Land Use/Cover Change. Construction Fund for Postgraduates in 3rd Period of Project 211. IEEE. 978-1-4244-9171-1/11. 2011.

LI, KUN; YU, ZHUANG. Comparative and Combinative Study of Urban Heat Island in Wuhan City with Remote Sensing and CFD Simulation. Sensors. 8, 6692-6703; DOI: 10.3390/s8106692. 2008.

LIU, J., PAN, Y.; ZHU, X.; ZHU, W.; Using phenological metrics and the multiple classifier fusion method to map land cover types. Journal of Applied Remote Sensing. 083691-2. Vol. 8, 2014.

LUCHIARI, AILTON. Identificação Da Cobertura Vegetal Em Áreas Urbanas por Meio De Produtos De Sensoriamento Remoto E De um Sistema De Informação Geográfica. Revista do Departamento de Geografia, 14. 47-58. 2001.

MAANTAY, J.A.; Maroko, A.R.; Porter-Morgan, H. Research note - a new method for mapping population and understanding the spatial dynamics of diseases in urban areas: asthma in the Bronx, New York. Urban Geography. v. 29, n. 7, n. 724-738. 2008.

MACHADO, Cláudia Soares; WAISMAN, Jaime. Alteração na Acessibilidade a Pontos de Interesse Decorrentes da Implantação do Rodoanel Mário Covas na Região Metropolitana de São Paulo. In: Anais do XIX Congresso de Pesquisa e Ensino em Transportes. 2005.

MACIEL, V. F. AND BIDERMAN, C. Assessing the effects of the São Paulo's metropolitan beltway on residential land prices. Journal of Transport Literature. vol. 7, n. 2, pp. 373-402. 2013.

MANFRÉ, L. A.; NÓBREGA, R. A. A.; QUINTANILHA, J. A., Evaluation of Multiple Classifier Systems for Landslide Identification in LANDSAT Thematic Mapper (TM) Images. ISPRS - International Journal of Geo-Information. Doi:10.3390/ijgi5090164. 2016. 
MARQUES, E.; REQUENA, C.; O Centro Voltou a Crescer? Trajetórias Demográficas e Heterogeneidade na São Paulo dos Anos 2000. São Paulo: Novos Estudos. №95, Março, 2013.

MARTIN, D. Geographic Information Systems: Socioeconomic Applications. London/New York, Routledge. 1996.

MARTIN, D.; Tate, N.J.; Langford, M. Refining population surface models: experiments with Northern Ireland census data. Transactions in GIS, v. 4, n. 4, p. 343360. 2000.

MEYER, R. e GROSTEIN, M. e BIDERMAN, C. São Paulo Metrópole. São Paulo: Editora da Universidade de São Paulo: Imprensa Oficial do Estado de São Paulo, 2004.

MONBEIG, P. Pioneiros e Fazendeiros de São Paulo. Editora Hucitec, São Paulo, 392p., 1998.

MORATO, R.G.; Kawakubo, F.S.; Machado, R.P.P. (2011). Mapa de densidade demográfica dasimétrico da área urbana do município de Alfenas (MG). In: Simpósio Internacional Caminhos Atuais da Cartografia na Geografia. 2. 2011. Anais. São Paulo, Brasil.

MORATO, R. G.; Kawakubo, F. S.; Presotto, A.; Luchiari, A. Avaliação da Quali dadede Vida Urbana em Taboão da Serra/SP Brasil. In: Antônio Nélson Rodrigues da Silva; Léa Cristina Lucas de Souza; José Fernando Gomes Mendes. (Org.). Planejamento Urbano, Regional, Integrado e Sustentável Desenvolvimentos recentes no Brasil e em Portugal. São Carlos, 2005, v., p. 271-286.

MOUETTE, Dominique. Os pedestres e o efeito barreira. Tese (Doutorado em Engenharia de Transportes) -Escola Politécnica, Universidade de São Paulo, São Paulo, 1998.

NIGRIELLO, Andreina. Oliveira, R. H. A rede de transporte e a ordenação do espaço urbano. Revista dos transportes Públicos - antP - ano 35 - 2013.

PAQUETTE, R.J.; ASHFORD, N.; WRIGHT, P.H., Transportation Engineering Planning and Design. The Ronald Press Company. New York, 1972.

PATEL, NIRAV N.; ANGIULI, EMANUELE.; GAMBA, PAOLO.; GAUGHAN, ANDREA.; LISINI, G.; STEVENS, F. R.; TATEM, A. J.; TRIANNI, G.; Multitemporal settlement and population mapping from Landsat using Google Earth Engine. International Journal of Applied Earth Observation and Geoinformation. 35. $199-208.2015$.

PÉREZ MACHADO, R.P.P. Um modelo geoespacial de uso do solo e demografia. $O$ caso do Município de São Paulo. São Paulo (Tese de Doutorado) FFLCH/USP. 226p. 2000.

Prefeitura de Barueri. Disponível em: http://www.barueri.sp.gov.br/. Acesso em: 22/09/2016.

Prefeitura de Carapicuíba. Disponível em: http://www.carapicuiba.sp.gov.br/index.php/carapicuiba/historico. Acesso em: 22/09/2016. 
Prefeitura de Cotia. Disponível em: http://www.cotia.sp.gov.br/portal/. Acesso em: 22/09/2016.

Prefeitura de Embu. Disponível em: http://embudasartes.sp.gov.br/. Acesso em: 22/09/2016.

Prefeitura de Osasco. Disponível em: http://cidades.ibge.gov.br/xtras/perfil.php?codmun=353440. Acesso em: 22/09/2016.

Prefeitura de Santana de Parnaíba. Disponível em: http://cidades.ibge.gov.br/xtras/perfil.php?codmun=354730. Acesso em: 22/09/2016.

PRESTES MAIA, F. Plano de Avenidas. São Paulo: Melhoramentos. 1930.

QIAN, Jing; Zhoua, Q.;Hou, Q. Comparison Of Pixel-Based And Object-Oriented Classification Methods For Extracting Built-Up Areas In Aridzone. ISPRS Workshop on Updating Geo-spatial Databases with Imagery \& The 5th ISPRS Workshop on DMGISs. 163. 2007.

RODRIGUE, J.; COMTOIS, C.; SLACK, B. The Geography of Transport Systems. New York: Routledge, 2nd edition, 2009.

ROGERS, A. S.; KEARNEY, M. S. Reducing signature variability in unmixing coastal marsh Thematic Mapper scenes using spectral indices. International Journal of Remote Sensing. 25:12, 2317-2335, DOI: 10.1080/01431160310001618103. 2004

SALLEH, SITI AEKBAL; ABD.LATIF, ZULKIFLEE; MOHD, WAN MOHD. NAIM WAN. CHAN, ANDY. Factors Contributing to the Formation of an Urban Heat Island in Putrajaya, Malaysia. Procedia - Social and Behavioral Sciences. 105. 840 - 850. 2013.

SANTOS, M. A.; Urbanização Brasileira. Editora Edusp, São Paulo, 174p., 1993

SMALL, CHRISTOPHER; PÉREZ MACHADO, REINALDO PAUL; BARROZO, L. V.; Luchiari, A. Mapping decades of urban growth and development with multi-temporal spectral mixture models. Anais XVII Simpósio Brasileiro de Sensoriamento Remoto - SBSR, João Pessoa-PB, Brasil, 25 a 29 de abril de 2015, INPE. 2015.

SPOSITO, Maria Encarnação Beltrão. Cidades Médias: Reestruturação das cidades e Reestruturação Urbana. In: BELTRÃO SPOSITO BELTRÃO, M. E. (org.). Cidades Médias: espaços em transição. São Paulo: Expressão Popular, 2007.

TAUBENBÖCK, H.; WEGMANN, M.; ROTH, A.; Mehl, H.; Dech, S. Urbanization in India - Spatiotemporal analysis using remote sensing data. Computers, Environment and Urban Systems. 33. 179-188. 2009.

VARSHNEY, AVNISH. Improved NDBI differencing algorithm for Built-Up regions change detection from remote-sensing data: an automated approach. Remote Sensing Letters. v. 4, n. 5, p. 504-512. 2013

VILLAÇA, Flávio. Espaço intra-urbano no Brasil. Editora: Studio Nobel. 1998. 
VOLPE, L. L. Análise da paisagem no entorno dos eixos viários: o exemplo do Rodoanel Mario Covas na RMSP. Artigo da dissertação de Mestrado em Geografia Física - Faculdade de Filosofia, Letras e Ciências Humanas. USP. São Paulo, 2009.

VOLPE, L. L. LOMBARDO, M. A. A análise do uso da terra no entorno do trecho oeste do Rodoanel Mario Covas na cidade de São Paulo por meio de técnicas de Sensoriamento Remoto. Revista do Departamento de Geografia - USP. Volume 21, p. 24-44. 2011.,

WANG, FEI.; QIN, ZHIHAO; LI, W.; Song, C.; Karnieli A.; Zhao, S.; An Efficient Approach for Pixel Decomposition to Increase the Spatial Resolution of Land Surface Temperature Images from MODIS Thermal Infrared Band Data. Sensors. 15, 304-330; doi: 10.3390/s150100304. 2015.

WASKE, BJÖRN. BRAUN, MATTHIAS. Classifier ensembles for land cover mapping using multitemporal SAR imagery. ISPRS Journal of Photogrammetry and Remote Sensing. 64. 450 - 457. 64.

WEGENER, M.; FÜRST, F.; Land-Use Transport Iteration: State or Art. Publication 46 (Berichte aus dem Institute für Raumplanung 46). Institute für Raumplanung, Universität Dortmund, Dortmund. 1999.

WEGENER, Michael. Overview of land use transport models. In: Handbook of transport geography and spatial systems. Emerald Group Publishing Limited. p. 127-146. 2004.

WENG, QJHAO. Remote sensing of impervious surfaces in the urban areas: Requirements, methods, and trends. Remote Sensing of Environment. 117. 34 - 49. 2012.

$\mathrm{XU}, \mathrm{H}$. A new index for delineating built-up land features in satellite imagery. International Journal of Remote Sensing. 29:14, 4269-4276, DOI: 10.1080/01431160802039957. 2008.

$\mathrm{XU}, \mathrm{H}$. Analysis of Impervious Surface and its Impact on Urban Heat Environment using the Normalized Difference Impervious Surface Index (NDISI). Photogrammetric Engineering and Remote Sensing. 76. 5, May 2010. 557565.DOI:10.14358/PERS.76.5.557. 2010.

YANG, X.; LIU, Z. Use of satellite-derived landscape imperviousness index to characterize urban spatial growth. Computers, Environment and Urban Systems. 29. 524-540. 2005.

ZHA, Y.; GAO, J.; NI, S. Use of normalized difference Built-Up index in automatically mapping urban areas from TM imagery. International Journal of Remote Sensing. v. 24, n. 3, p. 583-594, 2003.

ZHANG, Y.; ODEH, I. O. A.; HAN, C. Bi-temporal characterization of land surface temperature in relation to impervious surface area, NDVI and NDBI, using a subpixel image analysis. International Journal of Applied Earth Observation and Geoinformation. 11. 256-264. 2009.

ZHAO, HONGMEI. CHEN, XIAOLING. Use of Normalized Difference Bareness Index in Quickly Mapping Bare Areas from TM/ETM. IEEE. +0-7803-90504/05/\$20.00. 2005. 
ZHENFENG SHAO, YINGJIE TIAN \& XIAOLE SHEN. BASI: a new index to extract built-up areas from high-resolution remote sensing images by visual attention model, Remote Sensing Letters. 5:4, 305-314, DOI: 10.1080/2150704X.2014.889861. 2014.

ZHOU, YI. YANG, GUANG. WANG, SHIXIN. WANG, L.; WANG, F.; LIU, X. A new index for mapping Built-Up and bare land areas from LANDSAT-8 OLI data. Remote Sensing Letters. 5:10, 862-871, DOI: 10.1080/2150704X.2014.973996. 2014. 


\section{APÊNDICE}

Exemplo do Script utilizado no Rstudio para a elaboração da técnica de votação:

A única biblioteca externa que foi utilizada é a "rtiff".

\# Carrega a biblioteca rtiff na memória library (rtiff)

\# Use readTiff("caminho completo para o arquivo")

abril = readTiff("C://nome_da_pasta//2010_abril.tif")

maio <- readTiff("C://nome_da_pasta//2010_maio.tif")

junho <-readTiff("C://nome_da_pasta//2010_junho.tif")

agosto <- readTiff("C://nome_da_pasta//2010_agosto.tif")

novembro <- readTiff("C://nome_da_pasta//2010_novembro.tif")

\# Necessário para extrair a banda, pela forma que o rtiff trabalha.

list_img<-list( abril=abril@red, maio=maio@red , junho=junho@red

agosto=agosto@red,novembro=novembro@red)

\# Libera os objetos da memória

rm(abril, maio, junho, agosto, novembro)

\# Truque para somar célula a célula cada imagem.

soma <- Reduce('+', list_img )

\# Libera a lista de imagens da memória rm(list_img)

\# Escolhe baseado na quantidade de zeros ou uns em cada posição da matriz representativa da imagem.

saida $<$-ifelse $($ soma $<2$, yes $=0$, no $=1)$

\# Salva o arquivo no caminho desejado

writeTiff(saida, fn='/ C://nome_da_pasta//saida.tiff')

Após estes passos a imagem saída é o resultado da técnica de votação. 